\title{
Development Studies For a Novel Wet Oxidation Process
}

\author{
Topical Report
}

Patrick M. Dhooge

Lena B. Hakim

January 1994

Work Performed Under Contract No.: DE-AC21-92MC29107

U.S. Department of Energy

Office of Environmental Management

Office of Technology Development

Washington, DC
For

U.S. Department of Energy Office of Fossil Energy Morgantown Energy Technology Center Morgantown, West Virginia

By

Delphi Research, Incorporated

Albuquerque, New Mexico 


\section{DISCLAIMER}

This report was prepared as an account of work sponsored by an agency of the United States Government. Neither the United States Govemment nor any agency thereof, nor any of their employees, makes any warranty, express or implied, or assumes any legal liability or responsibility for the accuracy, completeness, or usefulness of any information, apparatus, product, or process disclosed, or represents that its use would not infringe privately owned rights. Reference herein to any specific commercial produch, process, or service by trade name, trademark, manufacturer, or otherwise does not necessarily constitute or imply its endorsement, recommendation, or favoring by the United States Government or any agency thereof. The views and opinions of authors expressed herein do not necessarily state or reflect those of the United States Govemment or any agency thereof.

This report has been reproduced directly from the best available copy.

Available to DOE and DOE contractors from the Office of Scientific and Technical Information, P.O. Box 62, Oak Ridge, TN 37831; prices available from (615) 576-8401.

Available to the public from the U.S. Department of Commerce, Technology Administration, National Technical Information Service, Springfield, VA 22161, (703) $487-4650$. 


\title{
Development Studies For a Novel Wet Oxidation Process
}

\author{
Topical Report
}

\author{
Patrick M. Dhooge \\ Lena B. Hakim
}

Work Performed Under Contract No.: DE-AC21-92MC29107

U.S. Department of Energy Office of Environmental Management Office of Technology Development 1000 Independence Avenue

Washington, DC 20585
For

U.S. Department of Energy

Ofince of Fossil Energy

Morgantown Energy Technology Center P.O. Box 880

Morgantown, West Virginia 26507-0880

By

Delphi Research, Incorporated

701 Haines Avenue, NW.

Albuquerque, New Mexico 87102

January 1994 


\begin{abstract}
A catalytic wet oxidation process (DETOX), which uses an acidic iron solution to oxidize organic compounds to carbon dioxide, water, and other simple products, was investigated as a potential method for the treatment of multicomponent hazardous and mixed wastes.
\end{abstract}

The organic compounds picric acid, poly(vinyl chloride), tetrachlorothiophene, pentachloropyridine, Aroclor 1260 (a polychlorinated biphenyl), and hexachlorobenzene were oxidized in $125 \mathrm{ml}$ reaction vessels. Results of chemical analysis demonstrated greater than $99 \%$ destruction of the organics uncier unmixed conditions. Previous tests have demonstrated better than 99.9999\% destruction of organics in a stirred reactor.

The metals arsenic, barium, beryllium, cadmium, cerium (as a surrogate for plutonium), chromium, lead, mercury, neodymium (as a surrogate for uranium), nickel, and vanadium were tested in the DETOX solution. Barium, beryllium, cerium, chromium, mercury, neodymium, nickel, and vanadium were all found to be very soluble $(>100 \mathrm{~g} / \mathrm{l})$ in the DETOX chloridebased solution. Arsenic, barium, cadmium, and lead solubilities were lower. Lead could be selectively precipitated from the DETOX solution. Chromium(VI) was reduced to relatively non-toxic chromium(III) by the solution. Metals levels in any residual solids after rinsing with DETOX condensate (dilute $\mathrm{HCl}$ ) and water were all sufficiently low to make the residuals non-hazardous by the RCRA Toxic Characteristic Leach Procedure (TCLP) test.

Six soils, a sand, a loam, a clay, a silt loam, a sandy clay loam, and a clay loam, were evaluated. The soils were contaminated with arsenic, barium, beryllium, chromium, lead, and neodymium oxides at approximately $0.1 \%$ by weight, and benzene, trichloroethene, mineral oil, and Aroclor 1260 at approximately $5 \%$ by weight total, and $5 . \mathrm{g}$ amounts treated with the DETOX solution in unstirred $125 . \mathrm{ml}$ reaction bombs. The metals were removed by the DETOX solution and rinsed to levels which made the soils nonhazardous by the RCRA TCLP test. About $80 \%$ to $90 \%$ of the organics were destroyed. It is apparent that without agitation the less volatile organic materials (i.e., the mineral oil and the Aroclor 1260) were difficult for the DETOX solution to access to obtain full oxidation. It is felt that soil treatment in a properly designed system is entirely possible despite incomplete oxidation of the less volatile organic materials in these unstirred tests. 
Engineering studies have identified two primary wastes/sites for potential demonstration of the process, namely polychlorinated biphenyl (PCB) oil at Rocky Flats Plant and tributyl phosphate (TBP) at Weldon Spring site. Conceptual configurations for the systems have been prepared, along with estimates of costs, secondary waste streams, and critical engineering issues. 


\section{ACKNOWLEDGEMENTS}

This study was conducted for the Morgantown Energy and Technology Center of the U.S. Department of Energy under Contract DE-AC21-92MC29107. The DOE Project Officer was V. P. Kothari.

We would also like to acknowledge the guidance and assistance provided by Charles Brown (EG\&G Rocky Flats Plant), Tom Baker (EG\&G Rocky Flats Plant), Jim Taylor (DOE Headquarters), Dave Hixson (Jacobs Engineering Group, Inc., Weldon Spring Site), and Steve McCracken (DOE, Weldon Spring Site) in the selection and planning of potential demonstration sites for Phase II. 


\section{Table of Contents}

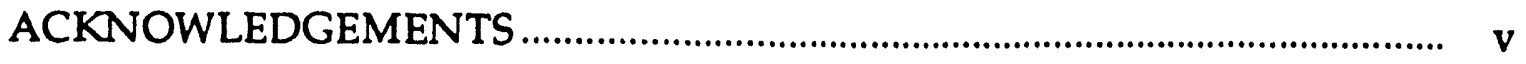

EXECUTIVE SUMMARY ............................................................................. xiii

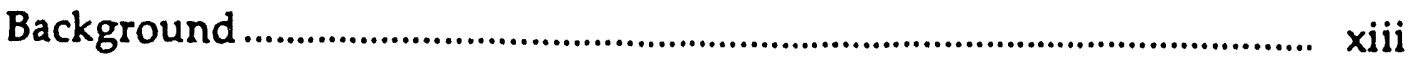

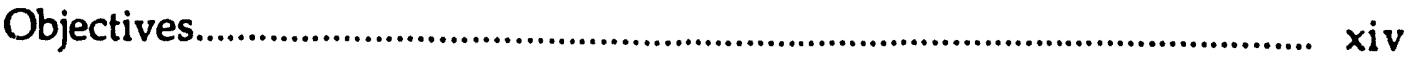

Project Description............................................................................. $\quad \mathrm{xv}$

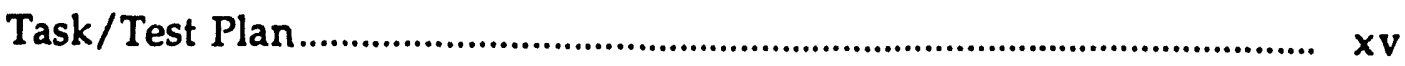

Experimental Results.......................................................................... xvi

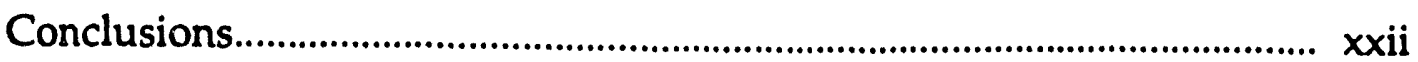

SECTION 1-INTRODUCTION ....................................................................... 1

1.1 Problem Statement ........................................................................... 1

1.2 Objective ....................................................................................... 1

1.3 Process Description .............................................................................. 2

1.4 Environmental Requirements ......................................................... 3

SECTION 2 -OXIDATION OF ORGANICS....................................................... 5

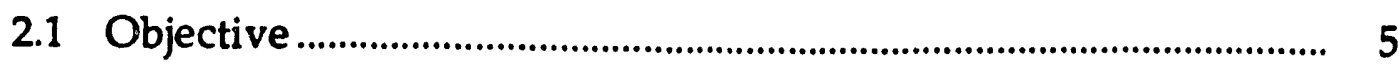

2.2 Procedure and Apparatus................................................................. 5

2.3 Results............................................................................................ 7

SECIIION 3-INORGANIC FATE TESTS …................................................ 15

3.1 Objective ......................................................................................... 15

3.2 Procedure and Apparatus................................................................ 15

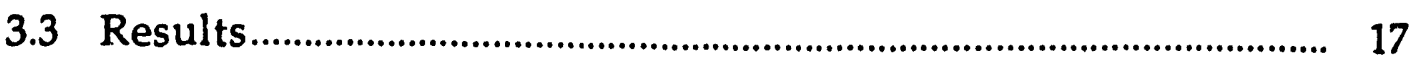

SECTION 4-C.ONTAMINATED SOIL TESTS …........................................... 27

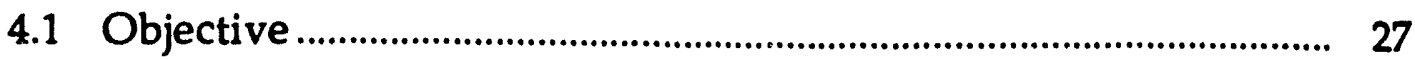

4.2 Procedure and Apparatus............................................................... 27

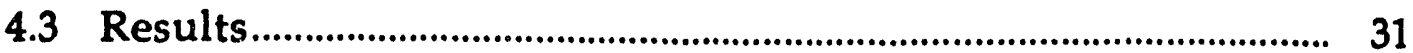




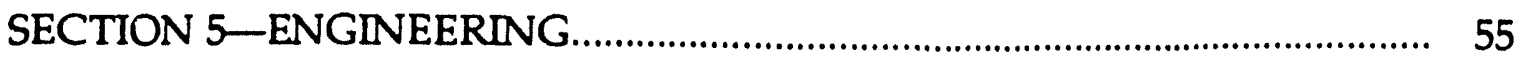

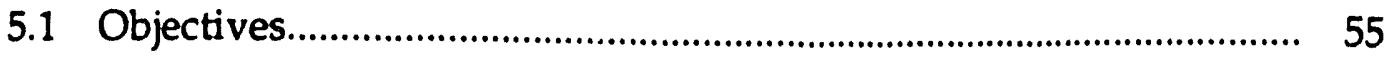

5.2 Procedure and Apparatus............................................................. 55

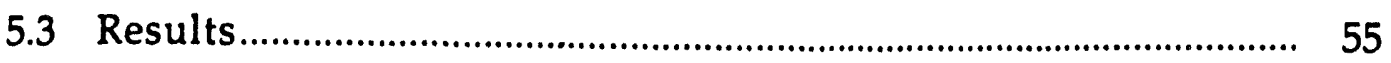

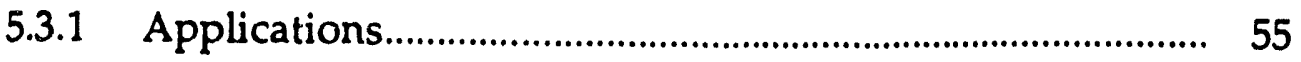

5.3.2 Application to PCB Oil at Rocky Flats Plant ...................... 56

5.3.2.1 Mass and Energy Balance ..................................... 56

5.3.2.2 Condenser.............................................................. 59

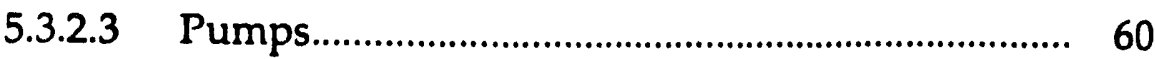

5.3.2.4 Configuration/Materials .......................................... 62

5.3.2.5 Monitors and Controls .......................................... 63

5.3.2.6 Secondary Waste Streams....................................... 63

5.3.2.7 Critical Engineering Issues...................................... 65

5.3.2.8 Health and Safety.................................................... 68

5.3.3 Tributyl Phosphate at Weldon Spring Site.......................... 68

5.3.3.1 Mass and Energy Balance ...................................... 71

5.3.3.2 Condenser.............................................................. 73

5.3.3.3 Pumping/Filtration................................................. 75

5.3.3.4 Rinsing/Extraction ............................................... 76

5.3.3.5 Configuration/Materials......................................... 76

5.3.3.6 Monitors and Controls ............................................. 78

5.3.3.7 Secondary Waste Streams....................................... 78

5.3.3.8 Critical Engineering Issues..................................... 80

5.3.3.9 Health and Safety ................................................... 81

5.3.4 Capital and Operating Costs .................................................. 81

SECTION 6-CONCLUSIONS........................................................................ 87

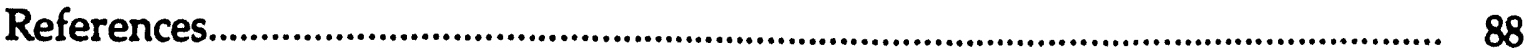

Glossary of Terms ............................................................................................ 89 


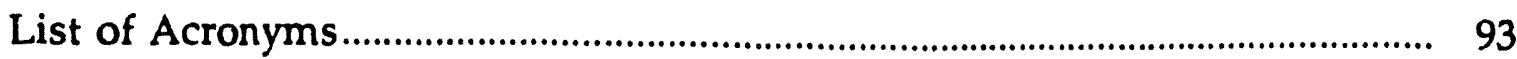

APPENDIX A-OTHER. DETOX DEVELOPMENT EFFORTS............................. 95

Development for Los Alamos National Laboratory ................................ 95

Development for Rocky Flats Plant......................................................... 95 


\section{List of Figures}

Figure

1 The DETOX Process ........................................................................... xiv

2 Metal Solubility in DETOX Process Solution......................................... xvii

3 Metal Solubility in DETOX Process Solution with Sulfate.................. xviii

4 Percent Residual Metal in Rinse versus Rinse Number for

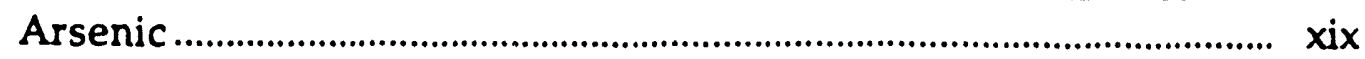

5 The DETOX System ............................................................................. x xii

6 The DETOX Chemistry ….................................................................... 2

7 Metal Solubility versus Acid Concentration ........................................ 18

8 Metal Solubility versus Phosphate Concentration.................................. 19

9 Metal Solubility versus Sulfate Concentration...................................... 19

10 Lead Solubility in Chloride-Based DETOX Solutions........................... 24

11 Texture Triangle.................................................................................... 28

12 Arsenic Rinse Results........................................................................ 34

13 Barium Rinse Results.................................................................... 35

14 Beryllium Rinse Results .............................................................. 35

15 Cadmium Rinse Results ................................................................ 36

16 Chromium Rinse Results............................................................... 36

17 Lead Rinse Results.......................................................................... 37

18 Neodymium Rinse Results................................................................ 37

19 Arsenic Removal From Contaminated Soils........................................ 41

20 Barium Removal From Contaminated Soils........................................ 41

21 Beryllium Removal From Contaminated Soils ................................... 42

22 Chromium Removal From Contaminated Soils................................. 42

23 Lead Removal From Contaminated Soils.............................................. 43

24 Neodymium Removal From Contaminated Soils................................ 43 
25 DETOX Treatment System Conceptual Schematic for Rocky Flats Plant Demonstration.

26a DETOX Treatment System Conceptual Schematic for Weldon Springs Site Demonstration.......................................................... 69

26b DETOX Treatment System Conceptual Schematic for Weldon Springs Site Demonstration.. 


\section{List of Tables}

Table

I Organics' Oxidation Times ............................................................... 8

II Organics Destruction Efficiencies ........................................................ 8

III Organics' Volatile and Semivolatile Residues................................. 11

IV Organics Non-volatiles Residues....................................................... 13

V Soluble Metals Data...................................................................... 18

VI Chromium(VI) Results ................................................................. 20

VII Barium Test Results .................................................................... 22

VIII Barium TCLP Results................................................................ 23

IX Soil Characteristics........................................................................... 29

X Plano Soil Rinse Test Results............................................................ 32

XI Plainfield Soil Rinse Test Results ................................................... 32

XII South Valley Soil Rinse Test Results................................................. 33

XIII Mountain Clay Soil Rinse Test Results .............................................. 33

XIV Kinney Brick Soil Rinse Test Results.............................................. 34

XV Contaminated Plano Soil Metals Results......................................... 38

XVI Contaminated Plainfield Soil Metals Results.................................... 38

XVII Contaminated South Valley Soil Metals Results .............................. 39

XVIII Contaminated Mountain Clay Soil Metals Results......................... 39

XDX Contaminated Kinney Brick Soil Metals Results ............................ 40

XX Contaminated True Clay Soil Metals Results.................................... 40

XXIa Contaminated Soils 24-Hour Volatile and Semivolatile

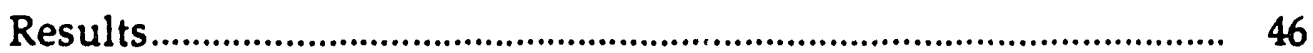

XXTb Contaminated Soils 24-Hour Volatile and Semivolatile Results........................................................................................... 47

XXIc Contaminated Soils 24-Hour Volatile and Semivolatile Results............................................................................................ 48 
XXIIa Contaminated Soils 48-Hour Volatile and Semivolatile

Results

XXIb Contaminated Soils 48-Hour Volatile and Semivolatile Results.

XXIIC Contaminated Soils 48-Hour Volatile and Semivolatile Results

XXIII Contaminated Soils Residual Non-volatile Organic Results ....... 52

XXIV Mass Balance for Oxidation of PCB Oil ............................................. 58

XXV Energy Balance for Oxidation of PCB Oil........................................... 58

XXVI RFP PCB's Condenser Calculations ................................................ 61

XXVII Flows, Pressures, Temperatures for Oxidation of PCB Oil............. 63

XXVII Mass Balance for Oxidation of Tributyl Phosphate at Weldon Spring Site

XXIX Energy Balance for Oxidation of Tributyl Phosphate at Weldon Spring Site

$X X X \quad$ WSS TBP Condenser Calculations

XXXI Flows, Pressures, Temperatures for Oxidation of TBP Oil............. 77

XXXII RFP DETOX Treatment Unit Components......................................... 82

XXXIII WSS DETOX Treatment Unit Components .................................... 83

XXXIV Operating Cost Components ................................................................. 84 


\section{EXECUTIVE SUMMARY}

\section{Background}

Great amounts of hazardous, toxic, and/or radioactive wastes have been generated at Department of Energy operational sites and in many areas of the private sector. These wastes may contain variable amounts of hazardous and/or toxic organic compounds, hazardous and/or toxic inorganic materials such as heavy metals, and radioactive elements. The problem of waste which is both hazardous and/or toxic, and radioactive (often designated "mixed" waste) at Department of Energy sites is particularly acute, since there are few, if any, methods for its treatment and the Federal Facilities Compliance Act (FFCA) mandates the development of effective methods of dealing with mixed waste at government facilities.

The work reported herein has resulted from PRDA DE-RA21-92MC28245, Research and Development for Environmental Restoration and Waste Management Technologies, Sub-Research Area 3.05-Innovative Chemical and Biological Reactor Systems.

The technology proposed for development to meet the Department of Energy's needs was the DETOX process, a patented chemical treatment which oxidizes organic compounds to simple products. Figure 1 shows reactants and products in the process. Treatment is performed in an acidic water solution using oxygen gas as the oxidant. Due to the novel combination of catalysts used in the solution, the process can oxidize most organic compounds at moderate pressure and temperature. The acidic water solution is capable of dissolving great amounts of many toxic and radioactive metals. Since treatment is performed in a water solution, the process is not especially sensitive to the water content of the waste. The process will also accept a large range of particle sizes and waste types, and is not especially sensitive to variations in waste content. 
Figure 1: The DETOX Process

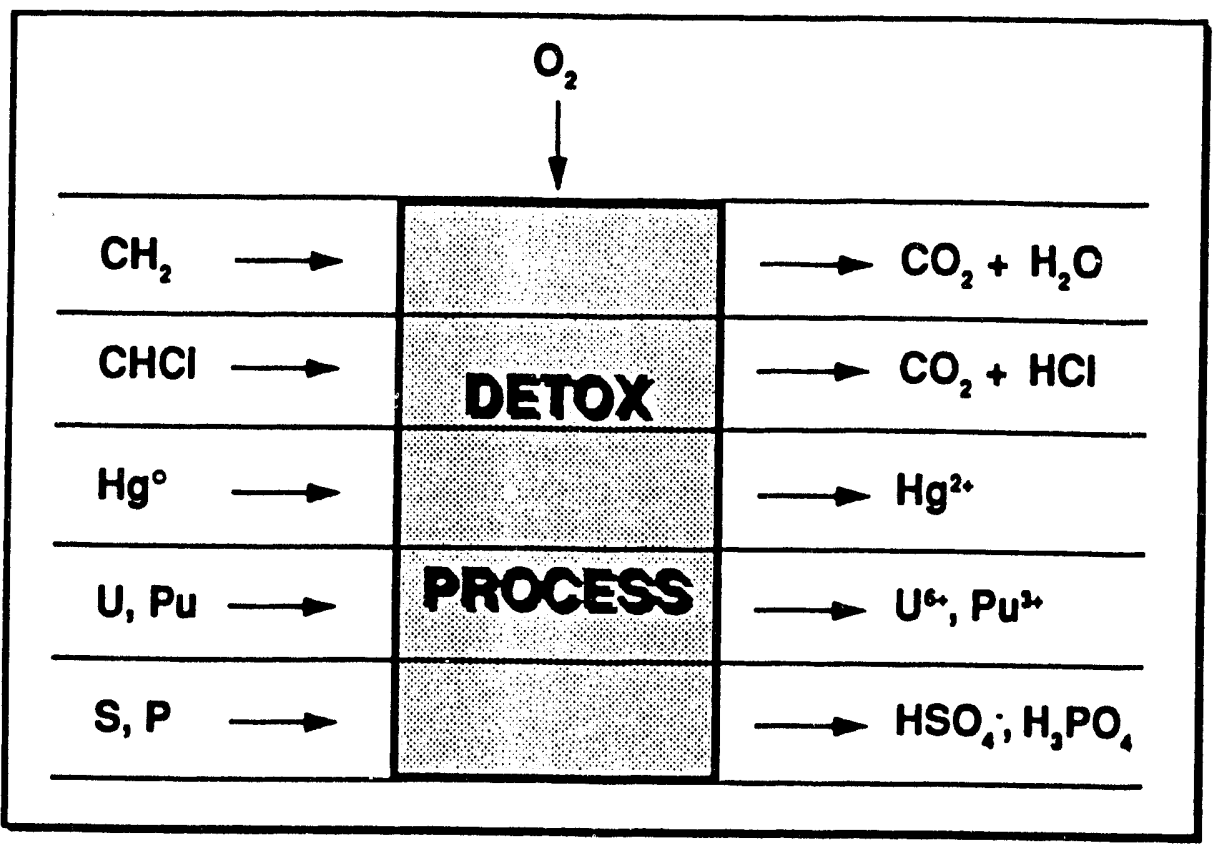

Although DETOX had shown promising results in testing on some organic and infectious waste types, the process had never been applied to complex hazardous and mixed wastes, which may contain a variety of organics and metals. The Phase I effort described in this report was designed to determine the practical range of application for the process in treatment of multicomponent wastes, and to perform a conceptual engineering study for the process in application to Department of Energy wastes.

\section{Objectives}

There were four main developmental objectives in the Phase I effort. These objectives were to measure the destruction efficiency of the process for a variety of organics, to determine the fate of a set of representative metals in the process solution, to determine the ability of the process to treat soils contaminated with hazardous metals and organics, and to conduct a conceptual engineering study for application of the process to wastes at Department of Energy sites. While this process may not provide stand-alone treatment of all applicable waste streams, and further processing of residual wastes, e.g. immobilization, may be required prior to ultimate disposal, it can be valuable in reducing the volume of many hazardous and mixed wastes, and in converting mixed wastes to a radioactive-only form. 


\section{Project Description}

Development of the DETOX process is planned to proceed through three phases. In Phase I, laboratory tests have established the range of possible applications for the process and a conceptual engineering study has determined the estimated size, configuration, secondary waste streams, critical issues, and cost for the process in application to Department of Energy wastes. In Phase II, a developmental prototype process system will be designed, built, and tested with mixed waste at a Department of Energy facility. In Phase $\mathrm{II}$, waste processing with the prototype system will be continued, while a commercial-sized system design is performed based on the information garnered during the prototype development effort.

\section{Task/Test Plan}

The Phase I effort consisted of five tasks.

Task 1 was preparation of information for the National Environmental Policy Act. This information had to be approved before any work was begun which might affect the environment.

In Task 2, the oxidation efficiency studies, picric acid, poly(vinyl chloride), tetrachlorothiophene, pentachloropyridine, Aroclor 1260 (a polychlorinated biphenyl, or $\mathrm{PCB}$ ), and hexachlorobenzene were reacted with the process solution in $128 . \mathrm{ml}$ titanium reaction bombs pressurized with oxygen. Amounts of oxygen used and carbon dioxide produced in the oxidation were measured, and the contents of the bombs after oxidation were submitted to independent commercial laboratories for analysis of any volatile, semivolatile, and non-volatile organic compounds remaining in the bombs after the oxidations.

The studies of Task 3 determined the fate of arsenic, barium, beryllium, cadmium, cerium (as a substitute for plutonium), chromium, lead, mercury, neodymium (as a substitute for uranium), nickel, and vanadium in the process solution. Tests were conducted in $23 . \mathrm{ml}$ Teflon ${ }^{\mathrm{TM}}-$ lined reaction bombs. After heating, the contents of the bombs were filtered and any solids rinsed with dilute $\mathrm{HCl}$ solution which should be similar to water condensed from the process during operation. Filtered process solutions, rinses, and solids were analyzed for the metal of interest. Tests were also conducted on the effect of varying anion concentrations on soluble metals, on reduction of chromium (VI) to chromium (III) by the process solution, on scavenging of sulfate with calcium ion, and on changes in lead solubility with process solution concentration and temperature. Solids from arsenic and barium 
tests were extracted by the Toxicity Characteristic Leaching Procedure to determine whether they were classified as hazardous.

Soils contaminated with hazardous metals and organics were treated in Task 4 , using the 128 . $\mathrm{ml}$ titanium reaction bombs. Tests were performed on the ability to rinse process solution containing dissolved hazardous metals from the soils. An additional set of tests were conducted to determine the ability of the process solution to treat soils contaminated with benzene, trichloroethene, mineral oil, Aroclor 1260, arsenic, barium, beryllium, chromium, lead, and neodymium (the metals were present as oxides). Contents of the bombs were analyzed for volatile, semivolatile, and nonvolatile organics remaining after treatment of the soils. Filtered process solutions and rinses were analyzed for metals. Treated soil residues were extracted by the Toxicity Characteristic Leach Procedure to determine whether they would be non-hazardous for metals.

The data obtained in the laboratory experiments was used in Task 5 to perform a conceptual engineering study of the DETOX technology in application to selected waste types at Department of Energy sites. Waste treatment applications were chosen for demonstration of the process. Mass and energy balances were calculated for the applications. Treatment system components were determined and sized. Necessary monitors and controls for the system were determined. Secondary waste streams were characterized. Critical engineering issues were determined, and costs estimated for application of the process to specific wastes and for a more general case. The scheduled end date of the effort was November 23, 1993.

\section{Experimental Results}

All six organic compounds were successfully oxidized in Task 2 . The amount of oxygen used and the amount of carbon dioxide produced were consistent with complete oxidation of the organics to simple products. Reaction rates for polychlorinated biphenyl and hexachlorobenzene were slower than for the other four organics, as would be expected for these chemically stable chlorinated aromatic compounds, but they were eventually oxidized with good efficiency. Absolute oxidation efficiency, that is, the percentage destruction of all organic material in the reaction bombs, was approximately 99\%. Destruction/removal efficiencies for the compounds being tested ranged from $>99.5 \%$ for Aroclor 1260 to $>99.9 \%$ for tetrachlorothiophene and pentachloropyridine. Based on past results achieved in identical unstirred reaction bombs, the oxidation efficiencies achieved here are typical for a reaction without good mixing (in a stirred bench scale reactor operated in our laboratory, oxidation efficiencies of $>99.9999 \%$ have been achieved). 
Metals' fate test results demonstrated the ability of the DETOX process solution to dissolve many toxic metals. Although the DETOX solution must be acidic to maintain the iron catalyst in solution, a range of solution acidity can be tolerated. Figure 2 shows the solubilities of selected metals in the process solution at different acidities. Metals solubilities are fairly insensitive to acidity over a range of acid concentration, thus the acidity of the DETOX solution during waste treatment would not have to be closely monitored. Figure 3 shows the effect of different amounts of sulfate anion in the DETOX solution on metals' solubilities. It was found to be desirable to scavenge sulfate anion from the process solution with calcium (as calcium chloride). Scavenging sulfate and phosphate anions using calcium will generate calcium sulfate and calcium phosphate salts as solids which may have to be removed from the DETOX solution by filtration, depending on the volume generated. The resulting calcium salt solids can be rinsed and disposed of as non-hazardous or low level radioactive wastes. Chromium(VI), a hazardous form of chromium ion, was found to be effectively reduced to chromium(III), a non-hazardous form, by the DETOX process solution under typical process conditions. The solubility of lead was determined at different DETOX solution temperatures and concentrations, and was found to be such that lead could be selectively precipitated from the DETOX process solution as the chloride salt. Arsenic and barium test residues were found to be nonhazardous when extracted by the Resource Conservation and Recovery Act Toxicity Characteristic Leaching Procedure.

\section{Figure 2: $\quad$ Metal Solubility in DETOX Process Solution}

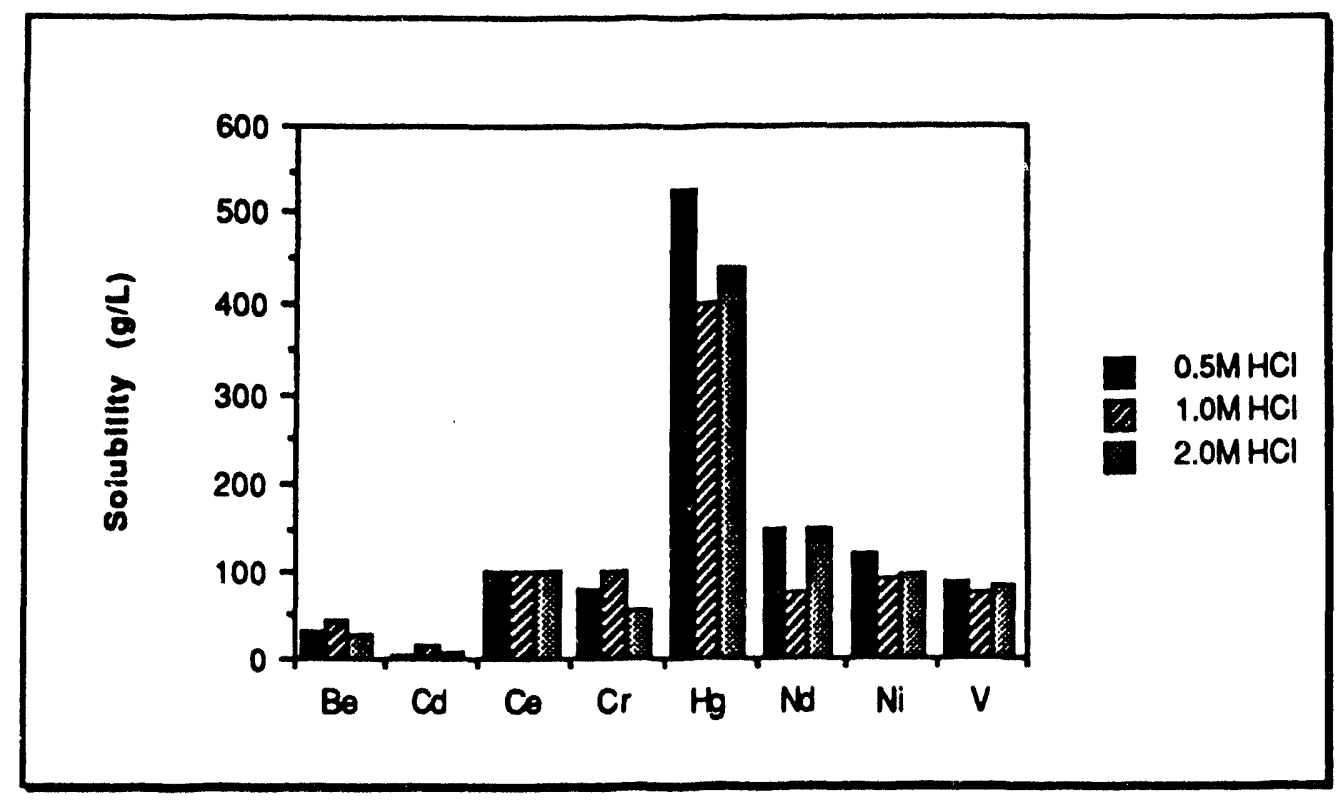


Figure 3: Metal Solubility in DETOX Process Solution with Sulfate

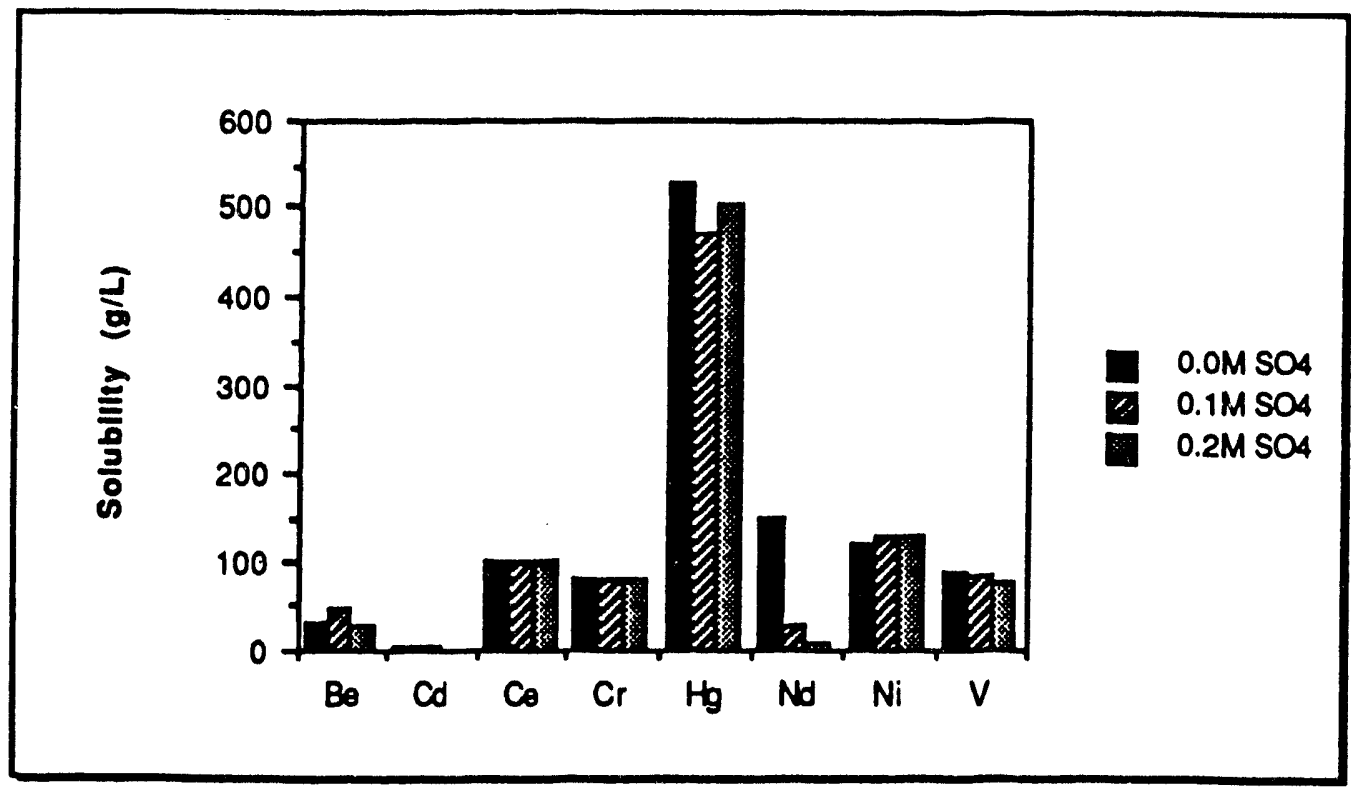

Soils testing showed that toxic metals could be washed from a wide variety of soils by treatment with the DETOX solution followed by three or four rinses of $1 \% \mathrm{HCl}$ solution, as shown in Figure 4 . The $1 \% \mathrm{HCl}$ solution simulates fluid condensed from the oxidation vessel when venting reaction products, and thus can be returned to the oxidation vessel after being used as a rinse. Previous studies by Delphi Research, Inc. for Los Alamos National Laboratory in sealed, unstirred oxidation vessels had demonstrated the dependence of organic compounds' oxidation rates on temperature, iron(III) concentration, and the presence of catalysts in the DETOX solution, but similar tests had not been performed with organics in soils. Treatment tests on soils contaminated with hazardous organics and metals showed that, in sealed, unstirred oxidation vessels, volatile organics could be destroyed with great efficiency (concentrations of $1 \%$ by weight benzene and trichloroethene in soils were reduced to undetectable levels by treatment with DETOX solution). Verification of good seals and oxidation of the organics was made by measurement of the vessel pressure and gas content after cooling. Volatilization of some of the organics from the soils undoubtedly occurred during the oxidation test, but these compounds would have remained sealed in the reaction vessel and would have been detected in the contents of the vessel in analysis, since the entire liquid and solid contents of the vessels were submitted for organics analysis. Non-volatile organics in the soils were destroyed with less efficiency, most likely due to poor contact between the soil particles and the DETOX solution. It is felt that with good mixing the 
destruction efficiencies for the non-volatile organics will approach those seen for the volatile organics. Based on the results of these tests, soil treatment residence times are estimated to be one to two hours.

Figure 4: Percent Residual Metal in Rinse versus Rinse Number for Arsenic

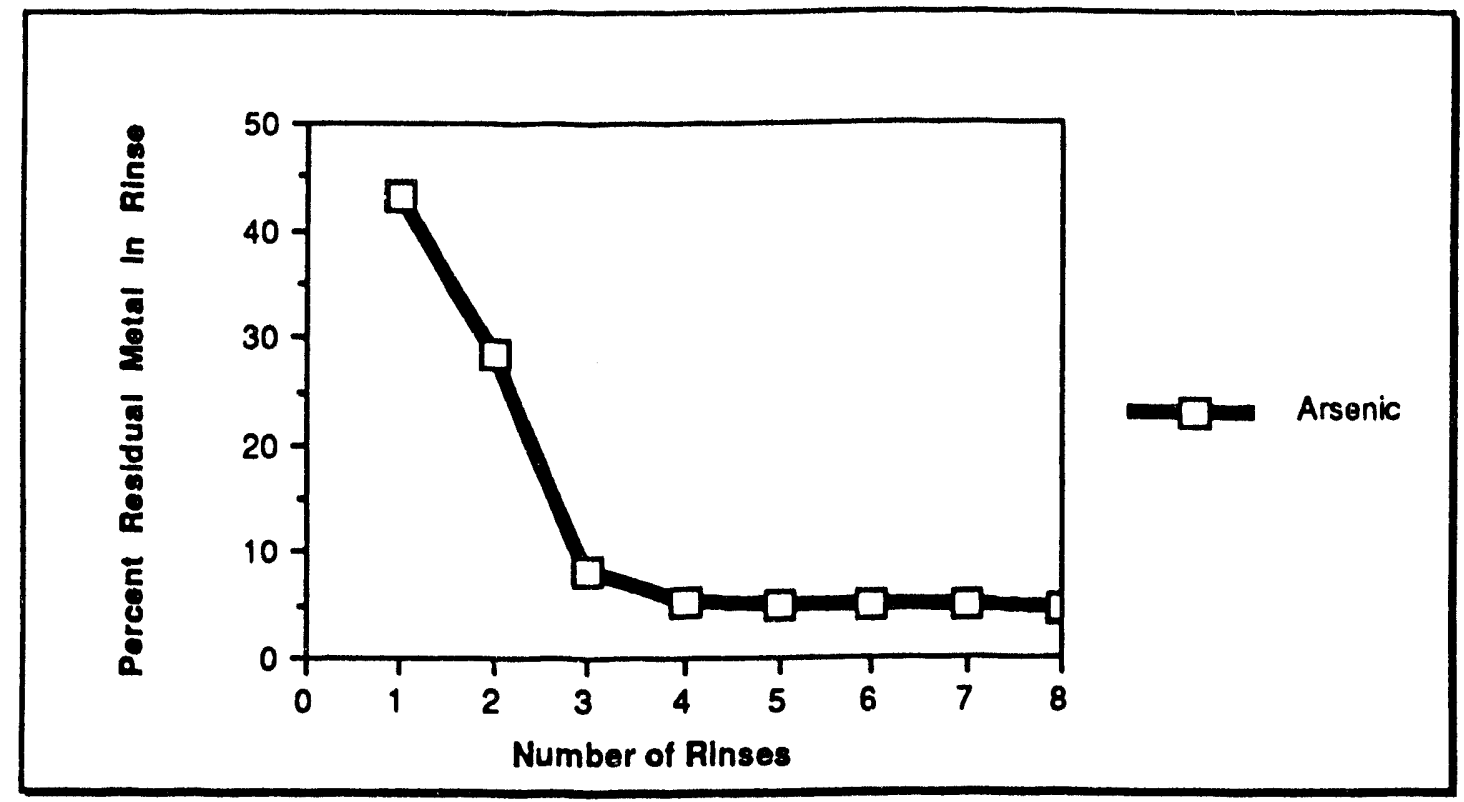

The conceptual engineering study for application of DETOX to waste treatment first chose likely applications. The wastes and sites chosen were polychlorinated biphenyl oils contaminated with chlorinated solvents and radionuclides at Rocky Flats Plant and tributyl phosphate contaminated with polychlorinated biphenyls, mercury, uranium, and thorium at Weldon Springs Site. Both wastes are considered mixed wastes. The PCB oil at Rocky Flats Plant is a hazardous waste under RCRA, a toxic waste under TSCA, and a radioactive waste under NRC regulations, currently stored awaiting development of a treatment/disposal method as directed under the Federal Facilities Compliance Act. Weldon Spring Site is a Superfund site, and as such the wastes on the site fall under CERCLA regulations; the tributyl phosphate is currently stored awaiting development of a treatment/disposal method as directed under the Federal Facilities Compliance Act. The DETOX process would be demonstrated on one or both of these wastes.

The treatment systems would be designed to fit on skids. One skid would be required for the Rocky Flats Plant demonstration system, while two skids would be needed for the Weldon Springs Site demonstration. Energy balance calculations have shown that for both systems the oxidation tank would have to be actively cooled to remove the heat of oxidation of the organic 
compounds. Tantalum-lined Grade 7 titanium was determined to be the most desirable material of construction for the oxidation tank and its condenser; other components can be of less exotic materials. A microcomputer-based data acquisition and control system can be used for operation of either of the demonstration systems, with redundant sensors and hardwired shut-offs for upset conditions. A simple schematic of the process system is shown in Figure 5.

Secondary waste streams from the process would be the neutralized process solution at the conclusion of waste processing, and sodium chloride dissolved in excess water for the Rocky Flats Plant application to polychlorinated biphenyls or water and calcium dihydrogen phosphate solids for the Weldon Springs Site application to tributyl phosphate. Approximately $11.3 \mathrm{~kg} / \mathrm{hr}$ of a $20 \%$ by weight sodium chloride brine will be produced during the oxidation of $5 . \mathrm{kg} / \mathrm{hr}$ PCB oil at Rocky Flats Plant, due to the chloride content of this waste. The brine solution should contain no radionuclides or organic compounds, and should be disposable as a non-hazardous material after analysis to demonstrate absence of regulated amounts of the hazardous waste components. Approximately $15 . \mathrm{kg} / \mathrm{hr}$ of wet calcium dihydrogen phosphate solids ( $20 \%-25 \%$ by weight water) will be produced from the oxidation of 25 . $\mathrm{kg} / \mathrm{hr}$ of tributyl phosphate at Weldon Spring Site. Although the solids will be rinsed thoroughly, they may contain some included, absorbed, and/or adsorbed radionuclide ions. The solids would most likely be immobilized and disposed of in the burial cell at Weldon Spring Site. Neutralizing either application's process solution with sodium hydroxide will precipitate iron as the hydrated oxide. The hydrated iron oxide precipitate is initially colloidal in nature, and will undoubtedly incorporate some of the other metals in the solution as included, absorbed, and/or adsorbed ions. Significant heavy metal concentrations in the process solution would give precipitates of heavy metal hydroxides/oxides upon neutralization, however, the low metal concentrations in the PCB oil at Rocky Flats Plant and the tributyl phosphate at Weldon Spring Site should not result in any heavy metal hydroxide/oxide precipitates during neutralization. For the applications at Rocky Flats Plant or Weldon Spring Site, the process solution need not be neutralized at the conclusion of PCB oil or tributyl phosphate destruction, since it will have accumulated very little, if any, metals or other inert material. Nevertheless, it may be desirable to demonstrate effective immobilization of neutralized process solution in these projects. The form of a neutralized process solution is a hydrated iron oxide saline mud. The amounts of neutralized process solution would be $223 . \mathrm{kg}$ for the Rocky Flats Plant application and 1475. kg for the Weldon Spring Site application. This material will most likely be classed as a low level radioactive waste, and might be a mixed waste due to heavy metal content. The neutralized process solution would need to be immobilized by solidification or encapsulation to convert it to a suitable. low level radioactive-only waste form for disposal; studies are in progress at Delphi Research, Inc. to investigate the fate of cerium, mercury, and 
neodymium in the neutralized process solution, and at Brookhaven National Laboratory and EG\&G Rocky Flats Plant to determine the best method for immobilization of the neutralized process solution.

Critical engineering issues for the process in application to waste treatment include suitable materials of construction, oxidation vessel temperature control, redundant control and safety subsystems, containment, serviceability, and cost. Materials of construction have been identified which should give at least a 10 year lifetime for the process equipment under typical operating conditions. Principal among these materials are the tantalum lining, valves, and piping which will be required for the oxidation vessel, its attendent inlet and outlet lines, and its condenser. Grade 7 titanium can be used as the pressure shell of the oxidation vessel, and will provide effective secondary containment for the hot process solution. Tempertaure control of the oxidation vessel will be achieved through the use of a commercial hot oil heating/cooling system in combination with a jacket on the oxidation vessel. It is recommended that redundant valving be used on all critical areas, i.e., inlets and outlets on the oxidation vessel, to provide sure containment of the vessel contents. Redundant, hardwired emergency shut down electronics should be incorporated into the design, with an independent emergency power supply for the unit's control electronics and pumps in the event of loss of line power. The unit should include secondary containment as a part of the design. Service-ability should be addressed in the design of the process unit, in particular separation of the areas exposed to radioactive materials from the remainder of the unit. Capital cost has been estimated to be in the range of $\$ 600,000$. to $\$ 800,000$. for the unit at Rocky Flats Plant, and $\$ 900,000$. to $\$ 1,200,000$. for the unit at Weldon Spring Site. Due to their small size and the need, at this early stage of development, for two operators, the operating costs for the Rocky Flats Plant and Weldon Spring Site units are estimated to be approximately $\$ 19.00 . / \mathrm{kg}$ and $\$ 4.40 / \mathrm{kg}$, respectively. Capital cost for a 100 . $\mathrm{kg} / \mathrm{hr}$ mixed waste treatment unit is estimated to be $\$ 2,100,000$. to $\$ 2,800,000$, and operating cost would drop to approximately $\$ 2.50 / \mathrm{kg}$. Over a 10 year lifetime, at 200. sixteen hour days per year of operation, the $100 . \mathrm{kg} / \mathrm{hr}$ unit would have a total cost of approximately $\$ 3.50 / \mathrm{kg}$ of mixed waste treated. This cost does not include any pre- or post-treatment of the residues, or any residues disposal cost. 
Figure 5: The DETOX System

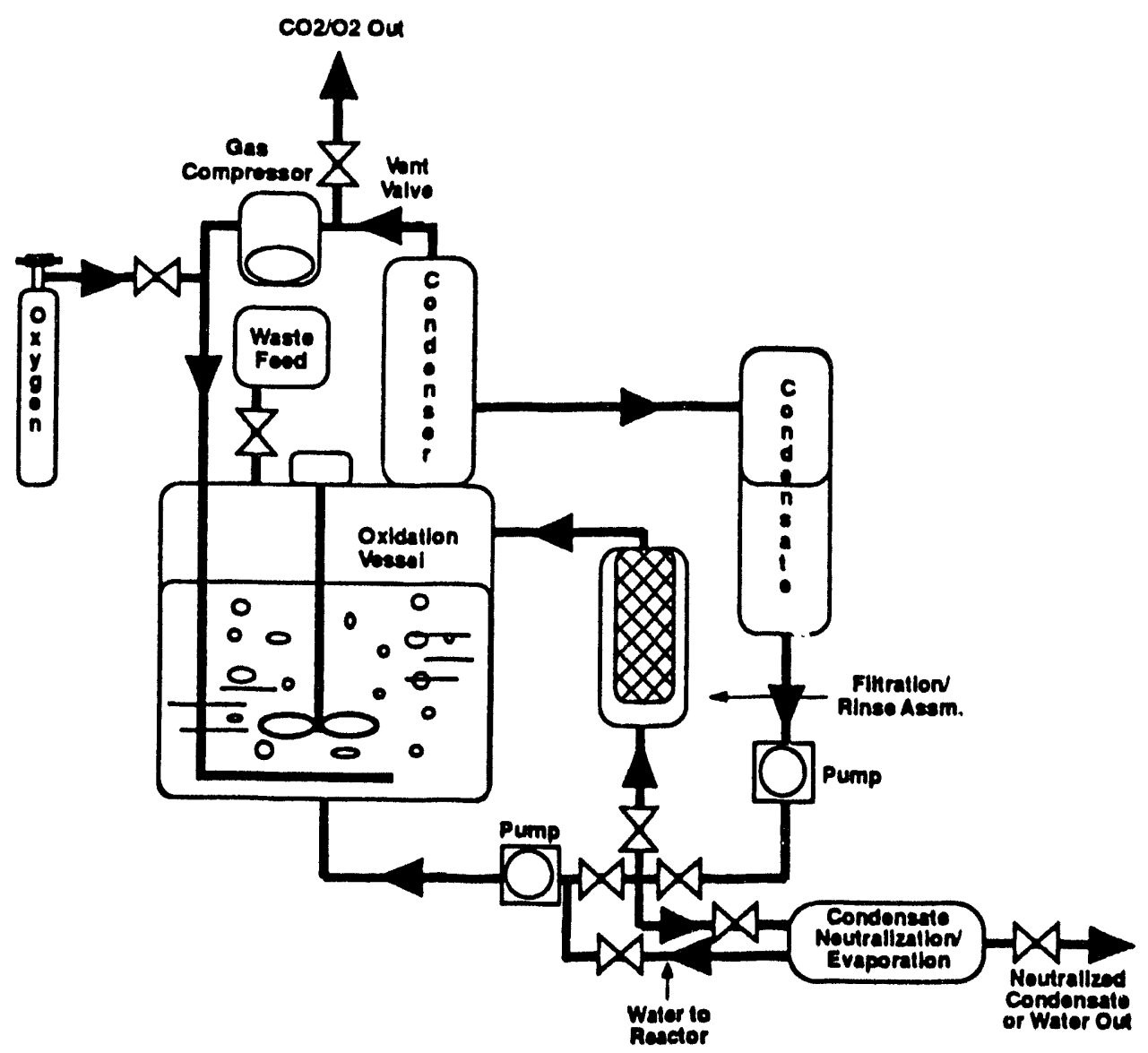

\section{Conclusions}

Based upon work performed in this and related projects (see Appendix A), it has been found that the DETOX process is capable of treating almost all organic, and most inorganic, wastes contaminated with hazardous organics and metals. The process will be able to accept a range of waste types in one unit, such that multiple waste sources can be treated at one installation. The process will be most valuable at present in converting various organic mixed wastes to a radioactive-only form, volume reduction of organic mixed or radioactive wastes, and treatment of inert materials contaminated with hazardous organics, metals, and/or radionuclides. At this point in development, there do not appear to be any major issues which would prevent the design, fabrication, and testing of a prototype DETOX waste treatment unit. 


\section{SECTION 1}

\section{INTRODUCTION}

\subsection{Problem Statement}

Complex multicomponent hazardous and mixed wastes and remediates are a common problem at Department of Energy operational sites and in many areas of the private sector. These materials can contain variable amounts of hazardous and/or toxic organic compounds, hazardous and/or toxic inorganic materials such as heavy metals, and radioactive metals. The hazardous, toxic, and/or radioactive materials may be dispersed in other organic materials, sludges, soils, or water solutions. The problem of mixed waste at Department of Energy sites is particularly acute, since there are few if any methods for its treatment and the Federal Facilities Compliance Act (FFCA) mandates the development of effective methods of dealing with mixed waste at government facilities. What is needed is a robust, fairly omnivorous process for destroying a wide variety of organic waste components, while concentrating the inorganics and radioactive metals in a matrix for ultimate recovery and/or disposal. The process should at the same time minimize air and water emissions, operate safely, and be cost effective.

\subsection{Objective}

The objective of this Project is to develop a catalytic wet oxidation process (DETOX), which utilizes a concentrated, acidic solution of iron chloride and cocatalysts, for the treatment of multicomponent wastes and remediates. Successful development will provide a versatile treatment method which can destroy hazardous organics in a variety of matrices while simultaneously concentrating many metals in the process solution for recovery and/or disposal. The Phase I effort described herein investigates the oxidation of six organic compounds, determines the fate of eleven toxic metals in the process solution, determines the ability of the process solution to treat six soil types contaminated with organics and heavy metals, and provides an engineering study of the application of the process to typical wastes at Department of Energy facilities. Additional efforts to apply the process to different waste streams is currently under way for the University of California, Los Alamos National Laboratory, and the Rocky Flats Plant (see Appendix A). While the process may not provide stand-alone treatment of all applicable waste types, it holds promise of being able to provide significant volume reduction of mixed wastes and remediates, and conversion of mixed waste types to radioactiveonly wastes. Some of the residues from the process would require additional 
treatment, such as immobilization, before ultimate disposal. Other residues, such as excess water and neutralized condensate brine from the process, should be non-hazardous, but under current law would require delisting before release.

\subsection{Process Description}

A patented process, DETOX is a combination of iron ions, a homogeneous oxidation cocatalyst (typically platinum and/or ruthenium ions), and an iron oxidation catalyst in an acid solution. Ferric iron in aqueous acidic solution oxidizes a wide range of organics to simple products (i.e., $\mathrm{CO}_{2}, \mathrm{H}_{2} \mathrm{O}, \mathrm{HCl}$ ) at temperatures of $373 .{ }^{\circ} \mathrm{K}$ to $523^{\circ} \mathrm{K}$. Figure 6 illustrates the process. The typical DETOX solution composition is about $60 . \%$ by weight ferric chloride and $4 . \%$ by weight $\mathrm{HCl}$ in water, with small amounts of dissolved platinum and ruthenium cocatalysts. Ferric iron is responsible for the oxidation of the organic compounds, and is reduced to ferrous iron in the reaction. The ferrous iron is reoxidized to the ferric state by reaction with oxygen. Thus, the iron ions act ultimately as a catalyst, being cycled between the ferric and ferrous states. Extensive previous testing performed by Delphi Research, Inc. both privately and under contract to the U.S. Air Force, the New Mexico Research and Development Institute, and Los Alamos National Laboratory has established the ability of ferric iron to oxidize organic compounds, the effects of temperature on the reaction rate, and the advantages of using the cocatalysts. The details of previous research are too involved to present in this report, but may be found in various reports, technical papers, and patents (1-7).

Figure 6: The DETOX Chemistry

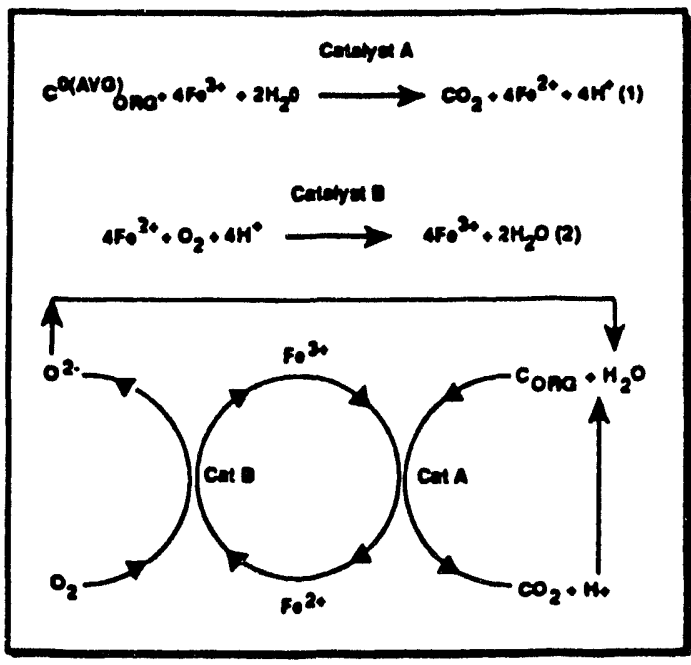




\subsection{Environmental Requirements}

The potential environmental impacts resulting from the Phase I effort, including estimated amounts of hazardous compounds generated, were addressed in a report of information required for the National Environmental Policy Act (NEPA). The NEPA documentation report was approved before any work was begun which might affect the environment. 
This page intentionally left blank 


\section{SECTION 2}

\section{OXIDATION OF ORGANICS}

\section{$2.1 \quad$ Objective}

One of the primary goals of this project was to determine whether the DETOX process ("the process") could successfully destroy a range of organic compounds with good efficiency, especially those known to be hazardous and/or toxic materials. The organic compounds chosen were picric acid (a nitrated aromatic organic), poly(vinyl chloride), tetrachlorothiophene, pentachloropyridine, Aroclor 1260 (a polychlorinated biphenyl), and hexachlorobenzene. Picric acid was chosen as an analog for common nitrated explosives which are found in wastes at some Department of Energy sites and as wastes from weapons dismantlement operations. Poly(vinyl chloride) is a common plastic used in packaging, piping, component encapusulation, and structural materials, and which presents a difficulty in incinerators due to its chlorine content. Tetrachlorothiophene and pentachloropyridine were chosen as both highly chlorinated organic compounds and as compounds containing reduced sulfur and nitrogen, representative of a variety of organic compounds which may be found in hazardous wastes at many Department of Energy Sites. Aroclor 1260 is representative of a class of compounds, polychlorinated biphenyls, which are found in Department of Energy wastes at almost all sites and in remediates at a number of sites, often in combination with radioactive metals, and which are considered quite toxic. Hexachlorobenzene was chosen as a very stable, highly chlorinated organic compound whose concentration in stack gases is often used as a measure of incinerator efficiency.

\subsection{Procedure and Apparatus}

The organic compounds were oxidized in Parr Instrument Company Model 4751, Grade 2 titanium reaction bombs, of $128 . \mathrm{ml}$ total volume. The bombs were equipped with valves such that they could be pressurized with oxygen before oxidation and gas samples taken after oxidation. The bombs were loaded with $50 . \mathrm{ml}$ of DETOX solution and a weighed amount of organic, sealed, pressurized with 690 . $\mathrm{kPag}$ of oxygen, then heated for an appropriate time at 473.K. The bombs were then cooled and pressure checked to verify that they had remained sealed during the test. The test procedure was formalized in an in-house document titled "Procedure for Organic Oxidation and Analysis." 
Gas chromatographic analysis of the oxygen remaining in the bombs and the carbon dioxide levels in the head space gases was conducted using a Carbosphere ${ }^{\mathrm{TM}}$ column and thermal conductivity detector, as per an in-house procedure designated "Analysis of Carbon Dioxide and Oxygen in DETOX Oxidation Tests." Samples were introduced with a gas tight sampling valve and evacuated sample loop. Standardization was by comparison to a calibration curve prepared using the pure gases oxygen and carbon dioxide over a range of injection pressures.

Samples were prepared for volatiles, semivolatiles, PCBs, and dioxin analyses by unsealing the cooled bombs, immediately transferring the entire contents of the bombs to a certified clean, one liter brown glass bottle provided by an independent laboratory, and diluting the solution to approximately $500 . \mathrm{ml}$. For the volatiles samples, a portion of the diluted solution was immediately transferred to completely fill a certified clean, 40 . ml brown glass bottle provided by an independent laboratory, leaving no head space. The bottles were then immediately sealed, labeled, and kept refrigerated, as per U.S. Environmental Protection Agency SW-846, Methods 624 and 8270, for volatiles and semivolatiles analysis, until delivery to an independent commercial analytical laboratory. The samples were shipped to the independent commercial laboratory in an ice chest, using ersatz ice to keep the samples cool until delivery. A chain of custody/analysis specification form was filled out, signed, and included in the ice chest with each batch of samples. The analyses were performed by U.S. Environmental Protection Agency Methods 624 and 8270, by a laboratory certified for these analyses by the Colorado Department of Health. Sampling/trip blanks were included with the volatiles samples. No blanks or spiked samples were submitted for the semivolatiles samples. No process solution blanks were submitted; previous analyses have established the levels of organic contaminants in the as-prepared process solution and in the process solution after heating.

To isolate non-volatile residual material after oxidation, the entire contents of a cooled bomb were filtered, neutralized to a $\mathrm{pH}$ of 7 , filtered again to remove all iron oxides, and evaporated to dryness, as per an in-house procedure designated "Procedure for Isolation of Non-Volatile Organics from DETOX Oxidations." The solids from the first filtration and the evaporate were placed in clean vials and sent to an independent commercial laboratory for determination of total carbon and hydrogen by standard elemental analysis.

There are four probable causes for the disappearance of organics from the reaction bombs in these studies. The organic can escape from the bomb due to bad seals, the organic can be converted to gaseous organic compounds which then escape from the bomb when it is vented, the organic can be oxidized directly by oxygen in the bomb, or the organic can be oxidized by the process. 
Escape of the organic has been eliminated as a possibility by pressure checks of the bombs after oxidation. Conversion to gaseous organics is eliminated both by previous studies in which gaseous organic products were analyzed for and not seen, and by the amounts of oxygen used and carbon dioxide produced in the reactions. Previous studies have demonstrated the increase in oxidation rates of organics in the presence of iron(III) and the fact that iron(III) acts as the oxidant in these oxidations, which eliminates the mechanism of direct oxidation by oxygen. The only remaining probable cause for the disappearance of organics in these tests is oxidation by the process solution.

\subsection{Results}

Results obtained in gas analyses indicated that picric acid, tetrachlorothiophene, poly(vinyl chloride), and pentachloropyridine oxidized completely during 24 hours in the reaction bombs. Picric acid gave some indication that the nitro groups on the molecule were participating as oxidants in the oxidation reaction. The amount of carbon dioxide produced in picric acid oxidation was approximately $100 . \%$ greater than could be accounted for by the amount of oxygen used. The reaction rate for oxidation of Aroclor 1260 was considerably slower, and that for hexachlorobenzene was relatively slow. There was a concern that hexachlorobenzene might not be oxidizing at all, so several tests were run in $23 . \mathrm{ml}$, Teflon ${ }^{\mathrm{TM}}$-lined bombs. Blanks containing no hexachlorobenzene were run simultaneously. Analytical results showed significant amounts of iron(II) in the bombs containing hexachlorobenzene after reaction, confirming that hexachlorobenzene was being oxidized by the DETOX solution. The apparent pseudo-first order oxidation rate constant obtained was about $1.4 \times 10^{-7} \mathrm{sec}^{-1}$. Hexachlorobenzene does oxidize in the DETOX solution, but perhaps at $1 / 10$ the rate of the other organics tested. Previous studies performed for Los Alamos National Laboratory have established the increases in organics' oxidation rates in the presence of iron(III) and the cocatalysts, and the almost first order dependence of reaction rate on iron(III) concentration. This type of test did not need to be conducted for the remainder of the organics tested here, as it was apparent from oxygen use and carbon dioxide production that these materials were oxidizing.

Table I gives the oxidation times which were used in the destruction efficiency tests before samples were collected and sent to an independent commercial laboratory for chemical analysis. It is important to note that though these times do reflect relative reaction rates, they do not reflect the actual reaction rates for the materials. Greater organic loading levels, well mixed conditions, and obviating the necessity to achieve $>99 . \%$ destruction of all organic material in the reaction vessel would result in much greater reaction rates for a waste treatment system. 
Table II gives results of the organic oxidations in terms of specific destruction efficiency (i.e., destruction of the specific compound tested) and absolute destruction efficiency, (i.e., the destruction efficiency for all organic compounds) in the reaction vessels. Some partial oxidation products remain in the reaction vessels. These partial products, in previous testing, were found to be typical of those formed in the oxidation of wastes using the DETOX process.

\section{Table I: $\quad$ Organics' Oxidation Times}

\begin{tabular}{|lc|}
\hline 1.8 Organic Material & Oxidation Time \\
\hline Hexachlorobenzene & 216 \\
Polychlorinated Biphenyl & 216 \\
Picric Acid & 24 \\
Pentachloropyridine & 24 \\
Poly(Vinyl Chloride) & 24 \\
Tetrachlorothiophene & 24 \\
\hline
\end{tabular}

Table II: $\quad$ Organics Destruction Efficiencies

\begin{tabular}{|c|c|c|}
\hline \multirow{2}{*}{ i. } & \multicolumn{2}{|c|}{ Destruction Efficiencies? } \\
\hline & Absolute $(\%)$ & Specific $(\%)$ \\
\hline Picric Acid & 99.7 & \\
\hline Poly(Vinyl Chloride) & 99.8 & \\
\hline Tetrachlorothiophene & 98.1 & 99.925 \\
\hline Pentachloropyridine & 99.5 & 99.984 \\
\hline Aroclor 1260 & 98.9 & 99.52 \\
\hline Hexachlorobenzene & 99.97 & 99.97 \\
\hline
\end{tabular}

- Unmixed reaction bombs at $473^{\circ} \mathrm{K}$ 
Table III gives the analytical results for residual volatile and semivolatile organic compounds after oxidation. The organic compounds detected in these analyses are very typical of what has been seen in previous studies of oxidation with the process. The principal mechanism by which oxidation occurs in the process apparently proceeds through formation of alcohols, aldehydes, ketones, and organic acids as oxygen is progressively added to the oxidized organic. However, another reaction pathway which apparently occurs with considerably less frequency leads to the addition of chlorides, rather than oxygen, to the oxidized organic, creating small amounts of more stable chlorinated organic intermediates. Previous studies conducted for Los Alamos National Laboratory, in which process oxidation reactions were interrupted and the amounts of volatile and semivolatile organics measured, have shown the presence of both oxygenated intermediates and chlorinated intermediates. However, it is apparent from these previous analytical results that formation of chlorinated intermediates represents only a minor reaction pathway in the process. Typical chlorinated intermediates seen in the study here are chlorinated ethanes and ethenes, which form in small amounts during the oxidation of a variety of organics in the DETOX solution. Hexachloroethane has been found to be oxidized at a slow rate by the DETOX solution in previous studies, thus, in time, this compound and the less chlorinated versions will be completely destroyed by the process. Cyclohexenes, cyclohexanols, and chlorinated benzenes are found as native contaminants in the ferric chloride reagent used to prepare the process solution. The cyclohexenes and cyclohexanols are eventually destroyed in the process solution, as can be seen by their absence in the much lengthier Aroclor 1260 and hexachlorobenzene oxidations. Chlorinated benzenes are present in much greater concentrations in the Aroclor 1260 oxidations, and are undoubtedly intermediates in the oxidation reaction. In the unmixed bombs used in these experiments destruction efficiencies have been somewhat limited by lack of mass transfer and by the volatility of the compounds. In previous stirred reactor tests specific destruction efficiencies of $>99.9999 \%$ have been achieved for toluene and 1,2,4-trimethylbenzene. During oxidation of waste organic compounds using the process, one of the concerns is potential release of amounts of volatile organics with the gaseous reaction products and the excess water. Chlorinated organics are usually hazardous to human health, and can contribute to ozone depletion, so it is desirable to minimize release of any of these compounds. One way in which this can be done is by refluxing the reaction vessel outlet to contain the organics. With the exception of trichloroethene, bromodichloromethane, and chloroform, all present in only very small amounts as reaction intermediates, the compounds seen in the analyses have boiling points greater than water, and so can be concentrated in the bottom of the reflux and kept in the reaction vessel until they are destroyed. The small amount of lighter organics which does manage to escape the reaction vessel will be dissolved in the much larger volume of the condensate. These organics can 
be removed from the condensate by sparging it with the oxygen gas being used in the reaction. The oxygen gas will return the lighter organics to the reaction vessel until they are destroyed.

Table IV gives the analysis results for non-volatile carbon and hydrogen remaining after oxidation. The results were consistent with good destruction efficiencies for the DETOX process. A small amount of non-volatile carbon was seen in a couple of instances in the insoluble fraction, representing only several micrograms of residual carbon.

From the results of the oxidations and analyses it is apparent that the DETOX catalyst solution will oxidize a variety of organic compounds. Previous studies have investigated hydrocarbon oils, simple aromatics, and biomass materials, but the results obtained here have widened the range of possible applications to chlorinated aromatics (including polychlorinated biphenyls), nitrated aromatics, chlorinated polymers, and compounds containing heteroatoms such as nitrogen and sulfur. All of these compounds are converted to simple products by the DETOX solution, and can be destroyed with great efficiency. The results for destruction efficiencies obtained in this study are very similar to results obtained for other organics in unmixed reaction vessels. By extrapolation, destruction efficiencies of $99.9999 \%$ or better would be expected for these organics studied in a "ell mixed reaction vessel. 


\section{Table III: Organics' Volatile and Semivolatile Residues}

\begin{tabular}{|c|c|c|c|c|c|}
\hline Organic: & $\operatorname{Run} \theta$ & $\begin{array}{l}\text { Volatile } \\
\text { Compounde }\end{array}$ & $\begin{array}{l}\text { Amoun! } \\
\left(\mu_{g}\right)\end{array}$ & $\begin{array}{l}\text { Semivolatile } \\
\text { Compounds }\end{array}$ & $\begin{array}{l}\text { Amount } \\
\text { (4) }\end{array}$ \\
\hline Poly(Vinyl Chloride) & 1 & Bromodichloromethane & 0.5 & 1,2,4,5-Tetrachlorobenzene & 13 \\
\hline \multirow[t]{8}{*}{0.30 grams } & & Tetrachloroethane & 5 & Pentachlorobenzene & 28 \\
\hline & & Hexachlorobutadiene & 5 & Hexachlorobenzene & 20 \\
\hline & & Pentachloroethane" & 6 & 1-Penten-3-ol & 12 \\
\hline & & Hexachloroethane" & 500 & & \\
\hline & 2 & Bromodichloromethane & 1 & Hexachloroethane & 55 \\
\hline & & Dibromochloromethane & 1 & 1,2,4,5-Tetrachlorobenzene & 20.5 \\
\hline & & Toluene & 5 & Pentachlorobenzene & 120 \\
\hline & & - 12,3,5-Tetrachlorobenzene & 2 & Hexachlorobenzene & 105 \\
\hline Picric Add & 1 & Trichloroethene & 2 & 1,2-Dichlorobenzene & 44 \\
\hline \multirow[t]{10}{*}{0.40 grams } & & Bromodichloromethane & 1 & 3-Chlorocyclohexene" & 13 \\
\hline & & Tetrachloroethane & 30 & 2-Chlorocydohexanol" & 500 \\
\hline & & 1,1,2,2-Tetrachloroethane & 6 & 1,2-Dichlorocyclohexane" & 200 \\
\hline & & Hexachlorobutadiene & 6 & 2-Bromocyclohexanol" & 22 \\
\hline & & Pentachloroethane" & 12 & & \\
\hline & & Hexachloroethane" & 900 & & \\
\hline & 2 & Hexachloroethane" & 50 & Hexachlorobenzene & 17 \\
\hline & & & & 3-Chlorocyclohexene" & 42 \\
\hline & & & & 2-Chlorocydohexanol" & 600 \\
\hline & & & & 1,2-Dichlorocyclohexane" & 440 \\
\hline Tetrachlorothiophene & 1 & Chloroform & 14 & 2-Bromocyclohexanol" & 50 \\
\hline \multirow[t]{9}{*}{0.60 grams } & & Trichloroethene & 41 & & \\
\hline & & Bromodichloromethane & 1 & & \\
\hline & & Tetrachloroethene & 700 & & \\
\hline & & 1,1,2,2-Tetrachloroethane & 55 & & \\
\hline & & Hexachlorobutadiene & 37 & & \\
\hline & & Pentachloroethane" & 180 & & \\
\hline & & Hexachloroethane" & 13500 & & \\
\hline & & Tetrachlorothiophene" & 500 & & \\
\hline & 2 & Trichlorcethene & 7 & 2-Bromocyclohexanol" & 70 \\
\hline
\end{tabular}


Table III: $\quad$ Organics Volatiles and Semivolatiles Residues (cont.)

\begin{tabular}{|c|c|c|c|c|c|}
\hline & & Bromodichloromethane & 2 & Tetrachlorothiophene ${ }^{\circ}(2)$ & 380 \\
\hline & & Tetrachloroethene & 410 & & \\
\hline & & 1,1,2,2-Tetrachloroethane & 35 & & \\
\hline & & Hexachlorobutadiene & 21 & & \\
\hline & & Pentachloroethane" & 55 & & \\
\hline & & Hexachloroethane & 6500 & & \\
\hline & & Tetrachlorothiophene" & 185 & & \\
\hline Pentachloropyridine & 1 & Trichloroethene & 6 & 2-Chlorocyclohexanol" & 11 \\
\hline 0.815 grams & & Bromodichloromethane & 1 & Pentachloropyridine" & 155 \\
\hline & & Tetrachloroethene & 500 & & \\
\hline & & Toluene & 1 & & \\
\hline & & Pentachloroethane" & 14 & & \\
\hline & & Hexachloroethane & 4900 & & \\
\hline & 2 & Tetrachloroethene & $\mathbf{5}$ & Hexachlorobenzene & 105 \\
\hline & & Pentachloroethane" & 4 & Chlorocyclohexanol" & 27 \\
\hline & & Hexachloroethane" & 1250 & Bromocydohexanol" & 90 \\
\hline & & & & Pentachloropyridine" & 115 \\
\hline Polychlorinated Biphenyl & 1 & Nothing delected & & 1,2,4,5-Tetrachlorobenzene & 36 \\
\hline 0.124 grams & & & & Pentachlorobenzene & 1300 \\
\hline & & & & Aroclor 1268 & 11000 \\
\hline & & & & $\begin{array}{l}\text { Pentachlorotrichloro- } \\
\text { ethenylbenzene" } \\
\text { Hexachlorobenzene }\end{array}$ & $\begin{array}{l}34.5 \\
9000\end{array}$ \\
\hline & 2 & Hexachloroethane" & 24 & 1,2,4,5-Tetrachlorobenzene & 11.5 \\
\hline & & & & Pentachlorobenzene & 1150 \\
\hline & & & & Hexachlorobenzene & 1750 \\
\hline & & & & Aroclor 1268 & 1000 \\
\hline Hexachlorobenzene & 1 & Nothing detected & & Hexachlorobenzene & 90 \\
\hline 0.302 grams & & & & & \\
\hline & 2 & Hexachloroethane & 60 & Hexachlorobenzene & 19000 \\
\hline $\begin{array}{l}\text { - Tentatively identified o } \\
\text { 1 If the same compound } \\
\text { the two values is listed } \\
2 \text { Both the volatiles and s }\end{array}$ & & $\begin{array}{l}\text { cted in both the volatiles } \\
\text { les results for tetrachloroth }\end{array}$ & & $\begin{array}{l}\text { as analyses, only the greater of } \\
\text { or this run. }\end{array}$ & \\
\hline
\end{tabular}




\section{Table IV: $\quad$ Organics Non-volatiles Residues}

\begin{tabular}{|c|c|c|c|}
\hline \multirow[b]{2}{*}{ Organies Oxidized } & \multirow[b]{2}{*}{$R_{i=1}$} & \multicolumn{2}{|c|}{ Soluble Fraction } \\
\hline & & Amount of Carbon (mp) & Amount of Hydrogen (mg) \\
\hline \multirow[t]{2}{*}{ Poly(Vinyl Chloride) } & 1st Run & $<25$ & 830 \\
\hline & 2nd Run & $<25$ & 595 \\
\hline \multirow[t]{2}{*}{ Picric Acid } & 1st Run & $<25$ & 680 \\
\hline & 2nd Run & $<25$ & 1000 \\
\hline \multirow[t]{2}{*}{ Tetrachlorothiophene } & 1st Run & $<25$ & 305 \\
\hline & 2nd Run & $<25$ & 20 \\
\hline \multirow[t]{2}{*}{ Pentachloropyridine } & 1st Run & $<25$ & 195 \\
\hline & 2nd Run & $<25$ & 1100 \\
\hline \multirow[t]{2}{*}{ Aroclor 1260} & 1st Run & & \\
\hline & 2nd Run & $<24$ & 173 \\
\hline \multirow[t]{2}{*}{ Hexachlorobenzene } & 1st Run & $<27$ & $<27$ \\
\hline & 2nd Run & $<35$ & 203 \\
\hline \multicolumn{2}{|c|}{ 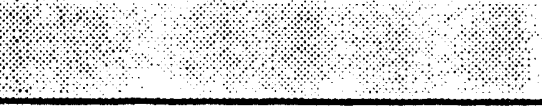 } & Non-Solu & Ie fraction \\
\hline \multirow[t]{2}{*}{ Poly(Vinyl Chloride) } & 1st Run & $2.8 \times 10^{-3}$ & $1.2 \times 10^{-3}$ \\
\hline & 2nd Run & $1.2 \times 10^{-2}$ & $2.3 \times 10^{-3}$ \\
\hline \multirow[t]{2}{*}{ Picric Acid } & 1st Run & $4.5 \times 10^{-4}$ & $2.7 \times 10^{-3}$ \\
\hline & 2nd Run & $8.5 \times 10^{-4}$ & $1.0 \times 10^{-3}$ \\
\hline \multirow[t]{2}{*}{ Tetrachlorothiophene } & 1st Run & $1.7 \times 10^{-3}$ & $2.8 \times 10^{-3}$ \\
\hline & 2nd Run & $5.5 \times 10^{-4}$ & $2.8 \times 10^{-3}$ \\
\hline \multirow[t]{2}{*}{ Pentachloropyridine } & 1st Run & $9.5 \times 10^{-4}$ & $4.1 \times 10^{-3}$ \\
\hline & 2nd Run & $2.7 \times 10^{-3}$ & $2.4 \times 10^{-3}$ \\
\hline \multirow[t]{2}{*}{ Aroclor 1260} & 1st Run & & \\
\hline & 2nd Run & $8.4 \times 10^{-4}$ & $6.8 \times 10^{-3}$ \\
\hline \multirow[t]{2}{*}{ Hexachlorobenzene } & 1st Run & $3.6 \times 10^{-4}$ & $1.0 \times 10^{-3}$ \\
\hline & 2nd Run & $3.7 \times 10^{-4}$ & $8.2 \times 10^{-4}$ \\
\hline
\end{tabular}


This page intentionally left blank 


\section{SECTION 3}

\section{INORGANIC FATE TESTS}

\subsection{Objective}

In processing hazardous and mixed waste containing toxic metals, one must know if, how, how often, and in what form the metals will be removed from the process in order to accurately estimate the quantities and compositions of secondary waste streams from the process. The answers to these questions depend chiefly on the solubility of the metals in the process solution and in the anticipated condensate from the process, which could be used as a recyclable rinse for any solids isolated during processing. Therefore, in order to determine the fate of a range of metals in the DETOX solution, a series of inorganic solubility tests were performed. Although much solubility data exists for metals and metal salts in fairly dilute aqueous solutions, such data is not available for the more highly concentrated DETOX medium. Solubility values can be calculated for the process medium, but need to be verified by experimentation. Since metals which may form sparingly soluble or insoluble phosphates, sulfates, chlorides, oxyacids, and/or oxides in the process solution might present difficulties, metals such as arsenic, barium, cadmium, chromium, lead, and mercury had to be evaluated for their solubility in the DETOX solution. Also, the fate of the metals in the presence of varying amounts of anions needed to be evaluated.

\subsection{Procedure and Apparatus}

The studies of metals' fates were conducted in Parr Instrument Company Model 4749, 23. $\mathrm{ml}$ general purpose, Teflon ${ }^{\mathrm{TM}}$-lined reaction bombs. All metals and metal compounds used were high purity or reagent grade materials.

In order to determine the fate of the representative metals during waste processing, the metals had to be exposed to the process solution at the anticipated operating temperature for a period of time sufficient to allow any reactions to occur. In a typical test a bomb was loaded with $10 \mathrm{ml}$ of DETOX solution and a weighed amount of the metal, metal oxide, or metal salt to be tested, sealed, and heated for about 18 . hours at $473 .{ }^{\circ} \mathrm{K}$. The bomb was then cooled and the resulting DETOX solution filtered to isolate solids. Solids formed during the heating period would contain any precipitate formed by the metal in the process solution. The solids were weighed to quantify the amount of precipitate, and then rinsed with a $10 . \% \mathrm{HCl}$ solution to simulate 
the use of condensate from a DETOX waste treatment system to rinse solids. Any material which was not soluble in the rinse was digested with aqua regia and/or nitric acid to put the metallic components into solution for analysis. In these studies, each metal was tested separately to determine its characteristics in the process solution. Since the majority of the metals tested here form discrete metal cation complexes in aqueous solution, there should be little change in individual solubilities for mixtures of these metals in the process solution. The only exception for these studies was arsenic, which forms the arsenate anion in the process solution. However, as determined in the studies, excess arsenate precipitates as iron(III) arsenate due to the very great amount of iron(III) present in the process solution. The test procedure was formalized in an in-house document designated "Procedure for Determining Solubility of Inorganics in DETOX Solutions." All of the resulting solutions, (i.e., the DETOX solution, the rinsate, and the digestion) were then analyzed by atomic absorption spectrophotometry (AAS) for the metal of interest as per standard techniques, using appropriate standard solutions and spikes, to determine the fractions of soluble metal, insoluble but rinsable metal, and insoluble metal.

For the arsenic and barium insolubles, the U.S. EPA's Toxicity Characteristic Leaching Procedure (TCLP) was performed to determine the potential status of these insolubles as hazardous materials. The procedure as given in the U.S. Code of Federal Regulations (CFR) 40, Part 261, Appendix II (Revised July 1, 1991) was followed for these tests, using Extraction Fluid \#1. Extraction Fluid \#1 is a sodium acetate buffer solution with a pH of approximately 4.93, specified by the U.S. Environmental Protection Agency as one of the standard extraction solutions for determining heavy metal content in materials which are being tested to determine their status as hazardous or non-hazardous wastes. Subsequent to extraction, AAS standard techniques were used to analyze for the metals of interest.

Chromium (VI) amounts were determined by using the diphenyl carbazide colorimetric method as given in the APHA-AWWA-WPCF Standard Methods for the Examination of Water and Wastewater, 15th Edition (1980). This is a highly specific method for analysis of chromium (VI).

AAS calibration was accomplished using standard solutions in the appropriate concentrations for the metals of interest. For all metals, checks were made by standard addition to determine whether there was any matrix effect from the DETOX solution. The only matrix effect found was enhanced barium absorption in the presence of calcium and iron. This was corrected by using the technique of standard additions. Cerium analysis had to be conducted by flame emission, rather than absorption. Both cerium and neodymium analyses had rather poor sensitivity. 
Solubility of metals in the process solution is a relatively straightforward determination, since there is no possible loss of metal due to evaporation at the process temperature, and the amounts of metals measured in the various fractions can be summed to verify that all of the metal added has been accounted for in the analytical results. All tests were performed in duplicate to verify the repeatability of the results obtained.

\subsection{Results}

Results of the tests with the "soluble" metals are given in Table $\mathrm{V}$ and shown graphically in Figures 7-9. Several unexpected results were obtained. Cadmium proved to be significantly less soluble than would be expected from the listed solubility of cadmium chloride in water, adjusted for the increased chloride concentration in the DETOX solution. The precipitated cadmium did appear to be in the form of the simple chloride salt, however, and it was soluble in water and $1 . \% \mathrm{HCl}$. Neodymium and cerium, the surrogates for uranium and plutonium, proved to be considerably more soluble in the DETOX solution than would be expected from the listed solubilities of their chloride salts. Cerium proved to be very soluble in the DETOX solution, and is believed to form a fairly stable supersaturated solution with a concentration as high as $400 .-500$. grams Ce per liter. The saturated solubility for cerium was greater than 100. grams per liter. It appears that it would be appropriate to limit the amount of sulfate anion in the DETOX solution, because of the negative effect on the solubility of several of the metals. Phosphate anion seems to have some deleterious effects on solubility, but they are not as pronounced compared to the effects exhibited in the presence of sulfate. This may occur because at the $\mathrm{pH}$ of the DETOX solution most phosphate is in the form of $\mathrm{H}_{3} \mathrm{PO}_{4}$. 
Table V: $\quad$ Solubl: Metals Data

\begin{tabular}{|c|c|c|c|c|c|c|c|}
\hline \multirow{2}{*}{ : } & \multicolumn{7}{|c|}{ Solubility in Grans per Liter in Medium } \\
\hline & A & $\mathrm{B}$ & C. & $\mathrm{D}$ & $\mathrm{E}$ & F & 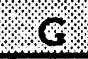 \\
\hline \multirow[t]{2}{*}{$\begin{array}{l}\text { Beryllium } \\
\text { Cadmium } \\
\text { Cerium } \\
\text { Chromiun } \\
\text { Mercury } \\
\text { Neodymium } \\
\text { Nickel } \\
\text { Vanadium } \\
\end{array}$} & $\begin{array}{c}45 . \\
16 . \\
100 . \\
100 . \\
400 . \\
80 . \\
94 . \\
78 .\end{array}$ & $\begin{array}{c}27 . \\
9.7 \\
100 . \\
56 . \\
440 . \\
150 . \\
99 . \\
87 .\end{array}$ & $\begin{array}{r}33 . \\
4.4 \\
100 . \\
82 . \\
530 . \\
150 . \\
120 . \\
92 .\end{array}$ & $\begin{array}{r}48 . \\
4.4 \\
100 . \\
82 . \\
470 . \\
27 . \\
130 . \\
87 .\end{array}$ & $\begin{array}{c}28 . \\
1.4 \\
100 . \\
82 . \\
500 . \\
7 . \\
130 . \\
75 .\end{array}$ & $\begin{array}{r}26 . \\
4.1 \\
100 . \\
74 . \\
410 . \\
91 . \\
110 . \\
84 .\end{array}$ & $\begin{array}{r}18 . \\
3.6 \\
100 . \\
69 . \\
300 . \\
83 . \\
120 . \\
87 .\end{array}$ \\
\hline & \multicolumn{3}{|c|}{$\begin{array}{l}\dot{A}=6.0 \mathrm{M} \mathrm{FeCl}_{3}+1.0 \mathrm{M} \mathrm{HCl} \\
\mathrm{B}=6.0 \mathrm{M} \mathrm{FeCl}_{3}+2.0 \underline{\mathrm{M}} \mathrm{HCl} \\
\mathrm{C}=6.0 \underline{\mathrm{M}} \mathrm{FeCl}_{3}+0.5 \underline{\mathrm{M}} \mathrm{HCl} \\
\mathrm{D}=\mathrm{A}+0.1 \mathrm{M} \mathrm{SO} 4\end{array}$} & \multicolumn{3}{|c|}{$\begin{array}{l}E=A+0.2 \underline{M} \mathrm{SO}_{4} \\
F=A+0.1 \underline{M} \mathrm{PO}_{4} \\
G=A+0.2 \underline{M} \mathrm{PO}_{4}\end{array}$} & \\
\hline
\end{tabular}

- Cerium is at least as soluble as the value listed

\section{Figure 7: Metal Solubility versus Acid Concentration}

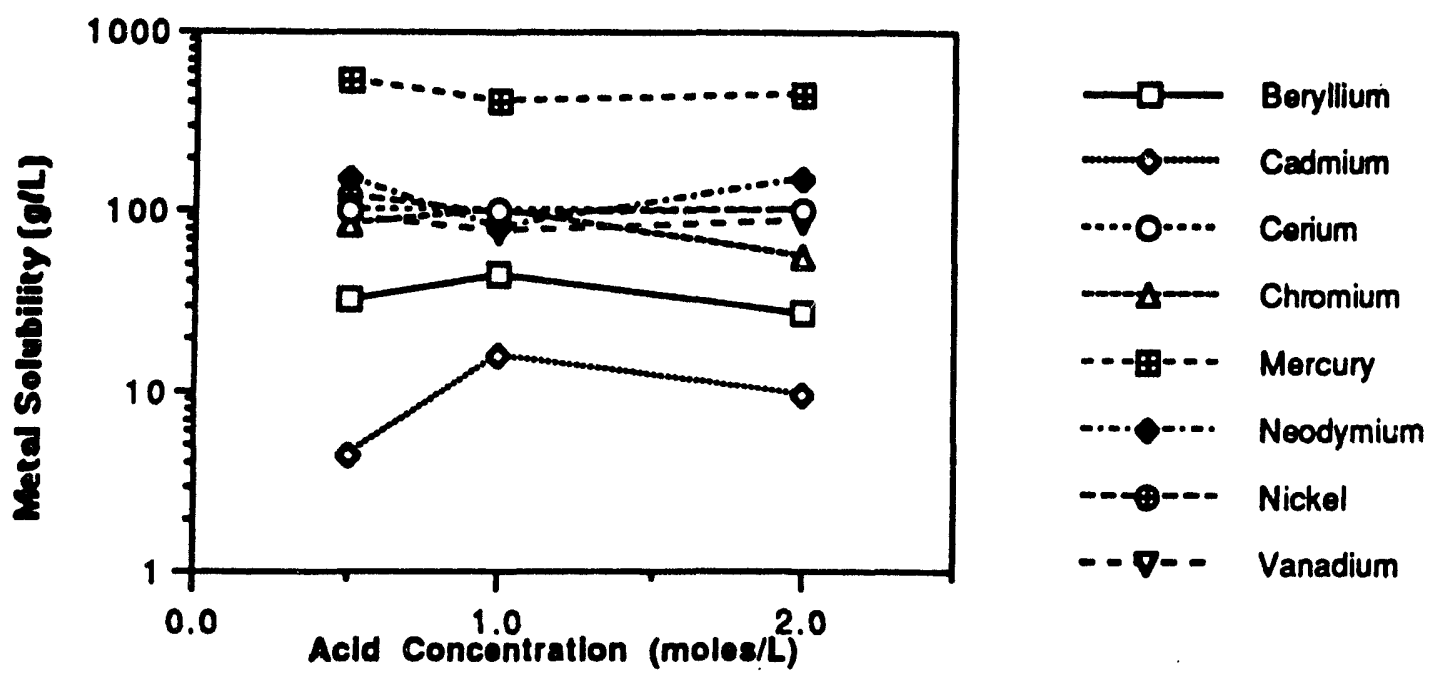




\section{Figure 8: Metal Solubility versus Phosphate Concentration}

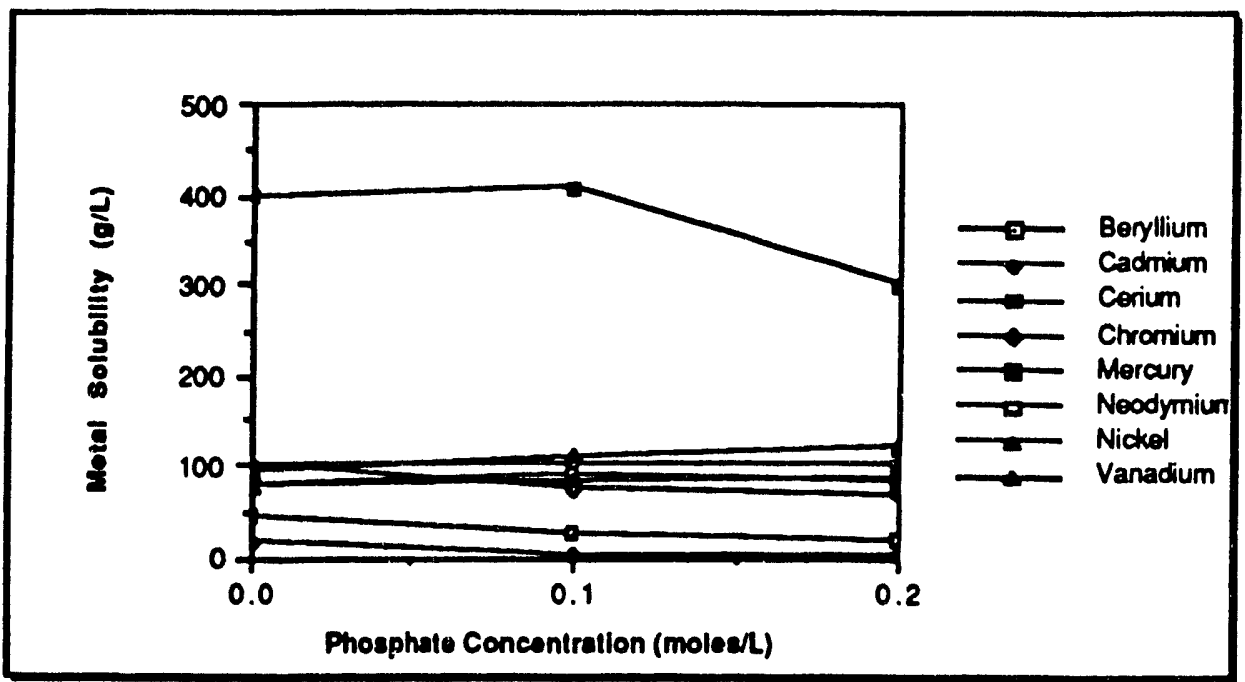

Figure 9: Metal Solubility versus Sulfate Concentration

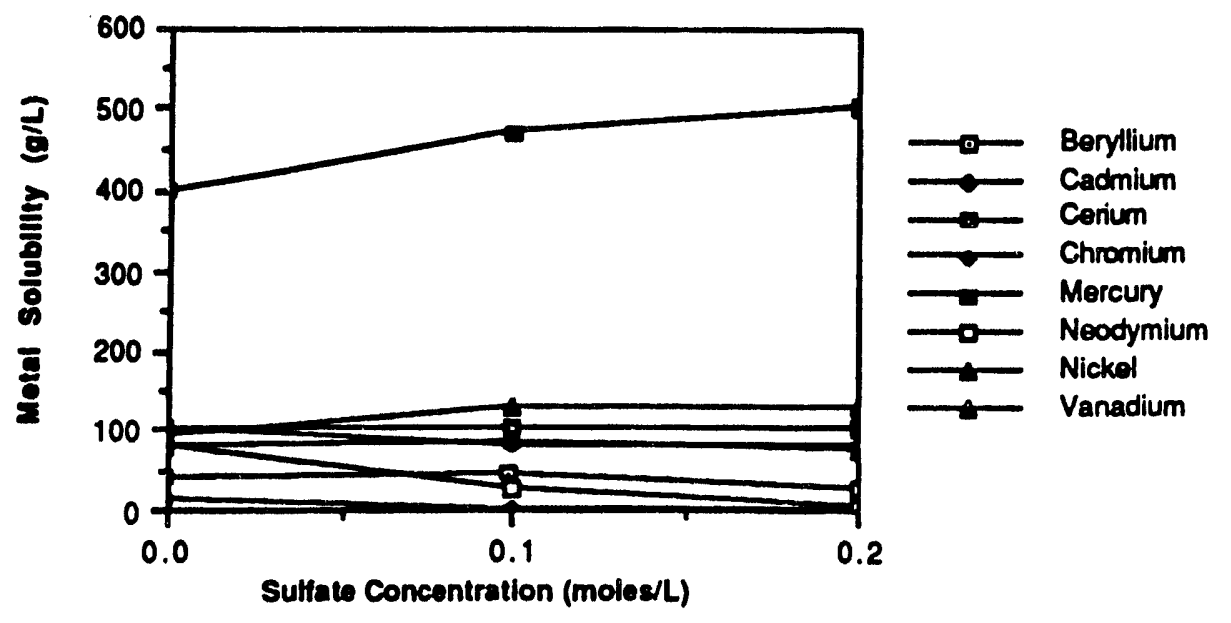


Results of tests for the fate of chromium in chloride- and sulfate-based DETOX solutions indicated that chromium was quite soluble in chloridebased DETOX, to the extent of about 100. grams per liter. Since chromium proved to be a soluble metal, it was added to the group of metals to be evaluated for solubility in the presence of varying acid and anion concentrations. Results can be found in Table V. More significant, however, were results of studies for the fate of chromium (VI) in the DETOX solution. It was felt, originally, that chromium might form an insoluble chloride, oxide, or oxychloride in the DETOX chloride-based solution. Therefore, it was decided to perform studies for the fate of chromium (VI) using both a chloride-based DETOX solution and a sulfate-based DETOX solution. The results of the chromium (VI) studies are given in Table VI. The sulfate-based DETOX solution, prepared with iron sulfate rather than iron chloride, proved to be unsuitable for chromium (VI), because it would not effectively reduce chromium (VI) to chromium (III). The fully oxidized chloride-based DETOX solution reduced chromium (VI) to chromium (III) with approximately $90 . \%$ efficiency. With the addition of iron (II), reduction of chromium (VI) was found to be complete. Iron (II) will be present in the case of the operating DETOX treatment system.

\section{Table VI: Chromium(VI) Results}

\begin{tabular}{|c|c|c|c|}
\hline $\operatorname{resto}$ & Conditions. & $\begin{array}{l}\text { Before Treatment: } \\
\text { cr (vi) }\left(m_{g}\right) \text {. }\end{array}$ & $\begin{array}{l}\text { Aftetreatment } \\
\text { cront (ng) }\end{array}$ \\
\hline 1 & Sulfate DETOX & 100 & 43 \\
\hline 2 & Sulfate DETOX & 100 & 54 \\
\hline 1 & Standard Chloride DETOX $\left(100 \% \mathrm{Fe}^{3+}\right)$ & 100 & 9.6 \\
\hline 2 & Standard Chloride DETOX $\left(100 \% \mathrm{Fe}^{3+}\right)$ & 100 & 9.6 \\
\hline 1 & Chloride DETOX $\left(90 \% \mathrm{Fe}^{3+}, 10 \% \mathrm{Fe}^{2+}\right)$ & 100 & $<0.25\left(\mathrm{ND}^{*}\right)$ \\
\hline 2 & Chloride DETOX $\left(90 \% \mathrm{Fe}^{3+}, 10 \% \mathrm{Fe}^{2+}\right)$ & 100 & $<0.25\left(N^{*}\right)$ \\
\hline
\end{tabular}

* = None Detected

Barium is a relatively common heavy metal contaminant, and is very similar to radium in its chemical properties. Barium chloride is somewhat soluble, but barium sulfate is very insoluble. Therefore, tests were conducted to determine the solubility of barium in the DETOX chloride-based solution containing different amounts of sulfate. Calcium was added as a scavenger ion to determine whether it could effectively remove sulfate from the DETOX 
solution and thus keep barium soluble. The goals of these tests were to determine the solubility of barium in the process solution, to determine the solubility of barium in the presence of sulfate anions in the process solution, and to determine the ability of calcium to increase barium solubility by scavenging sulfate. The results of these tests are given in Table VII. Barium is slightly more soluble in the DETOX chloride solution than would be expected from the listed solubility of barium chloride in water. When the chloride concentration of the DETOX solution is taken into account, barium should be soluble to the extent of about 1.2 grams per liter of DETOX solution. The addition of sulfate anions to the DETOX solution had the expected effect of precipitating barium as the insoluble sulfate. Addition of calcium chloride inhibited the precipitation of barium at approximately $1.0 \mathrm{M} \mathrm{Ca}$ in the DETOX solution. At $2.0 \mathrm{M} \mathrm{Ca}$ the solubility of barium was about 1.15 grams per liter even in the presence of an amount of sulfate equivalent to $0.1 \mathrm{M} \mathrm{SO}{ }_{4}^{2-}$. In these tests barium was added after sulfate. Additional tests were run where sulfate was added after barium in the presence of $2.0 \mathrm{M}$ and $4.0 \mathrm{M} \mathrm{Ca}$. Solubility of barium decreased significantly in the presence of $0.1 \mathrm{M}$ sulfate when sulfate was added to a DETOX solution already containing barium. The solubility of barium was stable, or actually increased slightly, when the equivalent of $0.2 \mathrm{M}$ sulfate was added to a DETOX solution already containing barium. Increasing the calcium concentration to the equivalent of $4.0 \mathrm{M} \mathrm{Ca}$ increased barium solubility above levels seen in the DETOX solution alone. The goals of determining barium solubility in the process solution, and in the presence of sulfate and calcium, were achieved. Addition of calcium to the DETOX solution will be of value in scavenging sulfate anion and thus increasing the solubility not only of barium, but also of several of the "soluble" metals. The data obtained in these tests can be used to specify the amount of calcium it is desirable to keep in the process solution in order to effectively scavenge sulfate. This amount appears to be approximately $2.0 \mathrm{M}$ or $5 . \%$ by weight. It was felt that it would be worthwhile to determine whether the solids from the barium tests would pass the EPA TCLP procedure, since any solids isolated from the process in waste treatment would have to be tested by this procedure to determine whether they contained hazardous amounts of extractable barium (as well as other toxic metals). The TCLP extraction and analysis of the extract was performed inhouse. All but two of the solids from the barium tests proved to be nonhazardous (i.e., less that 100. ppm of barium was found in the extracts). The TCLP results are given in Table VIII. These results establish the ability of solids produced from the process in application to barium-containing wastes to meet the Resource Conservation and Recovery Act's criterium as nonhazardous waste in terms of extractable barium content. 
Table VII: Barium Test Results

\begin{tabular}{|c|c|c|c|}
\hline Test Description & $\begin{array}{c}\text { [Sulfate] } \\
\text { (molealliter) }\end{array}$ & $\begin{array}{l}\text { [Calclum] } \\
\text { (moles/liter) }\end{array}$ & $\begin{array}{l}\text { Barium Solubillty } \\
\text { (gmiliter DETOX) }\end{array}$ \\
\hline Barium Chloride in DETOX & 0 & 0 & 1.55 \\
\hline DETOX + Sulfate + Barium & 0.1 & 0 & 0.33 \\
\hline Chloride (In That Order) & 0.2 & 0 & 0.03 \\
\hline DETOX + Calcium + Sulfate + & 0.1 & 0.5 & 0.55 \\
\hline \multirow[t]{7}{*}{ Barium (In That Order) } & 0.2 & 0.5 & 0.67 \\
\hline & 0.1 & 1 & 1.3 \\
\hline & 0.2 & 1 & 0.71 \\
\hline & 0.1 & 2 & 11.4 \\
\hline & 0.2 & 2 & 4.6 \\
\hline & 0.1 & 4 & 27 \\
\hline & 0.2 & 4 & 19.3 \\
\hline DETOX + Calcium + Barium + & 0.1 & 2 & 6 \\
\hline \multirow[t]{3}{*}{ Sulfate (In That Order) } & 0.2 & 2 & 6.8 \\
\hline & 0.1 & 4 & 11.7 \\
\hline & 0.2 & 4 & 22.3 \\
\hline \multicolumn{4}{|c|}{$\begin{array}{l}\text { Barium which was not soluble in the tests containing sulfate was in the form of the } \\
\text { insoluble barium sulfate. In the test without sulfate, barium which was not soluble in } \\
\text { the DETOX solution was in the form of excess barium chloride precipitate. }\end{array}$} \\
\hline
\end{tabular}


Table VIII: Barium TCLP Results

\begin{tabular}{|lc|}
\hline \multicolumn{1}{|c|}{ Concentrations in the Order Added } & ppm of Barium \\
\hline $\mathrm{Ba}+.1 \mathrm{M} \mathrm{SO} 4$ & 6.40 \\
$\mathrm{Ba}+.2 \mathrm{M} \mathrm{SO}$ & 11.90 \\
$\mathrm{Ba}+.1 \mathrm{M} \mathrm{SO}+.5 \mathrm{M} \mathrm{Ca}$ & 29.50 \\
$\mathrm{Ba}+.1 \mathrm{M} \mathrm{SO}+1.0 \mathrm{M} \mathrm{Ca}$ & 255.00 \\
$\mathrm{Ba}+.1 \mathrm{M} \mathrm{SO}+2.0 \mathrm{M} \mathrm{Ca}$ & 22.00 \\
$\mathrm{Ba}+.2 \mathrm{M} \mathrm{SO}+.5 \mathrm{M} \mathrm{Ca}$ & 2.20 \\
$\mathrm{Ba}+.2 \mathrm{M} \mathrm{SO}+1.0 \mathrm{M} \mathrm{Ca}$ & 15.20 \\
$\mathrm{Ba}+.2 \mathrm{M} \mathrm{SO}+2.0 \mathrm{M} \mathrm{Ca}$ & 7.30 \\
$2.0 \mathrm{M} \mathrm{Ca}+\mathrm{Ba}+.1 \mathrm{M} \mathrm{SO}$ & 5.60 \\
$2.0 \mathrm{M} \mathrm{Ca}+\mathrm{Ba}+.2 \mathrm{M} \mathrm{SO}$ & 18.70 \\
$4.0 \mathrm{M} \mathrm{Ca}+.1 \mathrm{M} \mathrm{SO}+\mathrm{Ba}$ & 132.00 \\
$4.0 \mathrm{M} \mathrm{Ca}+.2 \mathrm{M} \mathrm{SO}+\mathrm{Ba}$ & 69.00 \\
$4.0 \mathrm{M} \mathrm{Ca}+\mathrm{Ba}+.1 \mathrm{M} \mathrm{SO}$ & 17.40 \\
$4.0 \mathrm{M} \mathrm{Ca}+\mathrm{Ba}+.2 \mathrm{M} \mathrm{SO} 4$ & 1.90 \\
\hline
\end{tabular}

Arsenic was expected to form arsenate in the DETOX solution, and perhaps to form an arsenic acid precipitate. Tests showed an arsenic solubility of about 3.0 grams per liter DETOX solution. The oxidation state of the arsenic in the oxides used in these tests did not affect solubility. All arsenic was apparently oxidized to the +5 oxidation state by the DETOX solution. The form of precipitated arsenic was found to be iron (III) arsenate $\left(\mathrm{FeAsO}_{4} \cdot 2 \mathrm{H}_{2} \mathrm{O}\right.$ ), rather than arsenic acid. The evidence proving this was the formation of a green precipitate. The precipitate could not be dissolved in water, dilute acid, or base, but it could be dissolved in dilute $(0.1 \mathrm{M})$ citric acid, giving a yellow colored solution. Additional tests were conducted to identify the arsenic extraction efficiency of citrate solution. Although arsenic could not be entirely extracted by $0.1 \mathrm{M}$ citric acid, enough of the arsenic was extracted from inert solids (sand was used as the inert solid) so that the solids were found to be non-hazardous by the EPA TCLP test. Results were 4.0 and $4.6 \mathrm{ppm}$ arsenic in the extract for duplicate tests. This is the case when there is sufficient arsenic in the DETOX solution to allow a precipitate to form. In many instances the solubility of 3.0 grams per liter for arsenic will be sufficient to solubilize small amounts of arsenic found in large amounts of waste materials. In waste processing, it may be important to characterize the amount of arsenic in wastes in order to determine whether rinsing: any residual solids with citric acid solution would be necessary. Similarly, if it is 
suspected that selenium and/or antimony are present in any significant amounts, these elements should also be characterized in the waste, since they will act much like arsenic and residual amounts of their salts will probably have to be removed with dilute citric acid.

Mercury proved to be a soluble metal, and so was added to the list of soluble metals whose results are given in Table V. Lead was tested as the metal, the sulfate, and the oxide (litharge). Lead behaved as expected, with limited solubility in the DETOX solution. Lead solubility in the standard catalyst solution $\left(6.0 \mathrm{M} \mathrm{FeCl}_{3}\right)$ was only about 0.35 grams per liter at room temperature, but the solubility increased to about 0.57 grams per liter at 323. ${ }^{\circ} \mathrm{K}$, and to about $0.80 \mathrm{grams}$ per liter at $348 .{ }^{\circ} \mathrm{K}$. Excess lead was found to precipitate as pure lead chloride. Lead solubility at room temperature increased to about 3.1 grams per liter in a $3.0 \mathrm{M} \mathrm{FeCl}_{3}$ DETOX solution, then decreased to around 2.2 grams per liter in a $1.5 \underline{\mathrm{M}} \mathrm{FeCl}_{3}$ DETOX solution. Thus, there is an optimum concentration of the DETOX solution for treating $\mathrm{Pb}$-containing materials. Although the exact maximum solubility point was not identified, it is clear that this point exists at an iron chloride concentration somewhere between $6.0 \mathrm{M}$ and $1.5 \mathrm{M}$. In the more dilute catalyst solutions, the same trend of increasing solubility with temperature was seen. The results of these studies are illustrated in Figure 10. Lead solubility changes of approximately $20 x$ or more can be achieved by manipulation of the catalyst solution concentration and temperature, allowing preferential separation of lead from the catalyst solution. Sulfate appears to have a deleterious effect on the ability to remove lead from the solids when rinsing,. Thus. it is advisable to use calcium as a sulfate scavenger in the DETOX solution.

\section{Figure 10: Lead Solubility in Chloride-Based DETOX Solutions}

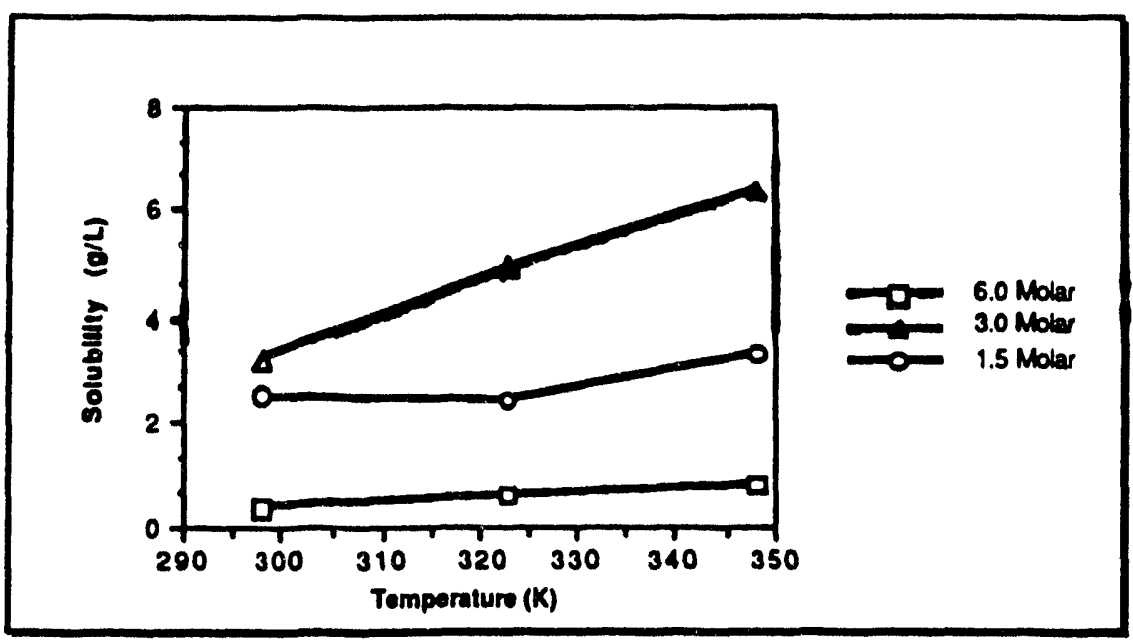


It is apparent that the process can handle a variety of toxic heavy metals, but that process units will sometimes require a solids separation/rinse system If a great amount of organic wastes are being treated with a process unit which does not have a solids removal system, the amount of any inorganic element which is suspected to be present at a concentration greater than that calculated based on the processing unit volume, total amount of waste, and the allowable maximum amounts of solids in the reaction vessel must be quantified to defermine how much of the element will dissolve in the process solution and how much will remain as solids. If a solids separation system is designed as part of the unit, it will probably not be necessary to determine the inorganic constituents of wastes closely, since solids separation will be performed as a matter of course during waste treatment. The only common element capable of driving iron(III) out of solution is calcium, therefore if a waste is suspected of containing a significant amount of calcium it should be analyzed for this element. Excessive calcium can be scavenged from the process solution using phosphate or sulfate anions. The other two reasonably common inorganic materials in wastes which should be characterized before waste processing are cyanide and sulfide. Both cyanide and sulfide will form poisonous acid gases when they come in contact with the process solution. These gases can be contained in the process solution and destroyed, but one must know if they will be generated in order to configure the treatment unit to handle them. 
This page intentionally left blank 


\section{SECTION 4}

\section{CONTAMINATED SOIL TESTS}

\subsection{Objective}

Not all wastes and remediates are "pure" materials. Many materials which need to be treated are sludges, soils, or other types of solids, or semi-solids, which contain a large fraction of "inert" components. The objectives of this task were to assess whether the catalytic wet oxidation process (DETOX) could successfully remove heavy metals and hazardous organics from soils, and to determine whether residues of the process solution could be effectively rinsed from the treated soils. While it may be possible to remove some organic and metallic contaminants from soils with simple rinsing, often the removal efficiency is not great. Flushing soils with water or water containing metal complexing agents can remove some metals, but one is left with a waste water containing complexing agent, toxic metals, and perhaps hazardous organic compounds. Flushing with water solutions of organic surfactants can remove some hazardous organic compounds, but again removal efficiency may not be great and one is left with a waste surfactant solution containing hazardous organic compounds and perhaps toxic metals. Removal of both hazardous organic compounds and toxic metals using flushing techniques would require at least two different flushing agents, and result in two different secondary waste streams which contain the contaminants. In contrast, treatment of contaminated soils with the process holds promise of simultaneously destroying hazardous organic compounds (thus eliminating them as a concern in any secondary waste stream) and extracting toxic metals with great efficiency. The resulting secondary waste streams from the process would be a small quantity of distilled water, which should not contain any contaminants, and the process solution after it has concentrated toxic metals from a great quantity of soil.

\subsection{Procedure and Apparatus}

Originally, artificial soils were proposed to be used for all soil tests. Consultation with soils scientists at Hyponex, and Dr. Emmitt Schulte at the University of Wisconsin, indicated that artificial mixtures would not be representative of real-world conditions in soils treatment, since particle sizes in the artificial mixtures would not match those of standard soil types. All soils experts agreed that it would be highly desirable to use actual soils in our studies. Therefore, we chose six soils which cover a range of possible soil 
compositions, namely, a sand, a silty loam, a sandy clay loam, a loam, a clay loam, and a clay. Figure 11 is the standard texture triangle used for classifying soil compositions.

Soil samples were collected from varying locations. Plano and Plainfield soils were collected from Wisconsin. Kinney Brick, Mountain Clay, and South Valley were collected from different locations in New Mexico. Due to the difficulty in obtaining a true clay soil for testing, a clay soil was prepared by adding clay (kaolin) to the clay loam soil (Mountain Clay). The proportions were $60 . \mathrm{gm}$ of the clay loam and $40 . \mathrm{gm}$ of kaolin, which resulted in a total clay content of $59.9 \%$ (well within the composition range for a true clay soil). The ingredients were slurried with water, mixed well, and allowed to dry under ambient outdoor conditions. The soil samples were characterized for texture (particle distribution), $\mathrm{pH}$, and organic content by an independent laboratory. Table IX summarizes the soils and their characteristics.

Figure 11: Texture Triangle

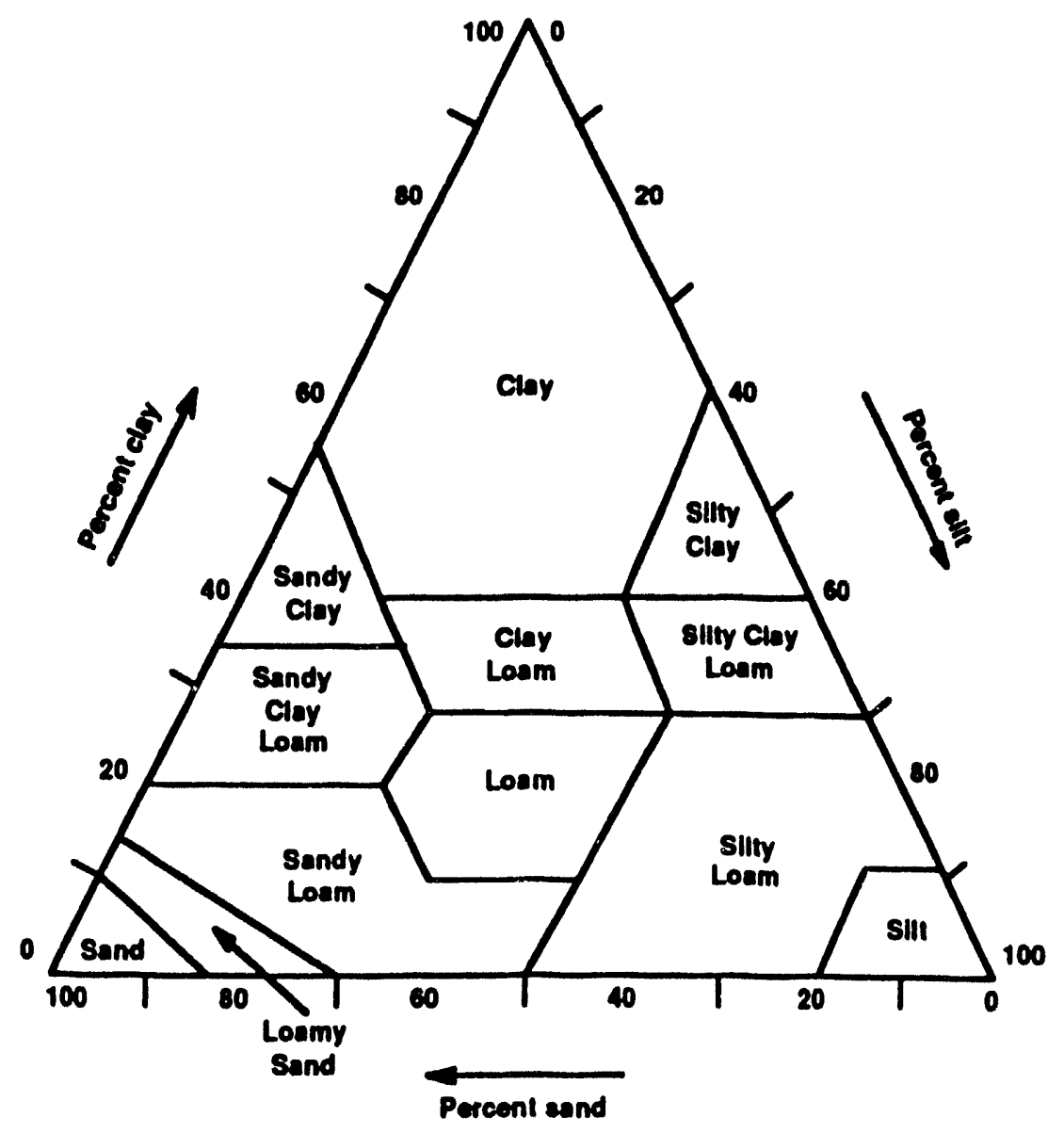


Table IX: $\quad$ Soil Characteristics

\begin{tabular}{|ll|}
\hline \multicolumn{1}{|c|}{ Solls Used } & \multicolumn{1}{|c|}{ Soll Type } \\
\hline Kinney Brick & Loam \\
Plano & Silty Loam \\
Mountain Clay & Clay Loam \\
True Clay & Clay \\
Plainfield & Sand \\
South Valley & Sandy Clay Loam \\
\hline
\end{tabular}

The project plan had called for soil testing in both chloride-based and sulfatebased process solutions. Since it has been found that sulfate is detrimental to metal solubility, and is not necessary for the dissolution of chromium metal in sulfate-based process solution, sulfate-based tests were replaced with TCLP metals tests. Hexachlorobenzene was originally chosen as one of the materials to be used as an artificial soil contaminant because it had already been used in the organics testing and was a highly stable organic compound well known as an indicator of oxidation efficiency. However, due to the extremely slow reaction rate for oxidizing hexachlorobenzene, and since it is virtually non-existent as a real-world contaminant in soils, it was decided to replace hexachlorobenzene with benzene and mineral oil. Benzene and mineral oil are fairly frequently found in contaminated soils.

In the soil rinse tests, $50 \mathrm{ml}$ of chloride-based process solution spiked with barium, beryllium, cadmium, cerium, chromium, lead, and neodymium was added to 5 . gm of each of six uncontaminated soil types. As in the organic oxidation, the mixtures were heated in $128 . \mathrm{ml}$ bombs. After heating, the solids were filtered from the process solution using a Gooch crucible with a Whatman GF/A glass fiber filter, and rinsed with $1 . \% \mathrm{HCl}$ and water. The rinse regimen for the soils was eight (8) washes with $5 . \mathrm{ml} 1 \% \mathrm{HCl}$ and three (3) washes with $5 . \mathrm{ml}$ deionized water. The filtrate and rinsates were analyzed for metals, and the rinsed soil solids were subjected to TCLP extraction to determine whether they would be classified as non-hazardous for heavy metal content. Soil solids, if rendered non-hazardous by treatment with the process, could be restored to their original location at the treatment site thus greatly reducing the volume of waste to be disposed. A set of baseline tests were run with unspiked process solution to determine any amounts of heavy metals naturally found in the soils; no significant amounts of heavy metals were found in any of the soils. 
For the contaminated soil treatment studies, the metal contaminants were approximately $0.1 \%$ of the metals arsenic (as the pentoxide), barium (as the oxide), beryllium (as the oxide), chromium (as sodium dichromate), and neodymium (as the trioxide), and $0.05 \%$ lead (as the oxide). The organic contaminants were approximately $3 . \%$ mineral oil, $1 . \%$ benzene, $1 . \%$ trichloroethylene, and $0.1 \%$ Aroclor 1260 (PCB's). Each soil was loaded into a small ceramic mill jar, and the metallic contaminants and less volatile organics were added. The volatile organics were added immediately before sealing the jar. The jar was then rotated on a mill (without any milling stones) for 24 . hours to mix the contaminants thoroughly into the soil. The soils were left sealed in the ceramic jars, except for brief periods when amounts were weighed out for tests. Exactly $50 . \mathrm{ml}$ of chloride-based DETOX solution was added to 5 . gm of each of six contaminated soil types, and the mixture heated in 128. $\mathrm{ml}$ bombs. The first set of treatment tests were heated at 473.K for 24. hours. It was expected that fairly complete oxidation of all the organic contaminants would be achieved in 24 . hours, but significant amounts of organic material remained after these tests. Because the results from the first set of tests were not as good as expected in organic destruction, the second set of tests were heated at $473 . \mathrm{K}$ for 48 hours. Separate tests were run for metal determinations, volatile and semivolatile determinations, and non-volatile determinations, since the method in which the post-test solutions and solids were handled was different for each of these three determinations. Volatile, semivolatile, and non-volatile samples were collected and maintained in the same manner as described in Section 2 for the organic oxidation efficiency studies. For the metal tests, the same rinse and analysis regimen was used as described for the soil rinse studies. The rinse regimen used in the rinse studies seemed to be too long, since the concentrations of metals in the rinses had leveled off or dropped to undetectable levels several rinses before the end of the regimen. Because the rinse regimen used in the rinse studies was probably excessively long, the total number of rinses for contaminated soil treatments was reduced to eight (8) (five [5] rinses with $1 . \% \mathrm{HCl}$ and three [3] rinses with deionized water).

The same reasoning applies for the oxidation of organic contaminants in soils as for the oxidation of organic compounds alone. The sealed bombs allow no loss of volatile organic compounds during heating, and verification of seals was demonstrated by pressure measurements of the bombs after cooling. There is a possibility that some of the carbon dioxide seen in the gas analyses is due to the presence of natural carbonate minerals in the soils, which would produce carbon dioxide by reaction with acid in the DETOX solution. However, this generation of carbon dioxide by native carbonates would not affect oxygen use, which would still be determined chiefly by the organic content of the soil. The metals are not volatile at the process temperature, and their concentrations in the process solution and rinses can be used to verify recovery of the amount of metal added. Finally, the real measure of 
oxidation efficiency is not in the measured amounts of carbon dioxide generated, but in the residual amounts of organic materials remaining in the reaction vessel.

\subsection{Results}

The rinse test results are given in Tables $X$ through XIV for the six soil types, and metal levels in the rinses are presented graphically in Figures 12 through 18. Cerium could not be analyzed accurately in these studies due to spectral interference from soil cations. It appears that five rinses with an equal weight of $1 \% \mathrm{HCl}$ are sufficient to remove residual heavy metals from soils treated with DETOX. The exception may be cadmium, which seems strongly retained by the Plano silt loam, the Valley sandy clay loam, and the Kinney loam. All rinsed solids were subjected to a TCLP test and analysis for the heavy metals. All six rinsed soils met the criteria for a non-hazardous material. For most treated and rinsed soils, the levels of the metals were below the detection limits for the analytical method. DETOX solution can be effectively rinsed from a range of soil types, with a reasonable amount of incremental rinses, using condensate from the DETOX reaction vessel and water. In soil treatment, all of the rinses can be returned to the reaction vessel, thus eliminating any secondary waste streams from rinsing.

In tests with the six soil types contaminated with metal oxides, the DETOX catalyst solution was able to effectively dissolve the metal oxides from the soils. The shorter rinse regimen, as surmised, removed a great majority of residual metallic contaminants from the treated soils. TCLP extractions on the rinsed soils confirmed that the soils had been rendered non-hazardous by treatment with DETOX. The results of the contaminated soils metals tests are given in Tables XV through XX, and the metals levels in the DETOX solution and rinses are illustrated graphically in Figures 19 through 24. 


\section{Table X: $\quad$ Plano Soil Rinse Test Results}

\begin{tabular}{|c|c|c|c|c|c|c|c|c|}
\hline \multirow[b]{2}{*}{ Solution } & \multirow[b]{2}{*}{ Arsenle } & \multicolumn{4}{|c|}{ Metrle (mg) } & \multirow[b]{2}{*}{ Chromtum } & \multirow[b]{2}{*}{ Lead } & \multirow[b]{2}{*}{ Noodyminum } \\
\hline & & Barlum & Berritium & Cadnitum & Ceriun: & & & \\
\hline Filtrate & 2.8 & 48 & 6.4 & 3.1 & $\cdots$ & 10.8 & 1.6 & 16 \\
\hline Rinse 1 (HC) & 2.2 & 2.7 & 029 & 0.56 & $\cdots$ & 0.7 & 0.1 & 0.7 \\
\hline Rinse 2 (Ha) & 0.88 & 3.7 & 0.3 & 0.61 & $\cdots$ & 0.66 & 0.13 & 0.7 \\
\hline Rinse 3 (HC) & 0.41 & 28 & 0.19 & 0.61 & $\cdots$ & 0.41 & 0.1 & 0.9 \\
\hline Rinse 4 (HO) & 0.24 & 2 & 0.16 & 0.6 & $\cdots$ & 0.27 & 0.12 & $<0.5$ \\
\hline Rinse 5 (Ha) & 0.34 & 3.8 & 0.11 & 0.6 & $\cdots$ & 0.19 & 0.14 & $<0.5$ \\
\hline Rinse 6 (HC) & 0.19 & 1.7 & 0.07 & 0.59 & $\cdots$ & 0.12 & 0.03 & $<0.5$ \\
\hline Rinse 7 (HC) & 0.11 & 0.2 & 0.01 & 0.53 & $\cdots$ & 0.02 & 0.01 & $<0.5$ \\
\hline Rinse 8 (HC) & 0.09 & 0.78 & 0.03 & 0.56 & $\cdots$ & 0.05 & 0.03 & $<0.5$ \\
\hline Rinse 9 (Water) & 0.03 & 0.5 & 0.02 & 0.56 & $\cdots$ & 0.04 & 0.08 & $<0.5$ \\
\hline Rinse 10 (Water) & 0.03 & 0.2 & $<0.005$ & 0.46 & $\cdots$ & 0.01 & 0.01 & $<0.5$ \\
\hline Rinse 11 (Water) & $<0.02$ & 0.2 & $<0.005$ & 0.08 & $\cdots$ & 0.04 & $<0.01$ & $<0.5$ \\
\hline
\end{tabular}

- Could not be analyzed due to spectral interferences.

\section{Table XI: $\quad$ Plainfield Soil Rinse Test Results}

\begin{tabular}{|c|c|c|c|c|c|c|c|c|}
\hline Sontion & anding & Bantum & Berrinim & Cadntum & Ceritum & Chrountum & Lead & Noodymfum \\
\hline Filtrate & 21 & 49 & 6.8 & 3.1 & $\cdots$ & 10 & 1.5 & 17 \\
\hline Rinse 1 (HC) & 13 & 3.7 & 0.46 & 0.61 & $\cdots$ & 0.6 & 0.13 & 1.4 \\
\hline Rinse 2 (HC) & 0.5 & 3.6 & 0.33 & 0.59 & $\cdots$ & 0.45 & 0.11 & 1.1 \\
\hline Rinse 3 (HC) & 02 & 1.6 & 0.15 & 0.55 & $\cdots$ & 0.21 & 0.05 & 0.9 \\
\hline Rinse 4 (HC) & 0.03 & $2 / 2$ & 0.08 & 0.49 & $\cdots$ & 0.02 & $<0.05$ & $<0.5$ \\
\hline Rinse 5 (HC) & 0.05 & $<r .02$ & $<0.005$ & 0.06 & $\cdots$ & 0.01 & $<0.05$ & $<0.5$ \\
\hline Rinse 6 (HC) & 0.02 & $<0.02$ & $<0.005$ & 0.01 & $\cdots$ & $<0.005$ & $<0.05$ & $<0.5$ \\
\hline Rinse 7 ( $\mathrm{HC}$ ) & 0.06 & $<0.02$ & $<0.005$ & 0.01 & $\cdots$ & $<0.005$ & $<0.05$ & $<0.5$ \\
\hline Rinse 8 (HC) & 0.03 & $<0.02$ & $<0.005$ & 0.005 & $\cdots$ & $<0.005$ & $<0.05$ & $<0.5$ \\
\hline Rinse 9 (Water) & 0.06 & $<0.02$ & $<0.005$ & 0.004 & $\cdots$ & $<0.005$ & $<0.05$ & $<0.5$ \\
\hline Rinse 10 (Water) & 0.02 & $<0.02$ & $<0.005$ & $<0.000$ & $\cdots$ & $<0.005$ & $<0.05$ & $<0.5$ \\
\hline Rinse 11 (Water) & $<0.02$ & $<0.02$ & $<0.005$ & $<0.002$ & $\cdots$ & $<0.005$ & $<0.05$ & $<0.5$ \\
\hline
\end{tabular}

- Could not be analyzed due to spectral interferences. 
Table XII: South Valley Soil Rinse Test Results

\begin{tabular}{|c|c|c|c|c|c|c|c|c|}
\hline Solutan & Arsenic & Barium & Berrilium & Cadminum & Ceniun ${ }^{-}$ & Chromtion & Lead & Noodymifum \\
\hline Filtrate & 9 & 48 & 6.6 & 2.9 & $\cdots$ & 11.3 & 1.3 & 27 \\
\hline Rinse 1 (HC) & 0.6 & 18 & 0.73 & 0.58 & $\ldots$ & 1.2 & 0.2 & 1.3 \\
\hline Rinse 2 (HC) & 0.2 & 5 & 1.4 & 0.58 & $\cdots$ & 1.4 & 0.33 & 26 \\
\hline Rinse 3 (HC) & 0.05 & 2.5 & 0.19 & 0.56 & $\cdots$ & 0.25 & 0.09 & 0.9 \\
\hline Rinse 4 (HC) & 0.02 & 2.4 & 0.11 & 0.54 & $\cdots$ & 0.19 & 0.06 & $<0.5$ \\
\hline Rinse 5 (HC) & 0.05 & 2.3 & 0.11 & 0.54 & $\cdots$ & 0.17 & 0.05 & $<0.5$ \\
\hline Rinse 6 (HC) & 0.03 & 4.3 & 0.16 & 0.57 & $\cdots$ & 022 & 0.08 & $<0.5$ \\
\hline Rinse 7 (HC) & $<0.02$ & 1.6 & 0.05 & 0.54 & $\cdots$ & 0.07 & 0.04 & $<0.5$ \\
\hline Rinse 8 (HC) & $<0.02$ & 0.5 & 0.01 & 0.47 & $\cdots$ & 0.02 & $<0.02$ & $<0.5$ \\
\hline Rinse 9 (Water) & $<0.02$ & $<0.01$ & $<0.005$ & 0.08 & $\cdots$ & 0.01 & $<0.02$ & $<0.5$ \\
\hline Rinse 10 (Water) & $<0.02$ & $<0.01$ & $<0.005$ & 0.03 & $\cdots$ & 0.01 & $<0.02$ & $<0.5$ \\
\hline Rinse 11 (Water) & $<0.02$ & $<0.01$ & $<0.005$ & 0.01 & $\cdots$ & 0.005 & $<0.02$ & $<0.5$ \\
\hline
\end{tabular}

- Could not be analyzed due to spectral interferences.

\section{Table XIII: Mountain Clay Soil Rinse Test Results}

\begin{tabular}{|c|c|c|c|c|c|c|c|c|}
\hline Solution & Anentic: & Eation & Beñulium & Cadintum & Cenitun & Chromition & tead & Neodymium \\
\hline Filtrate & 22 & 41 & 6.3 & 32 & $\cdots$ & 102 & 1.5 & 222 \\
\hline Rinse 1 (HC) & 1 & 9.4 & 0.57 & 0.61 & $\ldots$ & 1.7 & 0.21 & 1.9 \\
\hline Rinse 2 (HC) & 0.4 & 9.7 & 0.34 & 0.61 & $\cdots$ & 1.3 & 02 & 1.7 \\
\hline Rinse 3 (HC) & 0.3 & 4.2 & 0.1 & 0.56 & $\cdots$ & 0.45 & 0.07 & 0.6 \\
\hline Rinse 4 (HC) & 0.15 & 1.8 & 0.04 & 0.53 & $\ldots$ & 0.18 & 0.08 & 0.6 \\
\hline Rinse 5 (HC) & 0.09 & 0.3 & 0.01 & 0.27 & $\cdots$ & 0.05 & 0.03 & $<0.5$ \\
\hline Rinse 6 (HC) & 0.02 & $<0.2$ & $<0.005$ & 0.04 & $\cdots$ & 0.01 & $<0.03$ & $<0.5$ \\
\hline Rinse 7 (HC) & 0.08 & $<0.2$ & $<0.005$ & 0.01 & $\cdots$ & 0.01 & 0.03 & $<0.5$ \\
\hline Rinse 8 (HC) & $<0.02$ & $<0.2$ & $<0.005$ & 0.01 & $\cdots$ & 0.01 & 0.03 & $<0.5$ \\
\hline Rinse 9 (Water) & 0.02 & $<0.2$ & $<0.005$ & $<0.002$ & $\cdots$ & $<0.005$ & $<0.03$ & $<0.5$ \\
\hline Rinse 10 (Water) & 0.02 & $<0.2$ & $<0.005$ & $<0.002$ & $\cdots$ & $<0.005$ & $<0.03$ & $<0.5$ \\
\hline Rinse 11 (Water) & 0.03 & $<0.2$ & $<0.005$ & $<0.002$ & $\cdots$ & $<0.005$ & $<0.03$ & $<0.5$ \\
\hline
\end{tabular}

- Could not be analyzed due to spectral interferences. 


\section{Table XIV: Kinney Brick Soil Rinse Test Results}

\begin{tabular}{|c|c|c|c|c|c|c|c|c|}
\hline Splution & Arenole. & Barlan & Beryllium & eddmlum & Centun & Oromiun & Lead & Neodymilum \\
\hline Filtrate & 2.6 & 48.3 & 6.4 & 3.1 & $\cdots$ & 6.3 & 1.4 & 26.5 \\
\hline Rinse 1 (HC) & 0.5 & 3.7 & 0.21 & 0.57 & $\cdots$ & 0.43 & 0.09 & 0.8 \\
\hline Rinse 2 (HC) & 0.1 & 26 & 0.12 & 0.56 & $\cdots$ & 022 & 0.06 & 1.1 \\
\hline Rinse 3 (HC) & 0.03 & 2.8 & 0.09 & 0.55 & $\cdots$ & 0.18 & 0.03 & 0.8 \\
\hline Rinse 4 (HC) & 0.08 & 2.4 & 0.07 & 0.55 & $\cdots$ & 0.15 & 0.05 & $<0.5$ \\
\hline Rinse 5 (Ha) & 0.03 & 1.5 & 0.04 & 0.54 & $\ldots$ & 0.09 & 0.02 & $<0.5$ \\
\hline Rinse 6 (HC) & $<0.02$ & LOST & LOST & LOST & $\cdots$ & LOST & LOST & LOST \\
\hline Rinse 7 (HC) & 0.02 & 0.9 & 0.02 & 0.42 & $\cdots$ & 0.05 & $<0.01$ & $<0.5$ \\
\hline Rinse 8 (Ha) & 0.02 & 0.5 & 0.01 & 02 & $\cdots$ & 0.02 & 0.08 & $<0.5$ \\
\hline Rinse 9 (Water) & 0.02 & 0.4 & 0.01 & 0.12 & $\cdots$ & 0.02 & $<0.01$ & $<0.5$ \\
\hline Rinse 10 (Water) & $<0.02$ & 0.3 & 0.004 & 0.09 & $\cdots$ & 0.01 & $<0.01$ & $<0.5$ \\
\hline Rinse 11 (Water) & $<0.02$ & 0.2 & 0.01 & LOST & $\ldots$ & 0.01 & $<0.01$ & $<0.5$ \\
\hline
\end{tabular}

- Could not be analyzed due to spectral interferences.

\section{Figure 12: Arsenic Rinse Results}

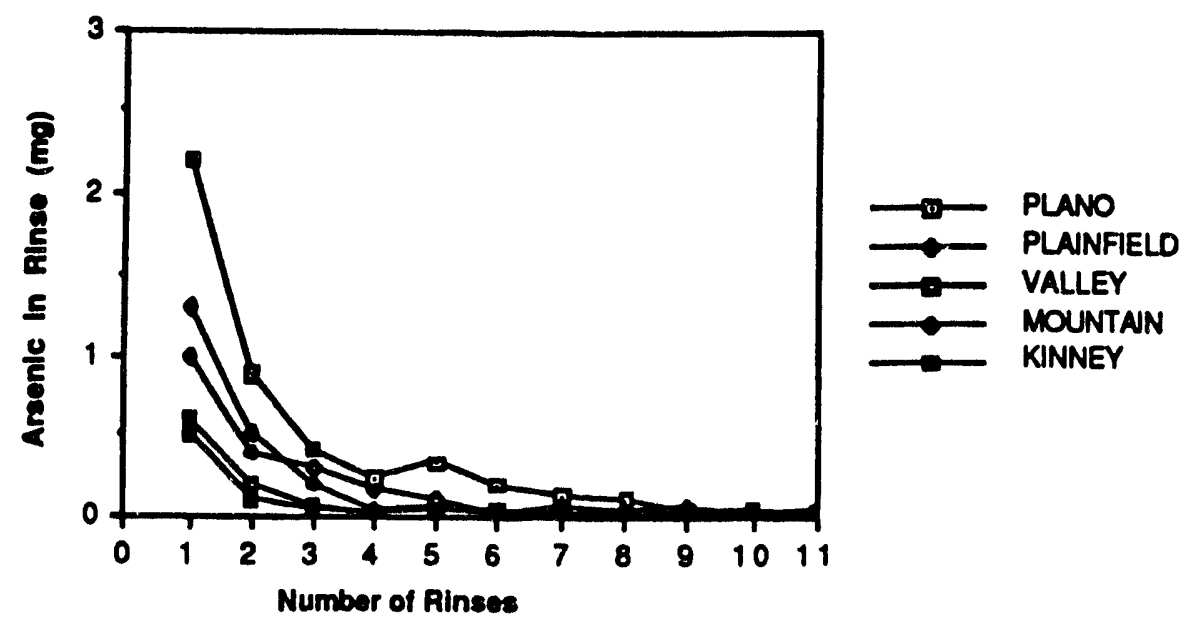


Figure 13: Barium Rinse Results

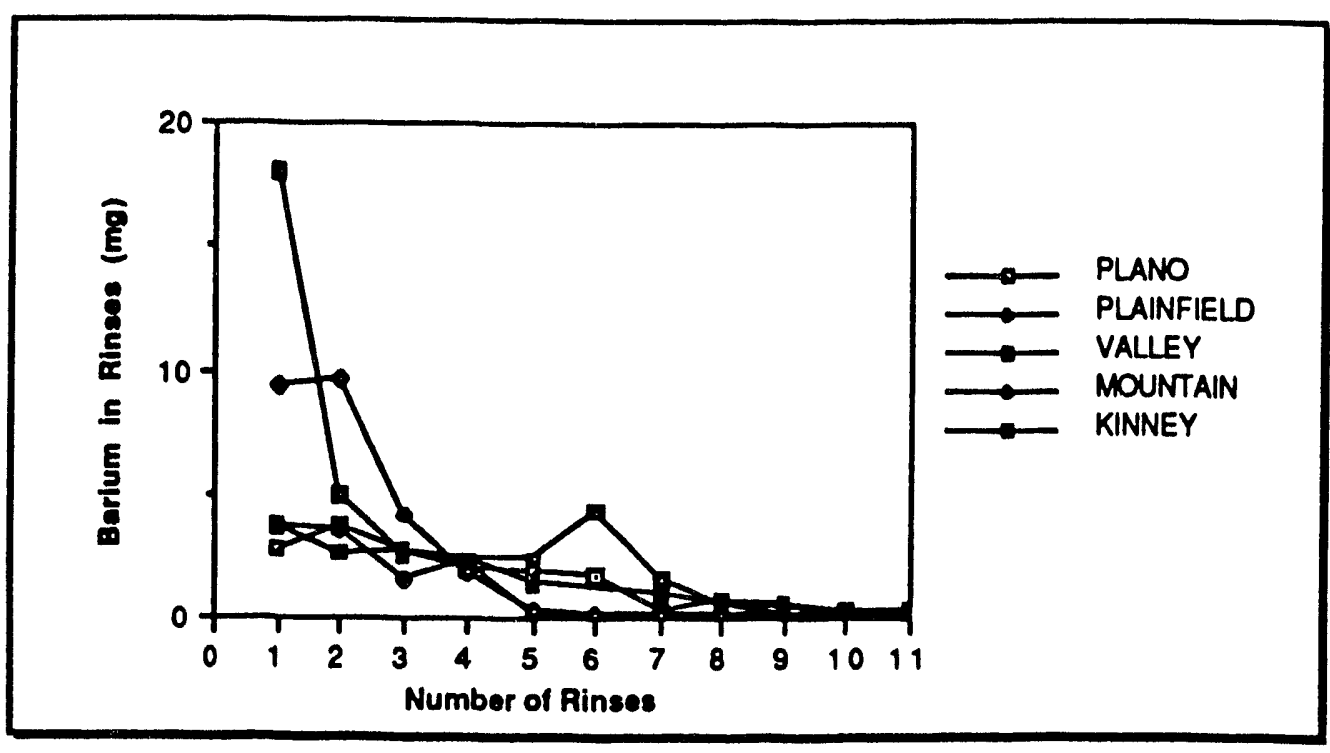

Figure 14: Beryllium Rinse Results

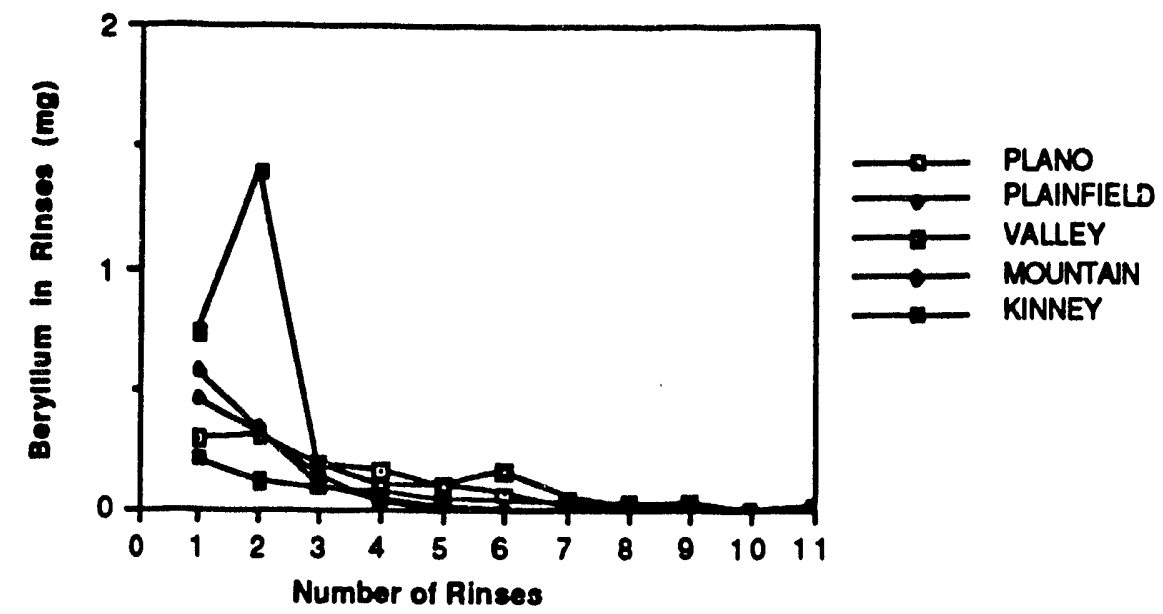


Figure 15: Cadmium Rinse Results

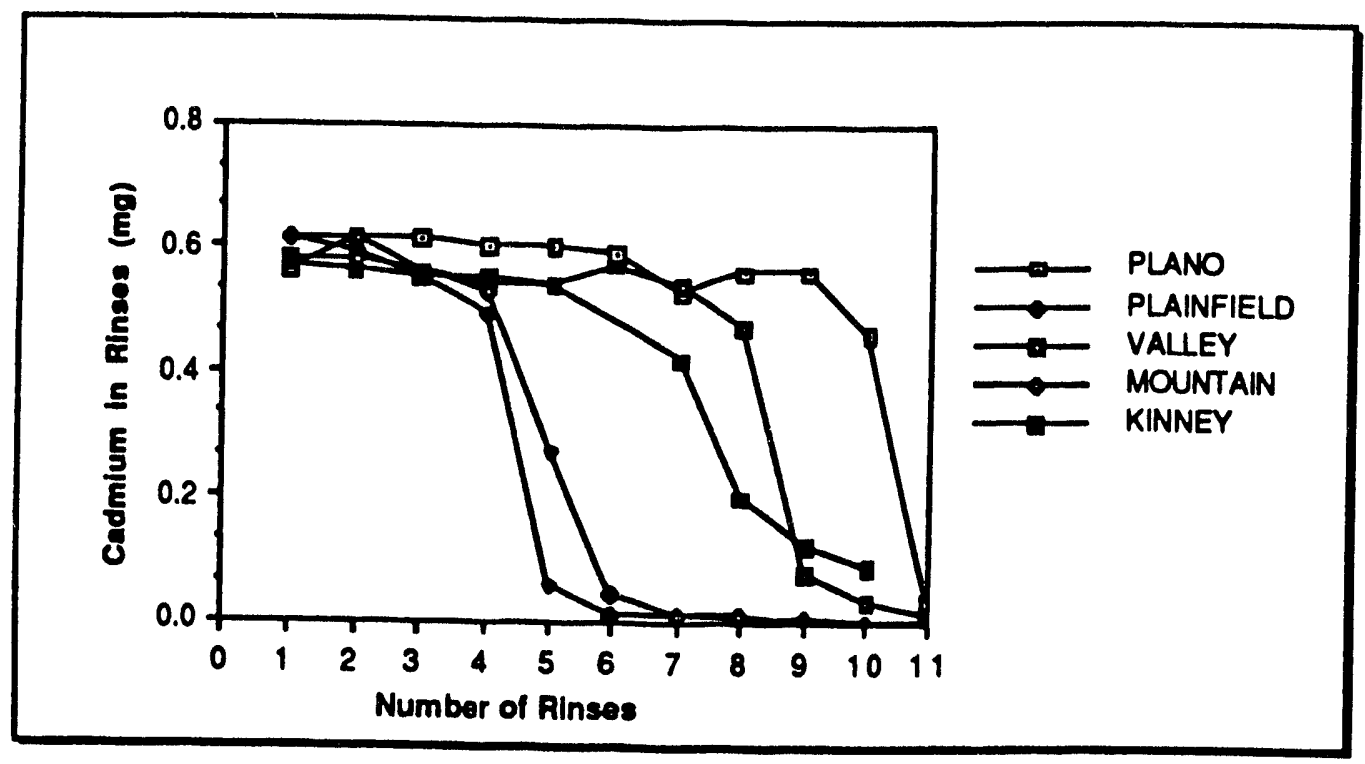

Figure 16: Chromium Rinse Results

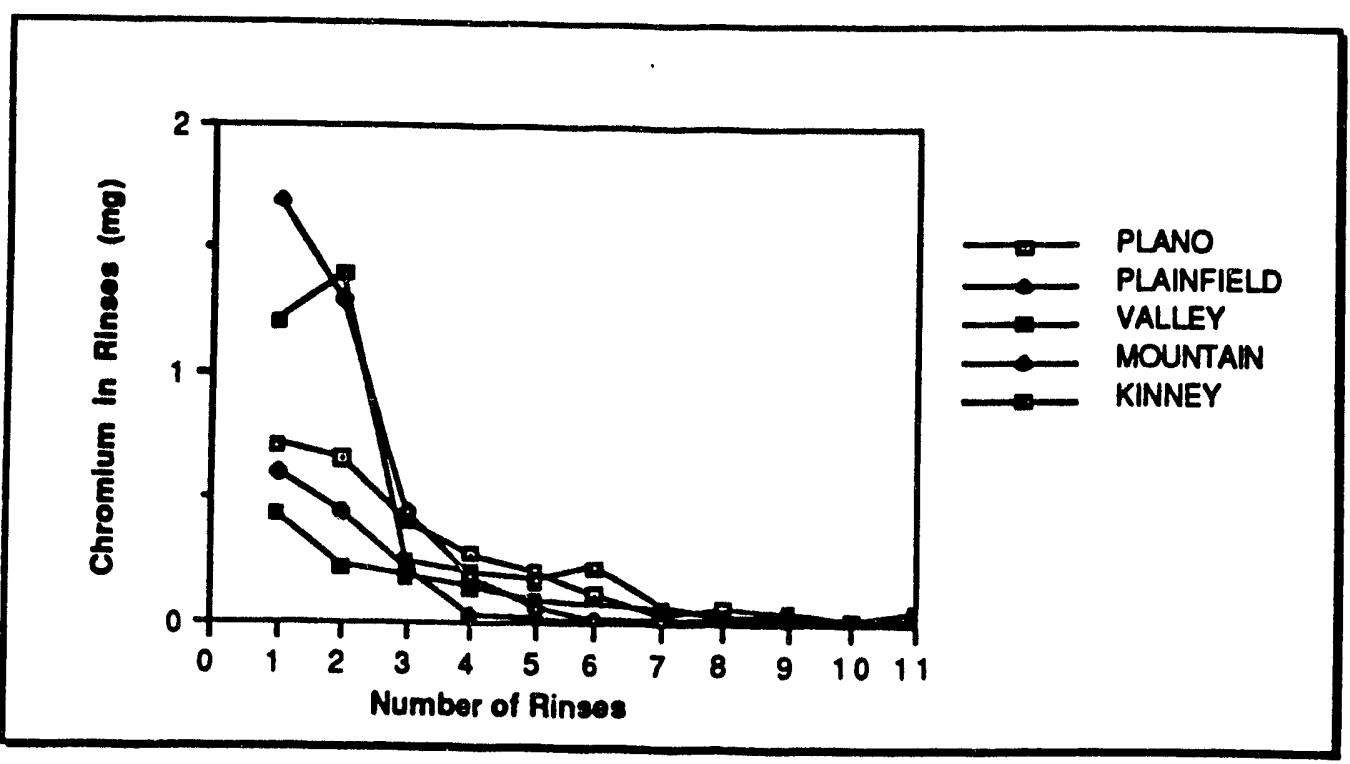


Figure 17: Lead Rinse Results

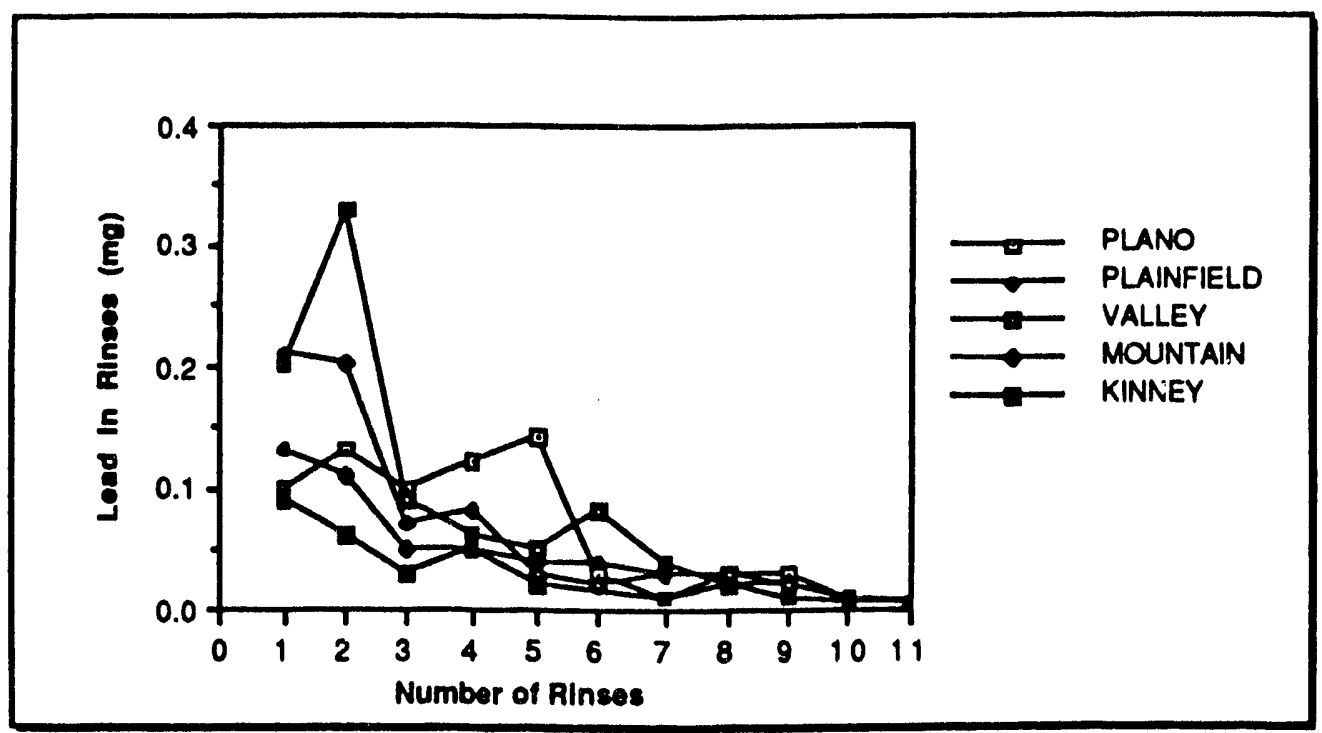

Figure 18: Neodymium Rinse Results
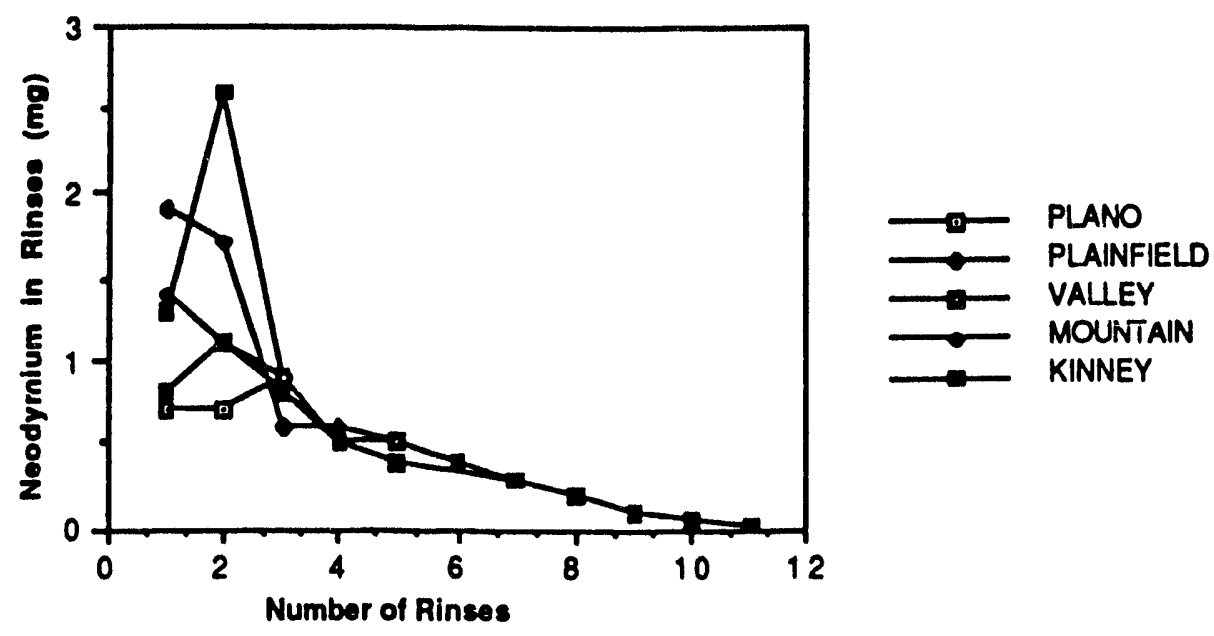
Table XV: Contaminated Plano Soil Metals Results

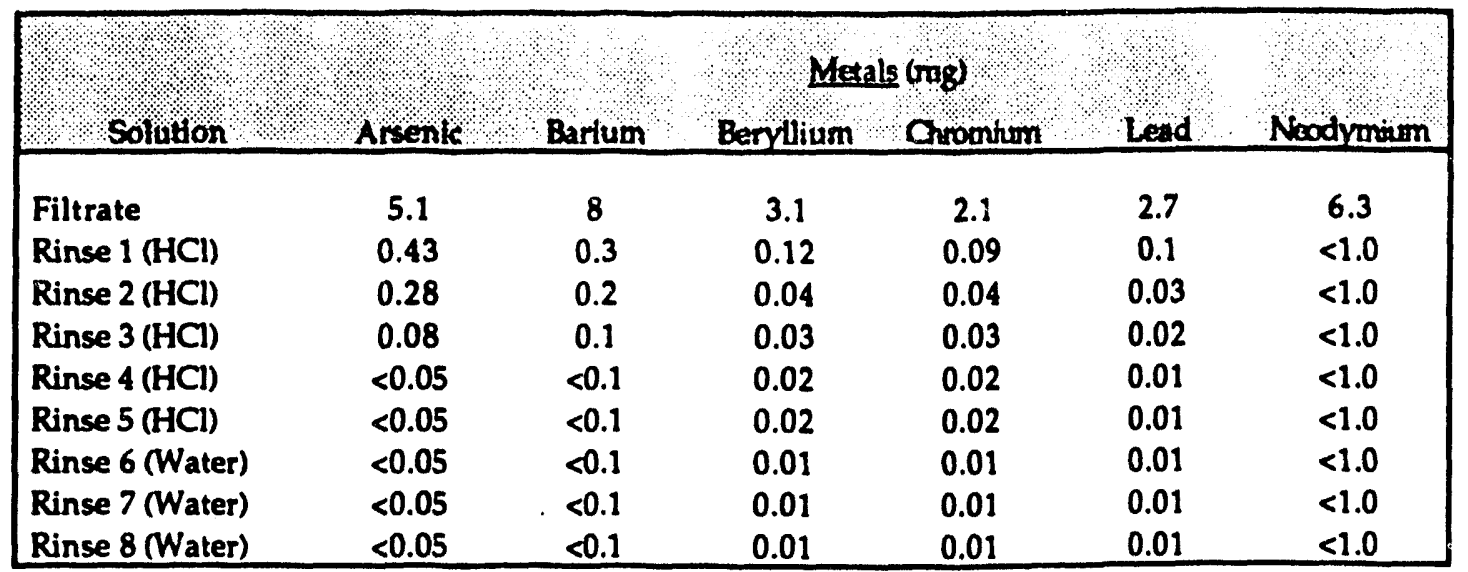

\section{Table XVI: Contaminated Plainfield Soil Metals Results}

\begin{tabular}{|c|c|c|c|c|c|c|}
\hline Solution & Hibsentic. & Banima & Beryllium & Qromitum & Lea & Nodnmun \\
\hline Filtrate & 8 & 7.5 & 3.1 & 2.6 & 3.2 & 6.3 \\
\hline Rinse $1(\mathrm{HCl})$ & 0.5 & 0.2 & 0.09 & 0.09 & 0.1 & $<1.0$ \\
\hline Rinse 2 (HCl) & 0.38 & $<0.1$ & 0.02 & 0.03 & 0.02 & $<1.0$ \\
\hline Rinse 3 (HCI) & $<0.05$ & $<0.1$ & 0.006 & 0.01 & 0.01 & $<1.0$ \\
\hline Rinse $4(\mathrm{HCl})$ & $<0.05$ & $<0.1$ & 0.008 & 0.01 & 0.01 & $<1.0$ \\
\hline Rinse 5 ( $\mathrm{HCl})$ & $<0.05$ & $<0.1$ & 0.007 & 0.01 & $<0.01$ & $<1.0$ \\
\hline Rinse 6 (Water) & $<0.05$ & $<0.1$ & $<0.005$ & 0.003 & $<0.01$ & $<1.0$ \\
\hline Rinse 7 (Water) & $<0.05$ & $<0.1$ & $<0.005$ & $<0.003$ & $<0.01$ & $<1.0$ \\
\hline Rinse 8 (Water) & $<0.05$ & $<0.1$ & $<0.005$ & $<0.003$ & $<0.01$ & $<1.0$ \\
\hline
\end{tabular}


Table XVII: Contaminated South Valley Soil Metals Results

\begin{tabular}{|c|c|c|c|c|c|c|}
\hline \multirow[b]{2}{*}{ Solution. } & \multicolumn{6}{|c|}{ Metals (mg) } \\
\hline & Arsenic & Barlum & Beryllium & Chrontum & Lead & Neodyomien \\
\hline Filtrate & 3.3 & 5.1 & 2.7 & 2.2 & 2.3 & 6.3 \\
\hline Rinse 1 (HCl) & 0.23 & 0.4 & 0.12 & 0.11 & 0.1 & $<1.0$ \\
\hline Rinse $2(\mathrm{HCl})$ & 0.1 & 0.1 & 0.03 & 0.03 & 0.03 & $<1.0$ \\
\hline Rinse 3 (HCl) & $<0.05$ & $<0.1$ & 0.02 & 0.02 & 0.01 & $<1.0$ \\
\hline Rinse 4 (HCl) & $<0.05$ & $<0.1$ & 0.006 & 0.01 & $<0.01$ & $<1.0$ \\
\hline Rinse 5 (HCl) & $<0.05$ & $<0.1$ & $<0.005$ & $<0.003$ & $<0.01$ & $<1.0$ \\
\hline Rinse 6 (Water) & $<0.05$ & $<0.1$ & $<0.005$ & $<0.003$ & $<0.01$ & $<1.0$ \\
\hline Rinse 7 (Water) & $<0.05$ & $<0.1$ & $<0.005$ & $<0.003$ & $<0.01$ & $<1.0$ \\
\hline Rinse 8 (Water) & $<0.05$ & $<0.1$ & $<0.005$ & $<0.003$ & $<0.01$ & $<1.0$ \\
\hline
\end{tabular}

\section{Table XVIII: Contaminated Mountain Clay Soil Metals Results}

\begin{tabular}{|c|c|c|c|c|c|c|}
\hline Solvition & Arsents & Baritun & Bervilium & Orominin & Lead & Neodymanim \\
\hline Filtrate & 2.9 & 6 & 2.8 & 2.3 & 2.9 & 6.3 \\
\hline Rinse 1 (HCl) & 0.18 & 0.2 & 0.07 & 0.07 & 0.1 & $<1.0$ \\
\hline Rinse 2 (HCl) & $<0.05$ & 0.1 & 0.02 & 0.03 & 0.02 & $<1.0$ \\
\hline Rinse 3 (HCl) & $<0.05$ & 0.1 & 0.008 & 0.02 & 0.01 & $<1.0$ \\
\hline Rinse 4 (HCl) & $<0.05$ & $<0.1$ & 0.007 & 0.01 & 0.01 & $<1.0$ \\
\hline Rinse 5 (HCl) & $<0.05$ & $<0.1$ & 0.006 & 0.01 & 0.01 & $<1.0$ \\
\hline Rinse 6 (Water) & $<0.05$ & $<0.1$ & $<0.005$ & 0.01 & $<0.01$ & $<1.0$ \\
\hline Rinse 7 (Water) & $<0.05$ & $<0.1$ & 0.006 & 0.01 & $<0.01$ & $<1.0$ \\
\hline Rinse 8 (Water) & $<0.05$ & $<0.1$ & $<0.005$ & 0.01 & $<0.01$ & $<1.0$ \\
\hline
\end{tabular}




\section{Table XIX: Contaminated Kinney Brick Soil Metals Results}

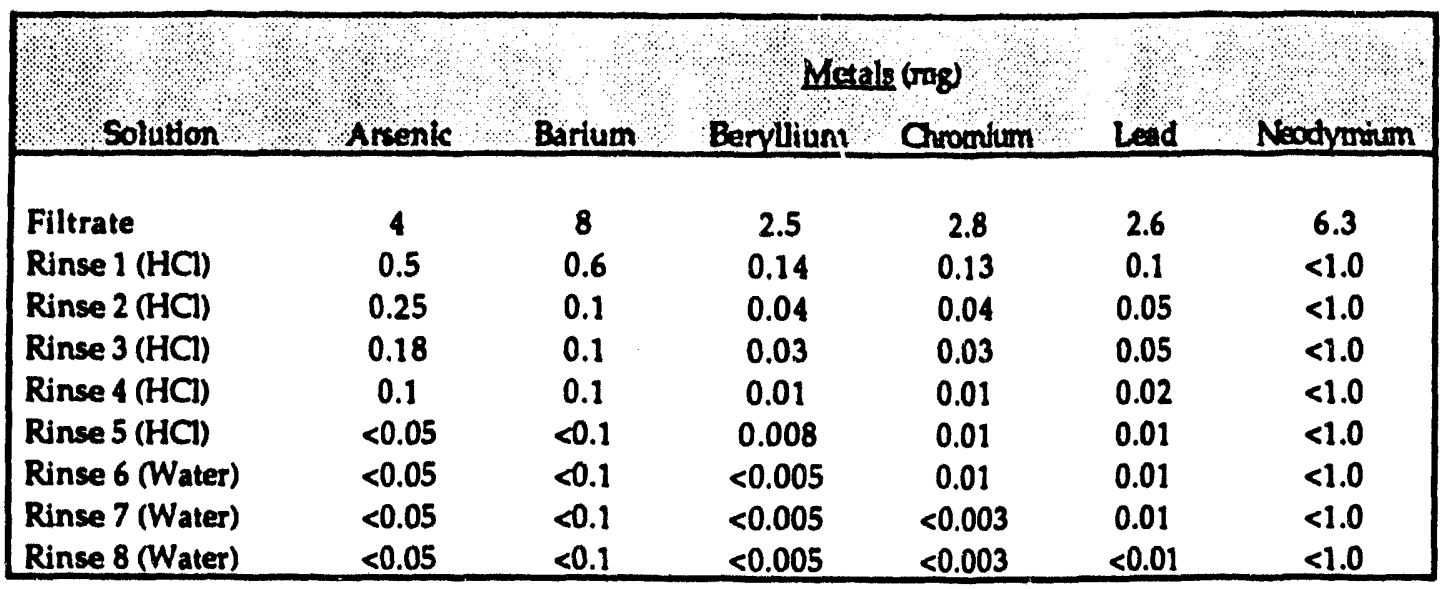

\section{Table XX: Contaminated True Clay Soil Metals Results}

\begin{tabular}{|c|c|c|c|c|c|c|}
\hline solution & arrent & Banums & Ecrollfum & Quoning & Lead & 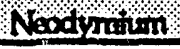 \\
\hline Filtrate & 3.4 & 6 & 3.7 & 1.4 & 2.3 & 6.3 \\
\hline Rinse $1(\mathrm{HCl})$ & 0.3 & 0.3 & 0.2 & 0.1 & 0.1 & $<1.0$ \\
\hline Rinse 2 (HCl) & 0.23 & 0.2 & 0.11 & 0.06 & 0.1 & $<1.0$ \\
\hline Rinse 3 (HCl) & $<0.05$ & 0.1 & 0.06 & 0.03 & 0.05 & $<1.0$ \\
\hline Rinse 4 (HCl) & $<0.05$ & 0.1 & 0.02 & 0.02 & 0.02 & $<1.0$ \\
\hline Rinse 5 (HCl) & $<0.05$ & $<0.1$ & 0.01 & 0.01 & 0.01 & $<1.0$ \\
\hline Rinse 6 (Water) & $<0.05$ & $<0.1$ & 0.01 & 0.01 & 0.01 & $<1.0$ \\
\hline Rinse 7 (Water) & $<0.05$ & $<0.1$ & 0.006 & 0.01 & 0.01 & $<1.0$ \\
\hline Rinse 8 (Water) & $<0.05$ & $<0.1$ & 0.01 & 0.01 & 0.01 & $<1.0$ \\
\hline
\end{tabular}


Figure 19: Arsenic Removal From Contaminated Soils

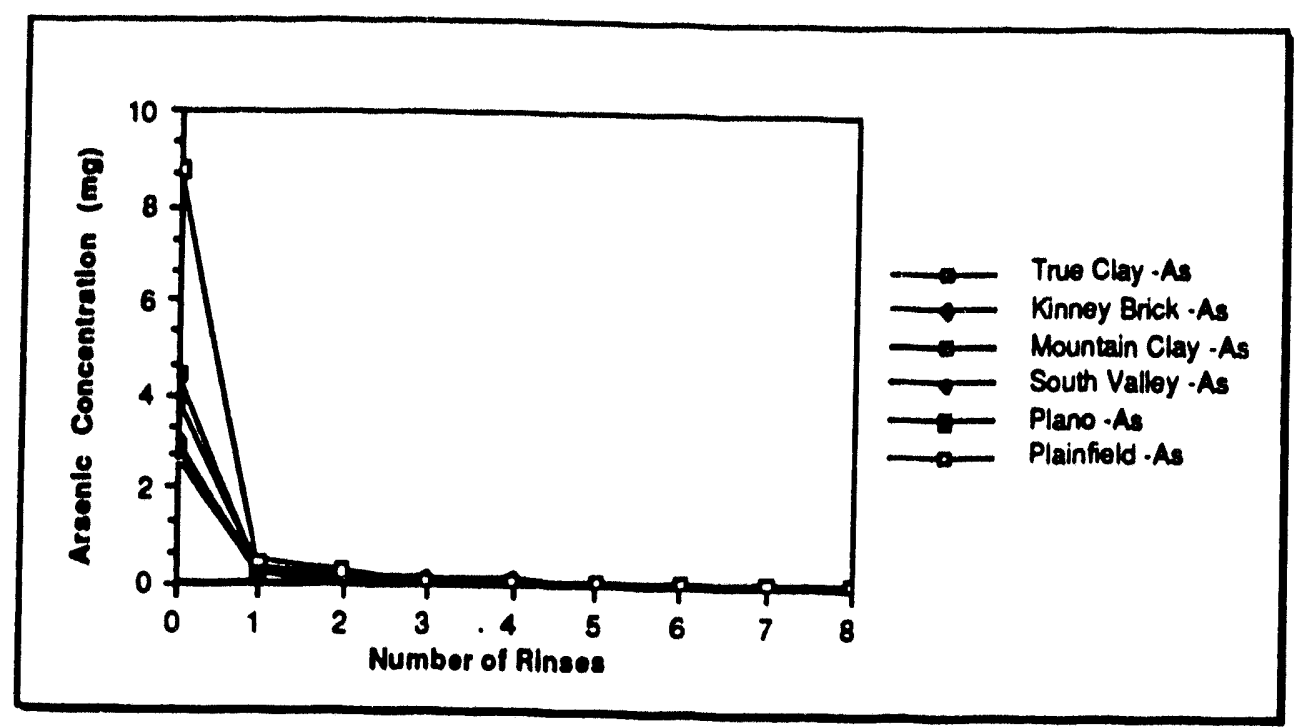

Figure 20: Barium Removal From Contaminated Soils

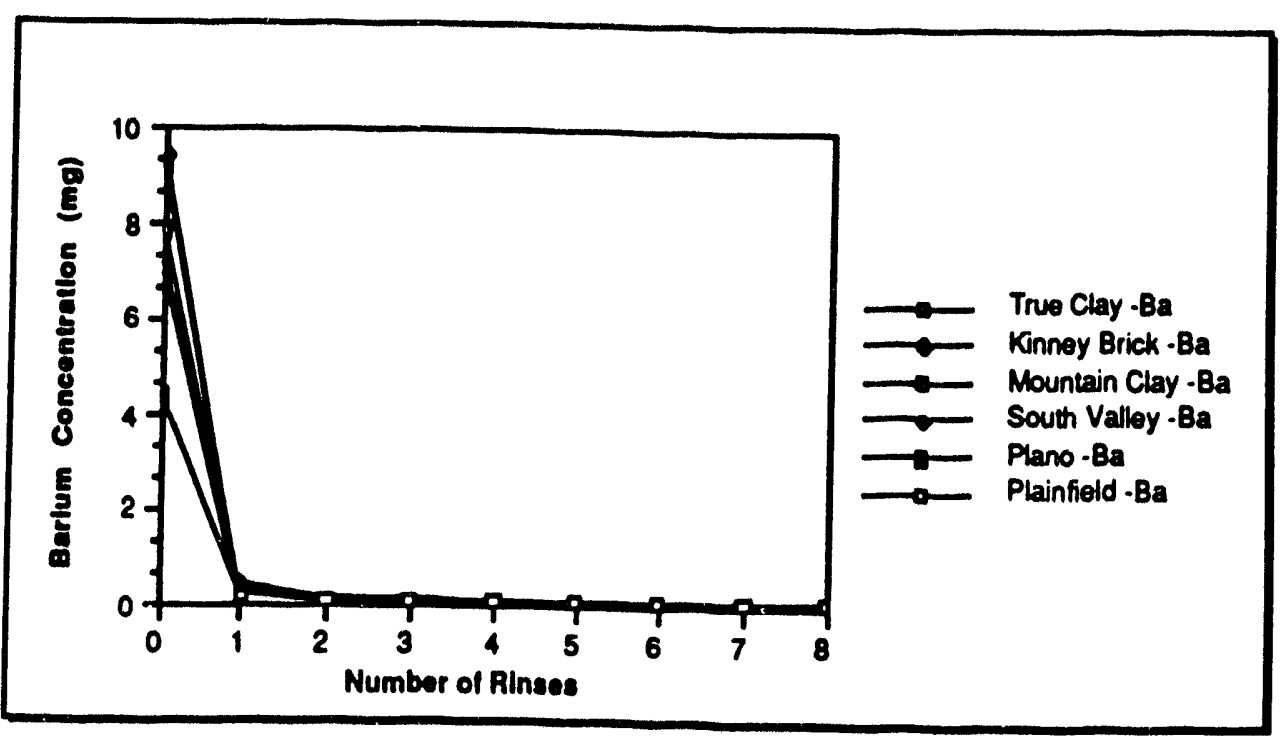




\section{Figure 21: Beryllium Removal From Contaminated Soils}

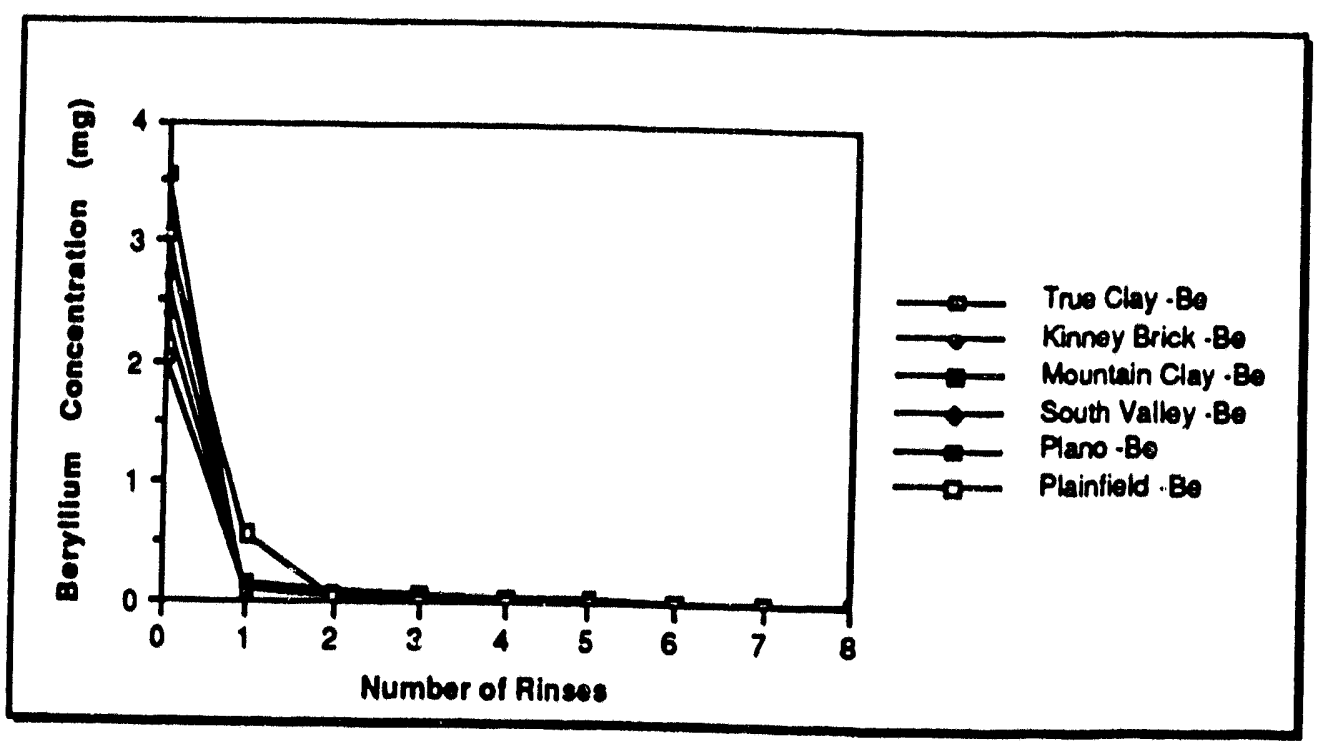

\section{Figure 22: Chromium Removal From Contaminated Soils}

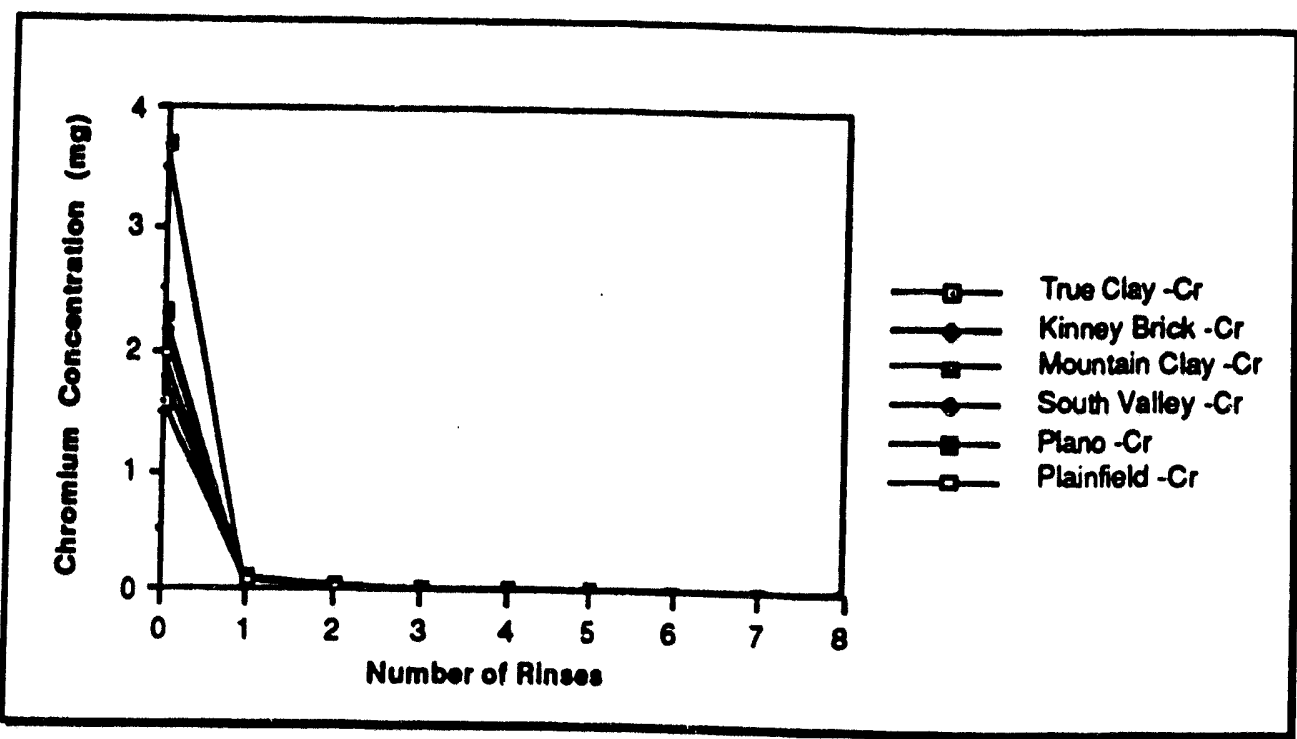


Figure 23: Lead Removal From Contaminated Soils

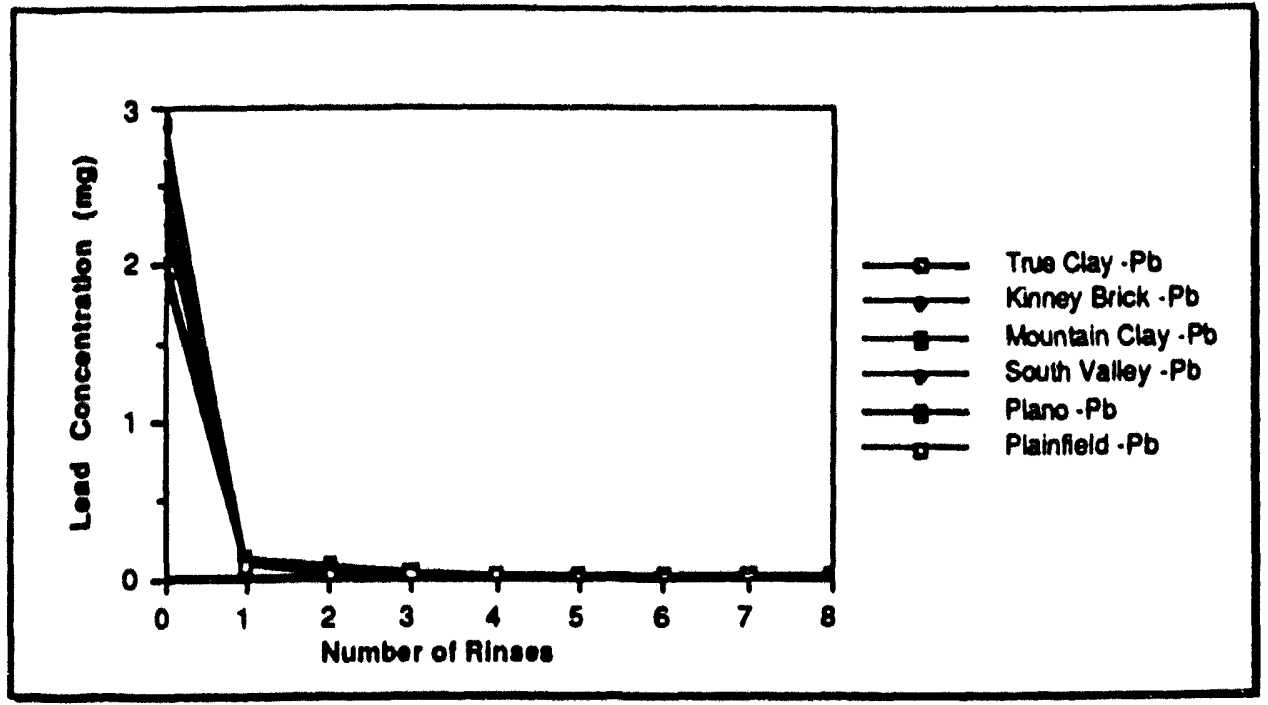

Figure 24: Neodymium Removal From Contaminated Soils

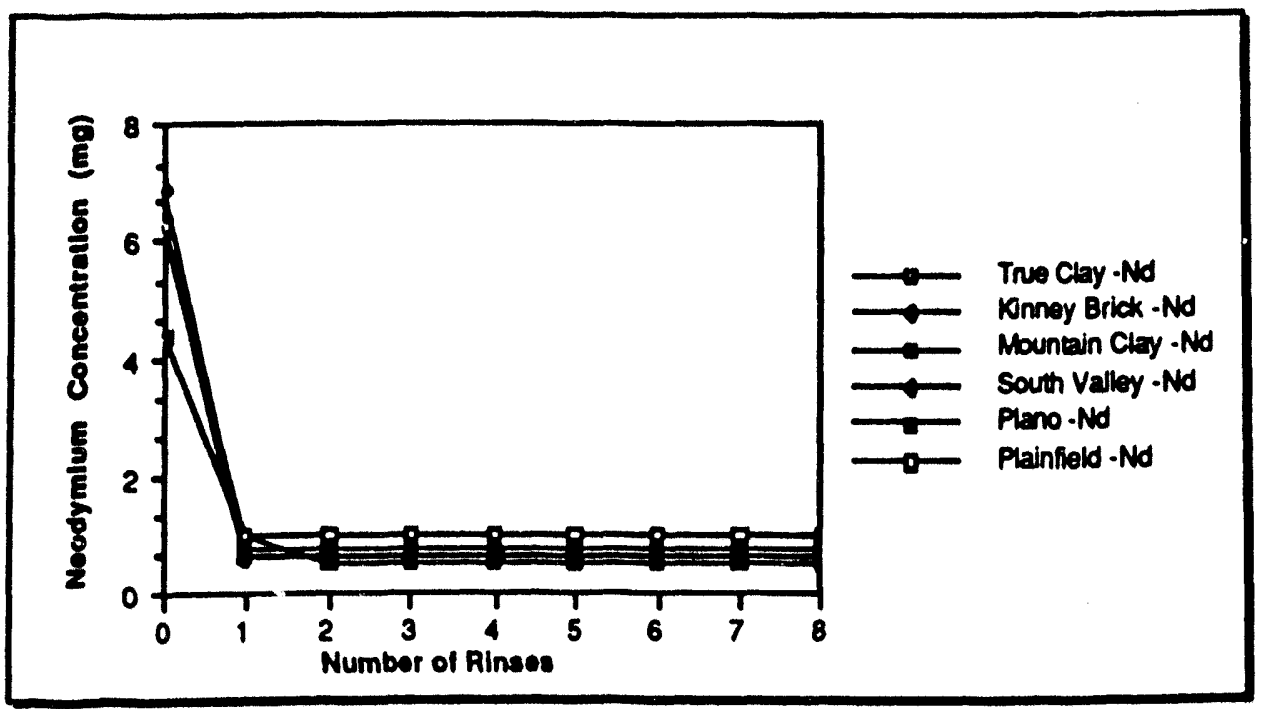


Results from volatile and semivolatile organic compounds analyses of the contaminated soils after treatment are given in Tables XXI(a), (b), and (c) through XXII(a), (b), and (c). Good trichloroethene (TCE) destruction was achieved. The greatest amount remaining in any soil was about 7. $\mu \mathrm{g}$ for the 24. hour clay soil test. No benzene was detected in any of the soils after oxidation. Aroclor 1260 was loaded in the soils at approximately $0.1 \%$ by weight, and this compound showed the most resistance to oxidation (as was known from the earlier organics oxidation tests); only about half of the Aroclor was oxidized in the 24 hour tests, and the amount remaining was highly dependent on the type of soil. For the 48. hour tests, considerably less volatile and semivolatile organics were detected. Table XXIII gives the results of non-volatile organic carbon and hydrogen analyses. The non-volatile carbon analyses indicated incomplete oxidation. Amounts of organic carbon remaining in the soils ranged from 0.7 to $2.6 \%$ by weight. There were no detectable amounts of soluble non-volatile organic compounds. In the worst case, about half of the organic content of the contaminated soils remained after treatment. Most of the residual material would have to be mineral oil, since there was not enough Aroclor 1260 added to give the non-volatile organic carbon values observed. In these unstirred tests the non-volatile and semivolatile organics in small particle-sized soils were protected from oxidation by the soil itself. A stirred environment would be more conducive to efficient oxidation of the organics. It is apparent that the more volatile organics, which are not protected by the soil, were well oxidized. From results obtained in previous studies for pure organics, the reaction rate is a function of contact area between the DETOX solution and the organic. Stirring will expose the organics much more effectively to the DETOX solution. It is felt that at least ten times more surface exposure would be obtained under stirred conditions. A combination of greater surface area of exposure and increased ability to access the organics should give two orders of magnitude or more increase in oxidation efficiency for contaminated soils under stirred conditions, although this will need to be verified in future studies.

The process solution can oxidize volatile organic compounds in soils, even in the absence of stirring, and can dissolve and remove heavy metals from the soils simultaneously. Despite the rather poor results obtained for nonvolatiles, it is felt that in a stirred system DETOX will be able to effectively oxidize these materials. The soils after treatment seemed to be similar in characteristics to their original form. They had been rinsed thoroughly, and dried by pulling air through them, so there was no free liquid content. Posttest weights for the residues were almost identical to the pre-test weights. The greatest change noted was in the Mountain Clay, which had the greatest organic content. Mountain Clay after treatment seemed to have a more claylike texture, possibly due to oxidation of its natural organic content. The soils were not analyzed for texture or $\mathrm{pH}$ after treatment. 
Ultimate disposal of soil residues after treatment will depend on the situation, the location, and particular regulations governing that situation and location. If the soil is classified as a hazardous waste (an example of this would be soils which have been tested in laboratories and contain traces of extraction solvents such as methylene chloride), then the treated soil would still be classified as hazardous by the Resource Conservation and Recovery Act derived-from rule. In cases where the residue falls under the derivedfrom rule, it would have to be officially delisted before it could be disposed of as a non-hazardous material. Since often there are no de-minimus rules for radioactivity content, even if radioactivity has been reduced to below natural background levels the soil would still have to be disposed of as a low level radioactive waste in many instances. However, in remediation of contaminated soils at sites, there are often established levels of residual contaminants which are acceptable after treatment. For remediation of contaminated soils, if the treated soil meets the established remediation levels the soil is considered "clean" for the purposes of the remediation effort and may be returned to the earth. 
Table XXIa: Contaminated Soils 24-Hour Volatile and Semivolatile Results

\begin{tabular}{|c|c|c|c|c|c|c|}
\hline Tesold & Temperature & oxidized tya & Volitiles. & $\begin{array}{l}\text { Anownt } \\
\text { (u) })\end{array}$ & Semivolatiles PCB & Amoun \\
\hline South Valley & $473 K$ & 256 & $\begin{array}{l}\text { Definitely Identified: } \\
\text { Tetrachloroethene } \\
\text { 1,2-Dichlorobenzene } \\
\text { 1,4-Dichlorobenzene } \\
\text { 1,2,3-Trichlorobenzene } \\
\text { 1,2,4-Trichlorobenzene } \\
\text { Tentatioely Identified: } \\
\text { Hexachloroethane }\end{array}$ & $\begin{array}{c}39 \\
165 \\
1350 \\
85 \\
800 \\
\\
70\end{array}$ & $\begin{array}{l}\text { Definitely Identified: } \\
\text { 1,4-Dichlorobenzene } \\
\text { 1,2-Dichlorobenzene } \\
\text { Hexachloroethane } \\
\text { 1,2,4,5-Tetrachlorobenzene } \\
\text { Hexachlorobenzene } \\
\text { PCB Compounds: } \\
\text { Aroclor } 1254 \\
\text { Aroclor } 1260 \\
\text { Aroclor } 1262 \\
\text { Tentatioely Identified: } \\
\text { Trichlorobenzene } \\
\text { Chloro-Benzoic Acid } \\
\text { Tetrachlorobenzene } \\
\text { Unknown } \\
\text { Unknown }\end{array}$ & $\begin{array}{c}1400 \\
320 \\
70 \\
50 \\
29.5 \\
\\
\\
\\
275 \\
2750 \\
235 \\
\\
\\
\\
37 \\
100 \\
18.5 \\
9.5 \\
10\end{array}$ \\
\hline Mountain Clay & $473 K$ & 256 & $\begin{array}{l}\text { Definitcly Identified: } \\
\text { Tetrachlorethene } \\
\text { 1,2-Dichlorobenzene } \\
\text { 1,3-Dichlorobenzene } \\
\text { 1,4-Dichlorobenzene } \\
\text { 1,2,3-Trichlorobenzene } \\
\text { 1,2,4-Trichlorbenzene } \\
\text { Chlorobenzene } \\
\text { Tentatiocly Identified: } \\
\text { 1,3,5,-Trichlorobenzene }\end{array}$ & $\begin{array}{c}225 \\
80 \\
700 \\
3300 \\
70 \\
600 \\
60\end{array}$ & $\begin{array}{l}\text { Definitely Identified: } \\
\text { 1,4-Dichlorobenzene } \\
\text { 1,3-Dichlorobenzene } \\
\text { 1,2-Dichlorobenzene } \\
\text { Benzoic Adid } \\
\text { 1,2,4-Trichlorobenzene } \\
\text { 1,2,4,5-Tetrachlorobenzene } \\
\text { PCB Compounds: } \\
\text { Aroclor } 1254 \\
\text { Aroclor } 1260 \\
\text { Aroclor } 1262 \\
\text { Tentatioely Identified: } \\
\text { Trichlorobenzene } \\
\text { Unknown } \\
\text { 4-Chloro-Benzoic Acid } \\
\text { Dichlorobenzoic Acid } \\
\text { 4,4-Dichlorobenzophen }\end{array}$ & $\begin{array}{c}2450 \\
800 \\
410 \\
1150 \\
850 \\
17.5 \\
\\
\\
600 \\
5000 \\
430 \\
\\
\\
43.5 \\
18.5 \\
600 \\
21 \\
28.5\end{array}$ \\
\hline
\end{tabular}


Table XXIb: Contaminated Soils 24-Hour Volatile and Semivolatile Results

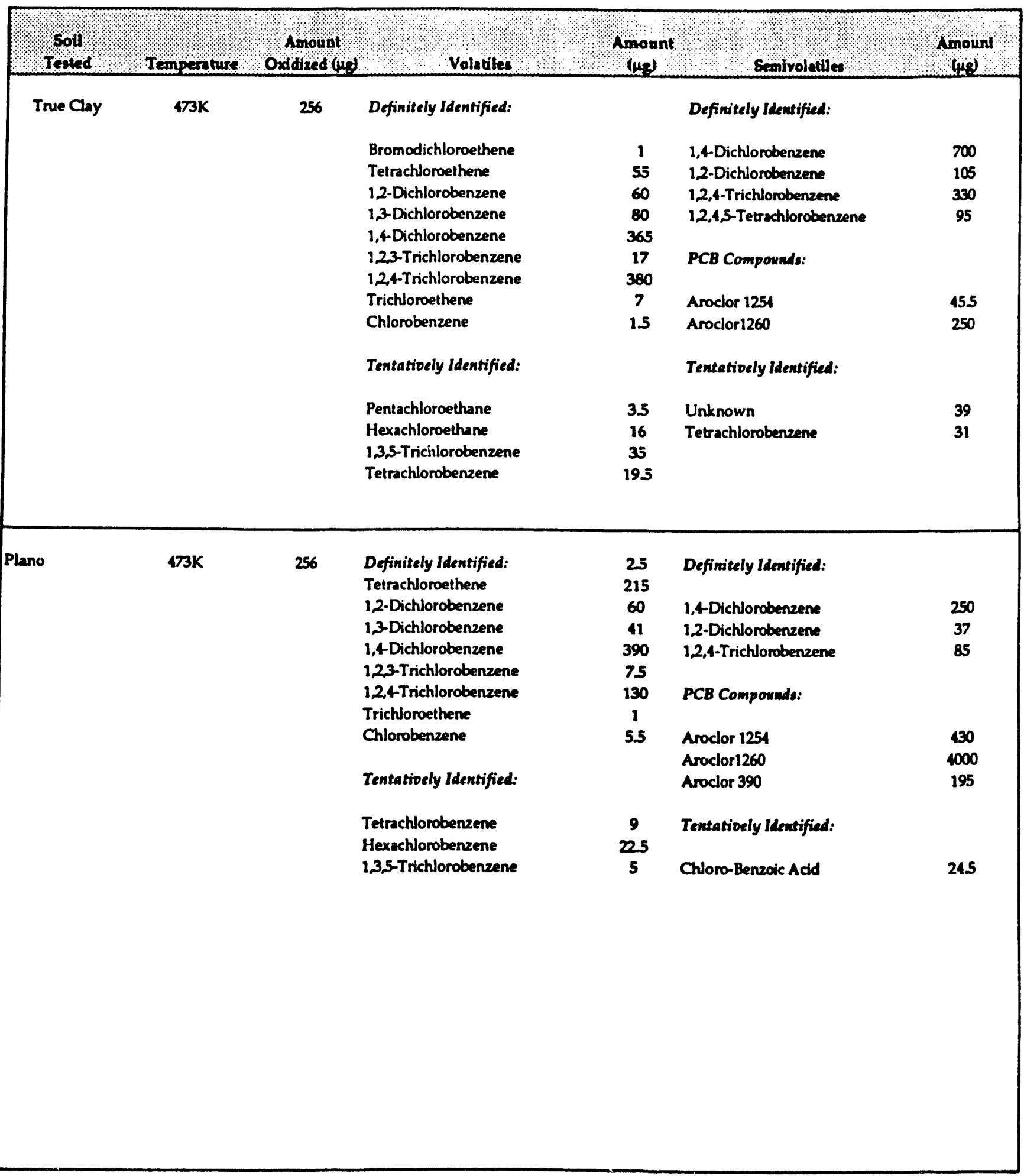


Table XXIc: Contaminated Soils 24-Hour Volatile and Semivolatile Results

\begin{tabular}{|c|c|c|c|c|c|c|}
\hline Tested & Temperature & $\begin{array}{l}\text { Amoint } \\
\text { Oxidized (18g) }\end{array}$ & ' & Amount & 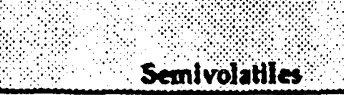 & $\begin{array}{l}\text { Amoun } \\
\text { (yg) }\end{array}$ \\
\hline Plainfield & $473 K$ & 256 & $\begin{array}{l}\text { Definitely Identified: } \\
\text { Trichloroethene } \\
\text { Bromodichloromethane } \\
\text { Tetrachloroethene } \\
\text { 1,2,-Trichlorobenzene } \\
\text { 1,2,4-Trichlorobenzene } \\
\text { 1,2-Dichlorobenzene } \\
\text { 1,4-Dichlorobenzene } \\
\text { Tentatioely ldentified: } \\
\text { Hexachlorobenzene } \\
\text { Tetrachlorobenzene }\end{array}$ & $\begin{array}{c}0.5 \\
1 \\
15.5 \\
38.5 \\
550 \\
25 \\
390\end{array}$ & $\begin{array}{l}\text { Definitely Identified: } \\
\text { 1,4-Dichlorobenzene } \\
\text { 1,2-Dichlorobenzene } \\
\text { 1,2,4-Trichlorobenzene } \\
\text { 1,2,4,5-Tetrachlorobenzene } \\
\text { PCB Compounds: } \\
\text { Aroclor } 1254 \\
\text { Aroclor } 1260 \\
\text { Arochlor } 1262 \\
\text { Tentatioely Identified: } \\
\text { Chloro-Benzoic Acid } \\
\text { Tetrachlorbenzene } \\
\text { 4Chlora-Cyclohexanol }\end{array}$ & $\begin{array}{c}145 \\
18.5 \\
480 \\
95 \\
\\
\\
260 \\
3500 \\
340 \\
\\
\\
21 \\
33.5 \\
8.5\end{array}$ \\
\hline Kinney Brick & $473 K$ & 256 & $\begin{array}{l}\text { Definitely Identified: } \\
\text { 1,4-Dichlorobenzene } \\
\text { Bromodichloromethane } \\
\text { 1,2-Dichlorobenzene } \\
\text { 1,3-Dichlorobenzene } \\
\text { Tetrachloroethene } \\
\text { Trichloroethene } \\
\text { 1,2,3-Trichlorobenzene } \\
\text { 1,2,4-Trichlorobenzene } \\
\text { Chlorobenzene } \\
\text { Tentatioely Identified: } \\
\text { Hexachloroethane } \\
\text { Pentachloroethane } \\
\text { 1,3,5-Trichlorobenzene }\end{array}$ & $\begin{array}{c} \\
495 \\
1 \\
115 \\
65 \\
85 \\
4.5 \\
125 \\
135 \\
1.5 \\
\\
\\
\\
28.5 \\
17.5 \\
80\end{array}$ & $\begin{array}{l}\text { Definitely Identified: } \\
\text { 1,4-Dichlorobenzene } \\
\text { 1,2-Dichlorobenzene } \\
\text { 12,4-Trichlorobenzene } \\
\text { 1,2,4,5-Tetrachlorobenzene } \\
\text { PCB Compounds: } \\
\text { Aroclor } 1254 \\
\text { Aroclor } 1260 \\
\text { Tentatiocly Identified: } \\
\text { Trichlorobenzene } \\
\text { Unknown } \\
\text { Chloro-Benzoic Acid } \\
\text { Tetrachlorobenzene }\end{array}$ & $\begin{array}{l}950 \\
200 \\
650 \\
27.5 \\
\\
85 \\
750\end{array}$ \\
\hline
\end{tabular}




\section{Table XXIIa: Contaminated Soils 48-Hour Volatile and Semivolatile Results}

\begin{tabular}{|c|c|c|c|c|c|c|}
\hline Soll & Temperaturs & Oxdized ( $1 \mathrm{~s})$ & Volatiles & $\begin{array}{c}\text { Amownt } \\
(\mu p)\end{array}$ & Semivolatiles & A nount \\
\hline South Valley & $473 K$ & 256 & $\begin{array}{l}\text { Definitely Identified: } \\
\text { Bromodichloromethane } \\
\text { Tetrachloroethene } \\
\text { 1,2-Dichlorobenzene } \\
\text { 1,3-Dichlorobenzene } \\
\text { 1,4-Dichlorobenzene } \\
\text { 1,2,3-Trichlorobenzene } \\
\text { 1,2,4-Trichlorobenzene } \\
\text { Tentatively Identified: } \\
\text { Hexachloroethane } \\
\text { Tetrachlorobenzene }\end{array}$ & $\begin{array}{c}1.5 \\
105 \\
41.5 \\
20 \\
700 \\
18 \\
550 \\
\\
50 \\
6\end{array}$ & $\begin{array}{l}\text { Definitely Identified: } \\
\text { 1,4-Dichlorobenzene } \\
\text { 12,4-Trichlorobenzene } \\
\text { 12,4,5-Tetrachlorobenzene } \\
\text { Hexachlonobenzene } \\
\text { Di-n-butylphthalate }\end{array}$ & $\begin{array}{c}550 \\
24.5 \\
55 \\
140 \\
70\end{array}$ \\
\hline Mountain Clay & $473 K$ & 256 & $\begin{array}{l}\text { Definitely Identified: } \\
\text { Tetrachloroethene } \\
\text { 1,2-Dichlorobenzene } \\
\text { 1,3-Dichlorobenzene } \\
\text { 1,4-Dichlorobenzene } \\
\text { 1,2,-trichlorobenzene } \\
\text { 1,2,4-Trichlorobenzene } \\
\text { Tentatioely Identified: } \\
\text { Tetrachloroethene }\end{array}$ & $\begin{array}{c}295 \\
55 \\
140 \\
1900 \\
50 \\
550 \\
\\
16\end{array}$ & $\begin{array}{l}\text { Definitely Identified: } \\
\text { 1,4-Dichlorobenzene } \\
\text { 12,4-Trichlorobenzene } \\
\text { Di-n-butylphthalate } \\
\text { Aroclor } 1254\end{array}$ & $\begin{array}{c}650 \\
115 \\
185 \\
3150\end{array}$ \\
\hline
\end{tabular}


Table XXIIb: Contaminated Soils 48-Hour Volatile and Semivolatile Results

\begin{tabular}{|c|c|c|c|c|c|c|}
\hline Toll & Tempentare & $\begin{array}{l}\text { Amount } \\
\text { Oxdized (14) }\end{array}$ & v & Amonnt & Semivolatiles & Anount \\
\hline True Clay & $43 K$ & 256 & $\begin{array}{l}\text { Definitely Identified: } \\
\text { Bromodichloromethane } \\
\text { 1,4-Dichlorobenzene } \\
\text { 1,2,-Trichlorobenzene } \\
\text { 1,23-Trichlorobenzene } \\
\text { 1,3-Dichlorobenzene } \\
\text { 1,2-Dichlorobenzene } \\
\text { Tetrachloroethene } \\
\text { Tentatiocly Identified: } \\
\text { Tetrachlorobenzene }\end{array}$ & $\begin{array}{c}2 \\
40.5 \\
50 \\
7 \\
10.5 \\
3.5 \\
10 \\
\end{array}$ & $\begin{array}{l}\text { Definitely Identified: } \\
\text { Aroclor } 1254\end{array}$ & 450 \\
\hline Plano & $43 K$ & 256 & $\begin{array}{l}\text { Definitely Identified: } \\
\text { Bromodichloromethane } \\
\text { Tetrachloroethene } \\
\text { 1,2-Dichlorobenzene } \\
\text { 1,3-Dichlorobenzene } \\
\text { 1,4-Dichlorobenzene } \\
\text { 1,2,-Trichlorobenzene } \\
\text { 1,2,4trichlorobenzene } \\
\text { Tentatioely Identified: } \\
\text { Trichloroethene }\end{array}$ & $\begin{array}{c}1.5 \\
115 \\
3 \\
3.5 \\
18 \\
3 \\
17.5 \\
\\
7\end{array}$ & $\begin{array}{l}\text { Definitely Identified: } \\
\text { Di-n-butylphthalate }\end{array}$ & 110 \\
\hline
\end{tabular}




\section{Table XXIIc: Contaminated Soils 48.Hour Volatile and Semivolatile Results}

\begin{tabular}{|c|c|c|c|c|c|c|}
\hline Soll & Temperature & $\begin{array}{l}\text { Amount } \\
\text { Oxddized lygt }\end{array}$ & Volaules & $\begin{array}{c}\text { Amouni } \\
\text { (4p) }\end{array}$ & Semivolatiles & Amount \\
\hline Plainfield & $473 K$ & 256 & $\begin{array}{l}\text { Definitely Identified: } \\
\text { Bromodichloromethane } \\
\text { Tetrachloroethene } \\
\text { 1,2,3-trichlorobenzene } \\
\text { 1,2,4-trichlorobenzene } \\
\text { Tentatioely Identified: } \\
\text { Hexachloroethane } \\
\text { Tetrachlorobenzene } \\
\text { Unknown }\end{array}$ & $\begin{array}{c}2 \\
3 \\
3 \\
5.5 \\
\\
\\
22.5 \\
30.5 \\
1\end{array}$ & $\begin{array}{l}\text { Definitely Identified: } \\
\text { 12,4-Tetrachlorobenzene } \\
\text { Pentachlorobenzene } \\
\text { Hexachlorobenzene } \\
\text { Di-n-butylphthalate }\end{array}$ & $\begin{array}{c}115 \\
49.5 \\
28 \\
90\end{array}$ \\
\hline Kinney Brick & $473 K$ & 256 & $\begin{array}{l}\text { Definitely Identified: } \\
\text { Bromodichloromethane } \\
\text { Tetrachloroethene } \\
\text { 1,2-Dichlorobenzene } \\
\text { 1,3-Dichlorobenzene } \\
\text { 1,4-Dichlorobenzene } \\
\text { 1,2,3-Trichlorobenzene } \\
\text { 1,2,4-Trichlorobenzene } \\
\text { Tentatioely Identified: } \\
\text { Hexachloroethane } \\
\text { Tetrachlorobenzene }\end{array}$ & $\begin{array}{c}1.5 \\
220 \\
14 \\
14.5 \\
375 \\
5.5 \\
85 \\
\\
12.5 \\
33.5\end{array}$ & $\begin{array}{l}\text { Definitely ldentified: } \\
\text { 1,4-Dichlorobenzene } \\
\text { 1,2,4-Trichlorobenzene } \\
\text { 1,2,4,-Tetrachlorobenzene } \\
\text { Hexachlorobenzene } \\
\text { Di-n-butylphthalate } \\
\text { Aroclor } 1254\end{array}$ & $\begin{array}{c}315 \\
110 \\
9 \\
31 \\
260 \\
9000\end{array}$ \\
\hline
\end{tabular}


Table XXII: Contaminated Soils Residual Non-volatile Organic Results

\begin{tabular}{|c|c|c|c|}
\hline \multicolumn{4}{|c|}{ Soluble Praction Amount of Non-yolatile Carbon and Hydrogen Residual Material in } \\
\hline Soil & $\begin{array}{l}\text { Organics } \\
\text { Oxidized (mg) }\end{array}$ & $\begin{array}{l}\text { Amount of } \\
\text { Carbon (mg) }\end{array}$ & $\begin{array}{l}\text { Amount of } \\
\text { Hydrogen (mg) }\end{array}$ \\
\hline $\begin{array}{l}\text { South Valley } \\
\text { Mountain Clay }\end{array}$ & $\begin{array}{l}256 \\
256\end{array}$ & $\begin{array}{l}<20.2 \\
<21.2\end{array}$ & $\begin{array}{l}28.3 \\
22.1\end{array}$ \\
\hline True Clay & 256 & $<15.6$ & 18.7 \\
\hline Plano & 256 & $<20.5$ & 57.3 \\
\hline Plainfield & 256 & $<23.0$ & 27.6 \\
\hline Kinney Brick & 256 & $<15.8$ & 34.7 \\
\hline \multicolumn{4}{|c|}{ Solible Fraction Lmount of Non-volatile Carbon and Hydrogen Residual Material in } \\
\hline Soil & $\begin{array}{c}\text { Organics } \\
\text { Oxidized (mg) }\end{array}$ & $\begin{array}{l}\text { Amount of } \\
\text { Carbon (mg) }\end{array}$ & $\begin{array}{l}\text { Amount of } \\
\text { Hydrogen (mg) }\end{array}$ \\
\hline $\begin{array}{l}\text { South Valley } \\
\text { Mountain Clay }\end{array}$ & $\begin{array}{l}256 \\
256\end{array}$ & $\begin{array}{l}<23.9 \\
<32.8\end{array}$ & $\begin{array}{l}33.4 \\
78.8\end{array}$ \\
\hline True Clay & 256 & $<26.1$ & 271 \\
\hline Plano & 256 & $<26.7$ & 26.8 \\
\hline Plainfield & 256 & $<33.1$ & 291.5 \\
\hline Kinney Brick & 256 & $<27.0$ & 493.3 \\
\hline \multicolumn{4}{|c|}{ 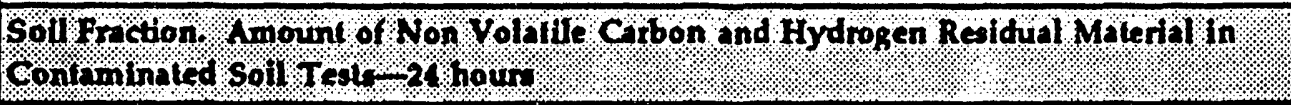 } \\
\hline Soil & $\begin{array}{l}\text { Organice } \\
\text { Oxidized (mg) }\end{array}$ & $\begin{array}{l}\text { Amount of } \\
\text { Carbon (mg) }\end{array}$ & $\begin{array}{l}\text { Amount of } \\
\text { Hydrogen (mg) }\end{array}$ \\
\hline $\begin{array}{l}\text { South Valley } \\
\text { Mountain Clay }\end{array}$ & $\begin{array}{l}256 \\
256\end{array}$ & $\begin{array}{c}36 \\
70.5\end{array}$ & $\begin{array}{l}5.5 \\
49\end{array}$ \\
\hline True Clay & 256 & 131.5 & 53 \\
\hline Plano & 256 & 94 & 47.5 \\
\hline Plainfield & 256 & 35.5 & 2.5 \\
\hline Kinney Brick & 256 & 99.5 & 26.5 \\
\hline
\end{tabular}



Table XXII: $\begin{aligned} & \text { Contaminated Soils Residual Non-volatile Organic Results } \\ & \text { (cont.) }\end{aligned}$

\begin{tabular}{|c|c|c|c|}
\hline \multicolumn{4}{|c|}{$\begin{array}{l}\text { Soil Fraction, Amount of Non Volatile Carbon and Hydrogen Residual Material in } \\
\text { Contuminted Soll Teats }-48 \text { hours }\end{array}$} \\
\hline Soil & $\begin{array}{c}\text { Organics } \\
\text { Oxidized (mg) }\end{array}$ & $\begin{array}{l}\text { Amount of } \\
\text { Carbon (mg) }\end{array}$ & $\begin{array}{l}\text { Amount of } \\
\text { Hydrogen (mg) }\end{array}$ \\
\hline $\begin{array}{l}\text { South Valley } \\
\text { Mountain Clay }\end{array}$ & $\begin{array}{l}256 \\
256\end{array}$ & $\begin{array}{l}43.5 \\
49.5\end{array}$ & $\begin{array}{c}17 \\
49.5\end{array}$ \\
\hline True Clay & 256 & 126.5 & 60.5 \\
\hline Plano & 256 & 81.5 & 39 \\
\hline Plainfield & 256 & 24.5 & 6.5 \\
\hline Kinney Brick & 256 & 67.5 & 22.5 \\
\hline
\end{tabular}


This page intentionally left blank 


\section{SECTION 5}

\section{ENGINEERING}

\subsection{Objectives}

The developmental studies conducted in this project were targeted for identification of applications for the DETOX process. Once appropriate applications had been identified, a conceptual engineering study was performed for the DETOX process as it would be configured in a treatment system. The objectives of this task were to identify specific applications for the DETOX process at DOE sites, calculate mass and energy balances, perform conceptual engineering of the various treatment system components, identify materials of construction, identify any secondary waste streams, identify critical engineering issues involved in application of the process, and estimate the capital and operating costs of a DETOX treatment system.

\subsection{Procedure and Apparatus}

As this task was a paper study, no apparatus was required. The general procedure was to identify several potential site applications, narrow those applications to the two or three most desirable for demonstration, submit these applications to the Department of Energy for review, and then perform the engineering study for the two most likely candidates.

\subsection{Results}

\subsubsection{Applications}

A variety of potential applications were identified, based on the results of the laboratory development studies. It appears that the DETOX process is fairly omnivorous, as it will destroy a wide range of organic compounds while simultaneously dissolving and concentrating heavy metals in the process solution for ultimate disposal. The inert solids in wastes can then be separated and rinsed, rendering them clean for delisting and ordinary disposal, reuse, or recycling. It is felt that the greatest benefit will come from application of the process to organic wastes contaminated with metals and to inert materials contaminated with small amounts of hazardous organics and/or heavy metals. For initial demonstration, relatively pure organics contaminated with metals were felt to be most desirable. 
Two wastes were chosen for the conceptual design studies. One of these wastes was approximately $1000 . \mathrm{kg}$ of PCB transformer oil and hydraulic fluid, in unknown proportions, stored in five drums at Rocky Flats Plant (RFP). The material is assumed to be contaminated with trace amounts of chlorinated solvents and radionuclides. It is a RCRA waste, a TSCA waste, and a low level radioactive waste. RFP has other assorted waste types, such as machining oils, solvents, and various solid wastes, which could be treated in a DETOX demonstration unit. The second demonstration candidate is approximately $27,000 . \mathrm{kg}$ of tributyl phosphate (TBP) located in drums at Weldon Springs Site (WSS). The TBP is fairly homogeneous (as it was all drained from two large tanks of similar content), and is known to be contaminated with PCB's, uranium, thorium, and trace amounts of mercury. Weldon Springs is a Superfund site, so the waste falls under CERCLA guidelines. Weldon Springs Site also has a variety of additional waste types, including solvents, oils, etc., which could be treated in a DETOX demonstration unit. Visits were made to both RFP and WSS to discuss the application of DETOX to their wastes in demonstration. Personnel at both facilities were receptive to demonstration of DETOX on wastes at their sites.

\subsubsection{Application to PCB Oil at Rocky Flats Plant}

A conceptual system schematic is given in Figure 25. The demonstration unit for RFP should be capable of oxidizing approximately $5 . \mathrm{kg}$ per hour of the PCB oils. It is assumed for this conceptual design that the average composition of the oils is $50 . \%$ by weight Aroclor 1254 and $50 . \%$ by weight hydrocarbon oil.

\subsubsection{Mass and Energy Balance}

The mass and energy balances for the RFP wastes are given in Tables XXIV and XXV.

In application to PCB oil at RFP, a significant amount of hydrochloric acid (HCl) will be produced, so it will be necessary to add water to the oxidation vessel to dilute the $\mathrm{HCl}$ being evaporated from the system. The condensate will be neutralized with soda ash or sodium hydroxide. Excess water will be evaporated from the neutralized condensate and reused in the oxidation vessel, thus minimizing the volume of salt solution to be disposed. The amounts of any metals in the PCB oils are assumed to be insignificant based on information supplied by RFP. The carbon dioxide produced in the reaction will be captured in a tank and analyzed before venting. 
Figure 25: DETOX Treatment System Conceptual Schematic for Rocky Flats Plant Demonstration

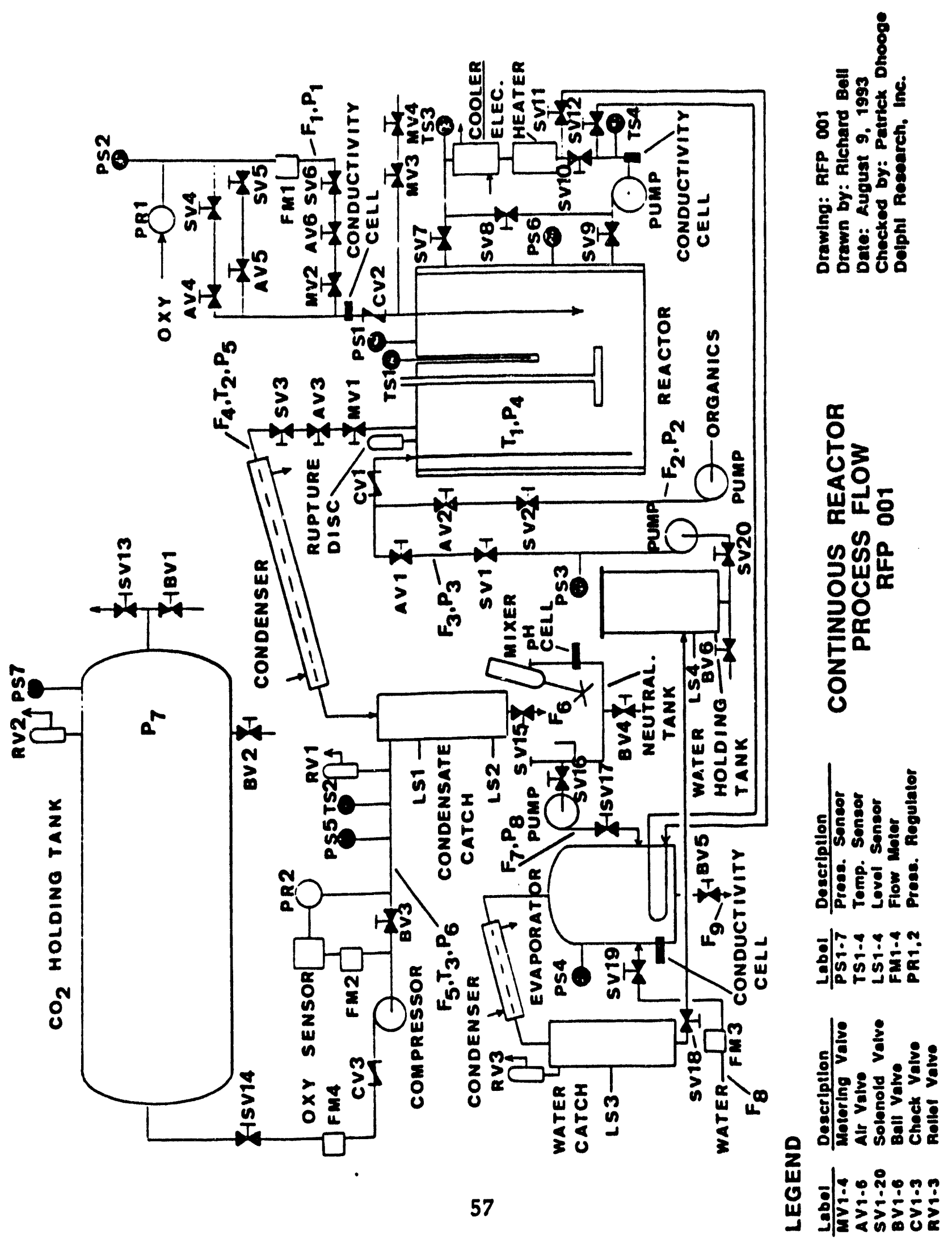


Table XXIV: Mass Balance for Oxidation of PCB Oil

\begin{tabular}{|clr|}
\hline Mass Balance for Oxidation of PCB Oil \\
\hline \multirow{2}{*}{ Mass In: } & Aroclor 1254 & $2,517.8 / \mathrm{hr}$ \\
& Hydrocarbon Oil & $2,483.8 / \mathrm{hr}$ \\
& Oxygen & $13,179.8 / \mathrm{hr}$ \\
& Water & $5,134.8 / \mathrm{hr}$ \\
& Sodium Hydroxide & $1,542.8 / \mathrm{hr}$ \\
& & $24,855.8 / \mathrm{hr}$ \\
& Total In & $1,706.8 / \mathrm{hr}$ \\
Mass Out: & Oxygen & $9,020.8 / \mathrm{hr}$ \\
& Carbon Dioxide & $2,255.8 / \mathrm{hr}$ \\
& Water & $24,855.8 / \mathrm{hr}$ \\
& Sodium Chloride & \\
& & \\
& Total Out &
\end{tabular}

\section{Table XXV: Energy Balance for Oxidation of PCB Oil}

\begin{tabular}{|c|c|c|}
\hline \multicolumn{3}{|c|}{ Fency Balance for Oxidation of $\mathrm{rCB}$ Oil } \\
\hline \multirow[t]{3}{*}{ Energy In: } & Heat of Combustion & $147,500 . \mathrm{kJ} / \mathrm{hr}$ \\
\hline & $\begin{array}{l}\text { Heat of Solution } \\
\text { (HC) } \\
\text { Heat of Reaction } \\
(\mathrm{HCl}+\mathrm{NaOH})\end{array}$ & $\begin{array}{l}2,900 . \mathrm{kJ} / \mathrm{hr} \\
2,200 . \mathrm{kJ} / \mathrm{hr}\end{array}$ \\
\hline & Total Energy in & $152,600 . \mathrm{kJ} / \mathrm{hr}$ \\
\hline \multirow[t]{4}{*}{ Energy Out: } & Reactor Vapor & $40,200 . \mathrm{kJ} / \mathrm{hr}$ \\
\hline & Water Return & $24,500 . \mathrm{kJ} / \mathrm{hr}$ \\
\hline & $\begin{array}{l}\text { Active Reactor } \\
\text { Tank Cooling }\end{array}$ & $87,900 . \mathrm{kJ} / \mathrm{hr}$ \\
\hline & Total Energy Out & $152,600 . \mathrm{kJ} / \mathrm{hr}$ \\
\hline
\end{tabular}


The oxidation of the PCB oil/hydraulic fluid (including heat of solution of $\mathrm{HCl}$ and heat of reaction of $\mathrm{HCl}$ with $\mathrm{NaOH}$ ) will produce approximately $153,000 \mathrm{~kJ} / \mathrm{hr}$, of which approximately $40,000 \mathrm{~kJ} / \mathrm{hr}$ will be removed by carbon dioxide, water, and $\mathrm{HCl}$ exiting the oxidation vessel. Approximately $25,000 \mathrm{~kJ} / \mathrm{hr}$ will be used to evaporate water from the neutralized condensate for return to the oxidation vessel. This will leave approximately $88,000 . \mathrm{kJ} / \mathrm{hr}$ excess heat which will have to be removed from the system. A large majority of this heat could be dissipated in piping and tank heat losses, but an active cooling system will undoubtedly be desirable for system safety.

\subsubsection{Condenser}

For extended operation of the DETOX process, carbon dioxide, water, and other products must be removed from the main oxidation vessel. Because the reaction is conducted at around $473 .^{\circ} \mathrm{K}$, water vapor will be the primary constituent in vapors vented from the oxidation vessel. Because the water must be returned to the reactor, and because any $\mathrm{HCl}$ produced must be condensed from the vapors in order to be neutralized for disposal, a condenser must be used on the oxidation vessel vapor outlet.

For oxidation of the PCB oil, it is assumed the condensate will be maintained at $10 . \%$ by weight $\mathrm{HCl}$. The vapors being passed through the oxidation vessel's output condenser will be approximately $25 . \%$ carbon dioxide, $5 . \%$ oxygen, $4 . \% \mathrm{HCl}$, and $66 . \%$ water by volume $(43 . \%, 6 . \%, 5 . \%$, and $46 . \%$ by weight, respectively). The heat loading on the condenser will be approximately $9.6 \times 10^{3} \mathrm{kcal} / \mathrm{hr}$. The parameters for a tube-in-shell condenser for this system are given in Table XXVI. A tube-in-shell configuration is relatively simple to calculate, and it is also relatively simple to fabricate and maintain.

One of the concerns in operation of the prototype process unit is the presence of volatile and/or semivolatile organic compounds in the outlet gases from the reaction vessel. Of the organic compounds which have been detected as reaction intermediates, concentrations in the process solution are in the milligrams per liter range, and only a few have boiling points less than water. Organic compounds with boiling points greater than water can be contained in the reaction vessel by using a reflux condenser on the gas outlet. While it is felt that this device will not be necessary due to the low concentrations of volatile and/or semivolatile organic compounds in the process solution, tests of a prototype unit with non-hazardous and non-radioactive materials will be able to determine whether such a device will be needed on the prototype before any hazardous and mixed wastes are treated with the unit. Organic compounds with boiling points less than water will come over into the 
condensate, and should be partitioned effectively into the aqueous phase at the concentrations which have been detected in laboratory studies. The condensate can be sparged with the oxygen being fed into the reaction vessel to remove volatile organics if they present a problem due to their concentration in the condensate.

\subsubsection{Pumps}

The RFP treatment unit, as shown in Figure 25, requires four pumps and one gas compressor. The organic feed pump is required to meter 4.1 liters per hour of PCB oil against a head pressure of 1620 . $\mathrm{kPa}$ or more. The water return pump is required to pump approximately 9.5 liters per hour of water against a head pressure of 1620 . $\mathrm{kPa}$ or more. The neutralized condensate plimp is required to pump approximately 14.1 liters per hour of $14.4 \%$ sodium chloride solution into an evaporator tank against about $175 . \mathrm{kPa}$ of head pressure. The cooling/heating oil pump is required to pump approximately 600 . liters per hour of thermal oil fluid against about $300 . \mathrm{kPa}$ of head pressure to control temperatures in the system. Finally, the compressor to pressurize the carbon dioxide product gas for storage, prior to testing and release, is required to pressurize 3100 . liters of gas per hour from approximately $265 . \mathrm{kPa}$ to a maximum pressure of $1500 \mathrm{kPa}$.

The RFP treatment unit is $n$ significant amounts of solids subsystem. nected to encounter or generate any thus, should not require a filtering 


\begin{tabular}{|c|c|c|c|c|c|c|c|}
\hline (1. & 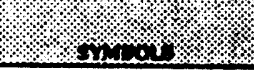 & vinut & oundes & 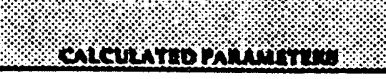 & . & Qotors & alevin \\
\hline 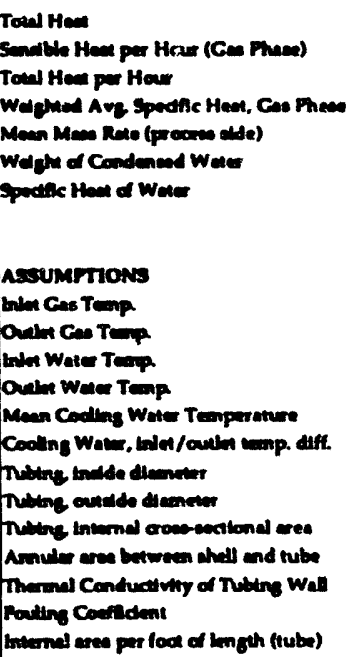 & 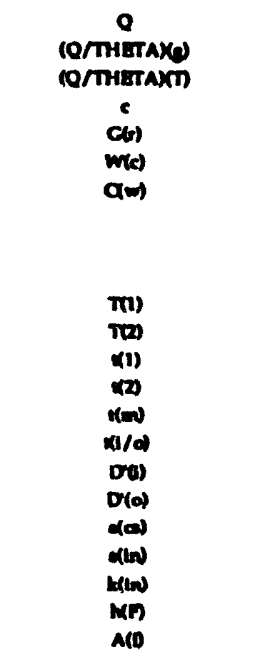 & 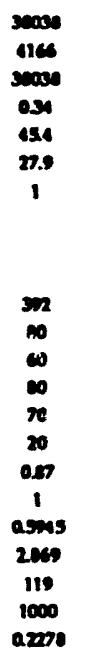 & 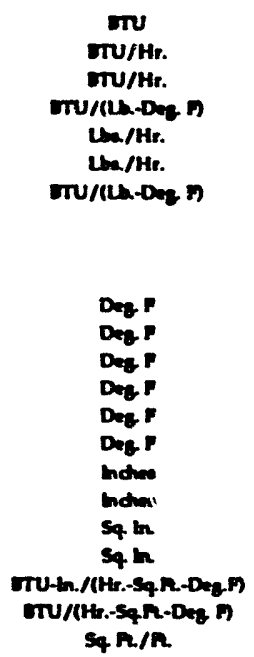 & 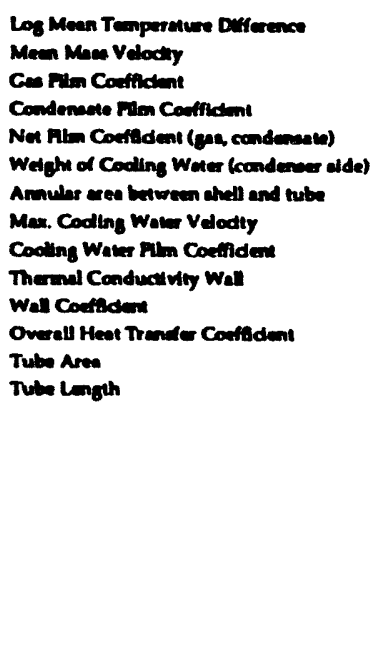 & 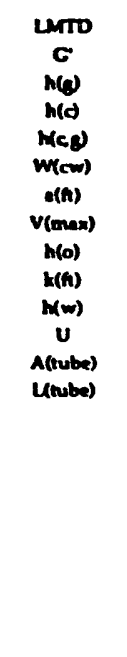 & 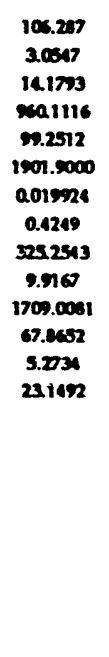 & 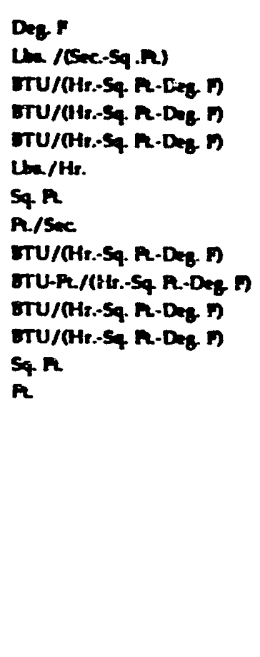 \\
\hline CONVEBSEON YACTOES & 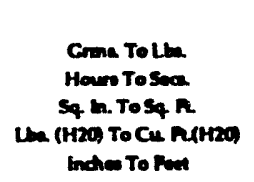 & 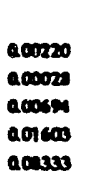 & & & & & \\
\hline
\end{tabular}




\subsubsection{Configuration/Materials}

The conceptual schematic for the unit has been given in Figure 25. It would be configured as a skid-mounted unit. The DETOX process is well suited for a skid-mounted configuration, because it can be utilized for smaller amounts of specialized wastes, then moved or removed as necessary.

RFP has indicated that the unit would be installed in a building where there is a bay with a roll door. This skid would, therefore, be designed such that it is capable of being transported on a standard flat bed trailer and moved through the bay door at RFP. As presently conceived, this unit should fit on one standard skid, with the exception of the carbon dioxide storage tanks. It will probably be desirable to maintain the carbon dioxide storage tanks on tank supports external to the building. Table XXVII gives the flows, pressures, and temperatures in the unit for DETOX in application to the RFP waste.

Materials of construction for the unit will range from tantalum to polypropylene. The oxidation vessel must be capable of withstanding highly corrosive conditions. Consultation with experts in titanium alloys and tantalum have indicated that Grade 7 titanium might be suitable for the oxidation vessel, but that tantalum would experience even less corrosion. It is felt, therefore, that the best combination would be a Grade 7 titanium reactor shell with a tantalum liner. The tantalum liner would give superior resistance to chemical attack, and a Grade 7 titanium shell would act as a corrosion-resistant secondary containment and pressure vessel. For valves and piping exposed to hot vapors from the DETOX solution, and the condenser, it would also be desirable to have tantalum construction. Teflon ${ }^{\mathrm{TM}}$-lines plug valves can be used as on/off valves on the oxygen inlet line, the organic feed line, and the water return line, but are not suitable for exposure to the hot vapors in the gas outlet line. For the gas outlet line, hardened zirconium can be used if it is not exposed to iron from the process solution, but it may be advisable to remain with tantalum for this area. The condensate catch tank can be a commercial glass-lined steel vessel or it can be fabricated of EPDM-lined steel. The condensate neutralization tank, water catch tank, and water return tanks can all be polypropylene backed with fiberglass shells. The evaporation tank can be of monel construction. Valves and lines for the low temperature, neutralized part of the process can be polypropylene or polypropylene-lined steel. Pump materials will vary depending on the medium being pumped. The heat transfer fluid pump can be a standard steel pump. The organics feed pump and aqueous fluid return pump can be Teflon ${ }^{\mathrm{TM}}$ diaphragm metering pumps with stainless steel heads. The neutralized condensate pump can be a Teflon ${ }^{\mathrm{TM}}$ diaphragm pump with PVC head. 
Table XXVII: Flows, Pressures, Temperatures for Oxidation of PCB Oil

\begin{tabular}{|c|c|c|c|}
\hline Location & $\begin{array}{l}\text { Flow } \\
(\mathrm{L} / \mathrm{hr})\end{array}$ & $\begin{array}{c}\text { Temperature } \\
\left({ }^{\circ} \mathrm{K}\right)\end{array}$ & $\begin{array}{c}\text { Pressure } \\
(\mathrm{kPa})\end{array}$ \\
\hline Oxygen to Reactor & 632 & 293 & 1620 \\
\hline Organics to Reactor & 4.1 & 293 & 1620 \\
\hline Water to Reactor from Evaporator & 9.5 & 293 & 1620 \\
\hline Reactor Vessel & & 473 & 1500 \\
\hline Gases to Condenser & 15500 & 473 & 275 \\
\hline $\mathrm{CO} 2+02$ to Compressor & 3100 & 300 & 265 \\
\hline $\mathrm{CO} 2+\mathrm{O} 2$ in Holding Tank & & 293 & 1500 Max. \\
\hline Condensate ( $10 \% \mathrm{HCl}$ in Water) to Catch & 13.4 & 300 & 83 \\
\hline Neutralized Condensate to Evaporator & 14.1 & 336 & 175 \\
\hline Water to Evaporator & 5.2 & 293 & 83 \\
\hline $20 \% \mathrm{NaCl}$ from Evaporator & 9.8 & 293 & 83 \\
\hline
\end{tabular}

\subsubsection{Monitors and Controls}

Figure 25 shows the monitors for the unit as envisioned. Temperature, pressure, oxygen, flow, level, $\mathrm{pH}$, and conductivity sensors for the system are shown on the figure. The amounts of organic, oxygen, and returned fluid added to the oxidation vessel will be metered or monitored. The amount of product gas and its oxygen content will be measured. The amounts of feeds and products thus measured will determine the mass balance of the system, and whether one or more of the feed rates needs to be changed. Temperature and pressure sensors at critical points on the unit will be used to control oxidation vessel temperature, heating/cooling fluid flow, organic and oxygen feed rate, and product gas flow. Hardwired shut-offs will be built into the unit to provide high reliability shutdown in the event of an upset condition. Operation and data acquisition will be controlled by a microcomputer with power conditioning and a backup power supply. Inputs from and outputs to the unit will be isolated from the PC to avoid any power surges to the control system. At critical points, sensors will be in duplicate to provide redundancy in critical measurements, such as oxidation vessel temperature and pressure.

\subsubsection{Secondary Waste Streams}

In the destruction of PCB oils at Rocky Flats Plant, there will be three end products of the reaction. These products will be the gases released from the 
system, the sodium chloride solution produced from neutralization of the condensate, and the DETOX solution after waste processing is concluded. The product gases, consisting of approximately $16.5 \mathrm{~kg}$ per hour of carbon dioxide containing small percentages of oxygen and water vapor, will be collected by compressing into tanks. The compressed gases will be tested for the presence of volatile organics, $\mathrm{HCl}$, and radioactivity before release. It is anticipated that the gases will not contain any radioactive materials, and environmentally compliant amounts of $\mathrm{HCl}$ and volatile organics. If the gases do contain small amounts of $\mathrm{HCl}$ and volatile organics, they can be passed through activated charcoal prior to release. When the charcoal is expended or at the conclusion of waste processing it can be introduced into the process solution and destroyed, thus eliminating it as a secondary waste stream. There will be approximately $11.3 \mathrm{~kg}$ per hour of $20 . \%$ sodium chloride brine produced by the process, or a weight somewhat over twice that of the waste which has been destroyed. The brine will not contain any radioactive metals, but even though it will be sparged or passed through activated charcoal it may contain small amounts of volatile organics. The brine may have to be delisted, as it will fall under the Resource Conservation and Recovery Act derived-from rule. If amounts of volatile organics in the brine are above regulatory levels, the brine can be retained in drums and introduced into the process solution in batches at the end of waste processing, where the small amounts of organics remaining will be destroyed. Excess water from the brine will be evaporated off the process solution, neutralized, and can be delisted and disposed of as a non-hazardous material. It is planned that the process solution at the conclusion of waste processing will be tested for the presence of hazardous organic compounds, toxic metals, and radioactive metals. If hazardous organic compounds are detected, the process solution will be heated again for some period until the organic compounds are destroyed. Following verification of the absence of organic compounds in any amounts which would render the process solution hazardous due to organic content, the process solution will be pumped from the oxidation vessel at the conclusion of all waste processing, neutralized, and solidified by one of three candidate processes (cementation, vitrification, or encapsulation). The process solution as removed from the reaction vessel will contain any radioactive and/or toxic metals which were present in the waste, and will be corrosive. Neutralization will remove the corrosive characteristic, and will precipitate the iron and some other metals, giving a sludge. The amount of neutralized process solution will be approximately $240 . \mathrm{kg}$, containing approximately $81 . \mathrm{kg}$ of water, approximately $47 . \mathrm{kg}$ of iron oxide, approximately $104 . \mathrm{kg}$ of sodium chloride, and an assumed $8 . \mathrm{kg}$ of residual inorganic material which was in the waste treated. The sludge will be a radioactive waste due to radionuclide content, and it may be a hazardous waste due to its toxic metal content. If it is not desirable to have a great chloride content in the final form of the process solution residue, there are at least two methods by which chloride may be removed. One method for chloride removal is to forego neutralization and heat the process solution, 
passing the vapors through sodium hydroxide solution or lime. Iron chloride in the presence of water spontaneously decomposes into hydrated iron oxide and $\mathrm{HCl}$, if the $\mathrm{HCl}$ is removed continuously. Another method for chloride removal is to neutralize the process solution with ammonium hydroxide, giving ammonium chloride which may be sublimated off the solids at approximately 573.K. Either of these methods will reduce the amount of final residue which must be immobilized and disposed to approximately $55 . \mathrm{kg}$, with very little chloride salt content.

\subsubsection{Critical Engineering Issues}

The most critical issue in engineering a process unit for reliable and safe waste treatment is identifying suitable materials of construction for areas of the unit which are exposed to hot process solution and the hot vapors from that solution. The reaction vessel poses the greatest challenge to materials of construction, since it combines a highly corrosive oxidizing environment in the presence of the process liquid with a highly corrosive reducing environment in the reaction vessel headspace. This combination of environments demands the use of tantalum metal or a highly corrosionresistant coating such as ceramic or glass. The temperature and pressure in the reaction vessel, combined with the presence of chlorinated compounds and radioactive metals, precludes the use of a Teflon ${ }^{\mathrm{TM}}$ lining due to absorption and diffusion problems. Glass and ceramic coatings are commercially applied to carbon steel, but carbon steel is an unsuitable base material for containing the process solution should the coating fail. A metallic lining material is much more resistant to cracking and breaking than ceramic or glass materials, and metallic linings have been used in the chemical process industry for many years. The corrosion rate of tantalum in conditions similar to the reaction vessel has been measured as being approximately $0.025 \mathrm{~mm}$ per year, which would allow the use of a $0.75 \mathrm{~mm}$ thickness tantalum lining for the reaction vessel. Where hot gases exit the reaction vessel, and through the condenser, tantalum is also the metal of choice, although it may be possible to use hardened zirconium in areas where there will be no exposure to iron from the process solution. Once the gases from the process have been cooled, less exotic materials may be used in the remainder of the process unit.

Temperature control for the reaction vessel is critical to maintaining a good reaction rate and to safe operation of the unit. A jacketed tank with hot oil flow will provide good temperature control under routine operating conditions. One of the potential failure modes of the unit would be reaction tank thermal runaway. Several features can be designed into the unit to prevent thermal runaway. Redundant temperature sensors will provide more reliable measurement of the reaction vessel temperature. Stopping the reaction vessel stirrer will immediately reduce the oxidation rate to slow heat 
generation. A backup power supply will allow coolant to continue circulating in the event of main power failure. Organic feed will be provided with redundant shut off valves to prevent accidental addition of excess. Design will allow for some amount of excess temperature and pressure. If all other methods of controlling temperature rise fail, an emergency water addition can be made to the reaction vessel to quench the reaction.

Control and safety subsystems will be configured with redundant sensors and redundant processors, so that control and safety shut-down reliability is high. Points of particular concern are reaction vessel temperature and pressure, condensate temperature, exit gas flow, water return line pressure, organic feed line pressure, oxygen supply line pressure, liquid levels, and primary containment breach. There will be several hardwired emergency switches controlled by reactor temperature and pressure, exit gas flow rate, cooling water flow, conductivity cells (for containment breach), and acid gas concentration exterior to the reaction vessel.

Containing the process solution, vapors, and condensate liquids is critical to successful operation of a process unit. The most important component is the reaction vessel, which will contain the hot, pressurized process solution with hazardous organics and radionuclides. In order to insure continued containment of the contents of this vessel, it can be constructed of a Grade 7 titanium pressure shell lined with tantalum. There would be at least two conductivity sensors or acid vapor sensors installed in the pressure shell to detect any breach of the vessel lining. Grade 7 titanium is well capable of containing the process solution until it can be cooled and removed. Lines which handle the hot vapors from the reaction vessel will be double-walled with leak sensors. If desired, positive pressure of inert gas can be applied between the walls of the tubing to insure that leaks are of inert gas into the primary piping rather than of process vapors into the secondary piping; a sensor for inert gas in the vapor output can be used to detect any leaks in the piping at an early stage. Cooling water can be maintained at a greater pressure than the process side of the condenser to insure that any leaks are to the process side of the condenser, and increased flow of liquid into the condensate catch tank can be used to detect any leaks in the condenser. The condensate liquid can be collected in a lined tank with two sensors between the lining and shell to detect a breach of the lining. Once the condensate is neutralized it should be hazardous only to the extent that it may contain small amounts of some volatile organic compounds. It is recommended that the entire process unit be enclosed in a plastic box to provide additional reliability of containment. Process gases will be contained in a pressure vessel, and tested for levels of organic compounds and hydrochloric acid vapor before release.

Service-ability is an important consideration when designing systems which will treat hazardous and mixed wastes. A primary end effect of design will be 
to maximize the reliability of components and materials used in the unit in order to minimize the need for service. For all components for which such information is available, reliability records will be requested from suppliers to determine the highest reliability components and to help define the reliability of the unit. It will be well worthwhile in cost to use more reliable and redundant components rather than to incur the expense of having to replace or repair them after the system has been installed at Rocky Flats Plant and exposed to radioactive materials. It is highly recommended that spare sensors be pre-installed on the system such that switching a sensor electrical connection will be all that is necessary to correct a sensor failure. Since the cost of sensors is only a small part of the capital cost of the system, spare sensors are an inexpensive means of greatly improving reliability. Use of highly corrosion-resistant components is another means of minimizing service, and again the added cost for this is more than offset by the potential cost of servicing a system which has been installed and exposed to radioactive material. Since any radioactive material will be contained in the waste feed line, waste feed pump, and reaction vessel, these should be most accessable for any necessary repair work. It is recommended that the reaction vessel and waste feed system be contained in a separate, shielded submodule on the skid. All other valves, pumps, and the stirrer motor should be easily accessable for adjustment, servicing, or replacement.

System cost is a secondary but important engineering issue. Although the primary engineering considerations for the treatment unit are safety and reliability, cost is also an important factor in design engineering. Where possible, commercially available components should be specified in the design. Standard materials with well-defined histories in chemical service should be used to maximize confidence in reliability and to minimize any development costs. It is felt that input from representatives of regulatory agencies and any applicable public interest groups should be included in the design process to minimize costs of any redesign efforts resulting from failure to address their concerns in the initial design. Probably the most important aspect of minimizing total cost for the unit, as well as giving a high confidence level for performance, is maximizing reliability in the design and fabrication process. Repairs and maintenance on a poorly designed and/or fabricated unit can well exceed the original capital cost of the unit. Any anticipated options for organic feed or other operating parameters which will affect design and fabrication should be considered in the original unit design, since the cost of retrofitting these options onto the unit after it has been exposed to hazardous materials will be much greater. Finally, the unit design and control should be as robust as reasonably possible, in order to be able to withstand any upset conditions or operator errors without damage to the unit or release of any hazardous materials. 


\subsubsection{Health and Safety}

The health and safety of the prototype operators is of paramount importance in operation of the unit. EG\&G Rocky Flats Plant has indicated that they would be operating the protoytype unit in accordance with applicable Department of Energy and Rocky Flats Plant health and safety regulations. This will include use of appropriate procedures, protective gear, monitors, and safety support systems. PCB oil wou' $t$ be loaded into the reaction vessel, from the drums it is currently stored in, using a diaphragm metering pump. The pump and line would have secondary containment to help protect the operators from exposure due to any leaks in the feed line or pump. Radiation monitors would inspect the personnel and transfer area after any loading operation to determine whether any exposure had occurred. Any exposure would be immediately investigated to determine the source and correct the problem causing the exposure. During operation, the designed safety features of the unit, including alternate power, redundant monitors and controls, emergency shut downs, secondary containment, acid gas sensors external to the unit, and radioactivity sensors external to the unit, will minimize the chance of operator exposure to the waste materials or to other safety risks involved with operation of the unit. Unloading will involve pumping the cooled process solution out of the reaction vessel through either the organics feed line or the oxygen introduction line into a container or containers for post-treatment and eventual disposal. It is our opinion that the organics feed line is the better choice, since it will already have been exposed to radioactive material.

\subsubsection{Tributyl Phosphate at Weldon Spring Site}

A conceptual system schematic is given in Figure 26. The demonstration unit for WSS should be capable of oxidizing $25 . \mathrm{kg}$ per hour of TBP. It is assumed that the waste is essentially pure TBP with some minor contaminants. 


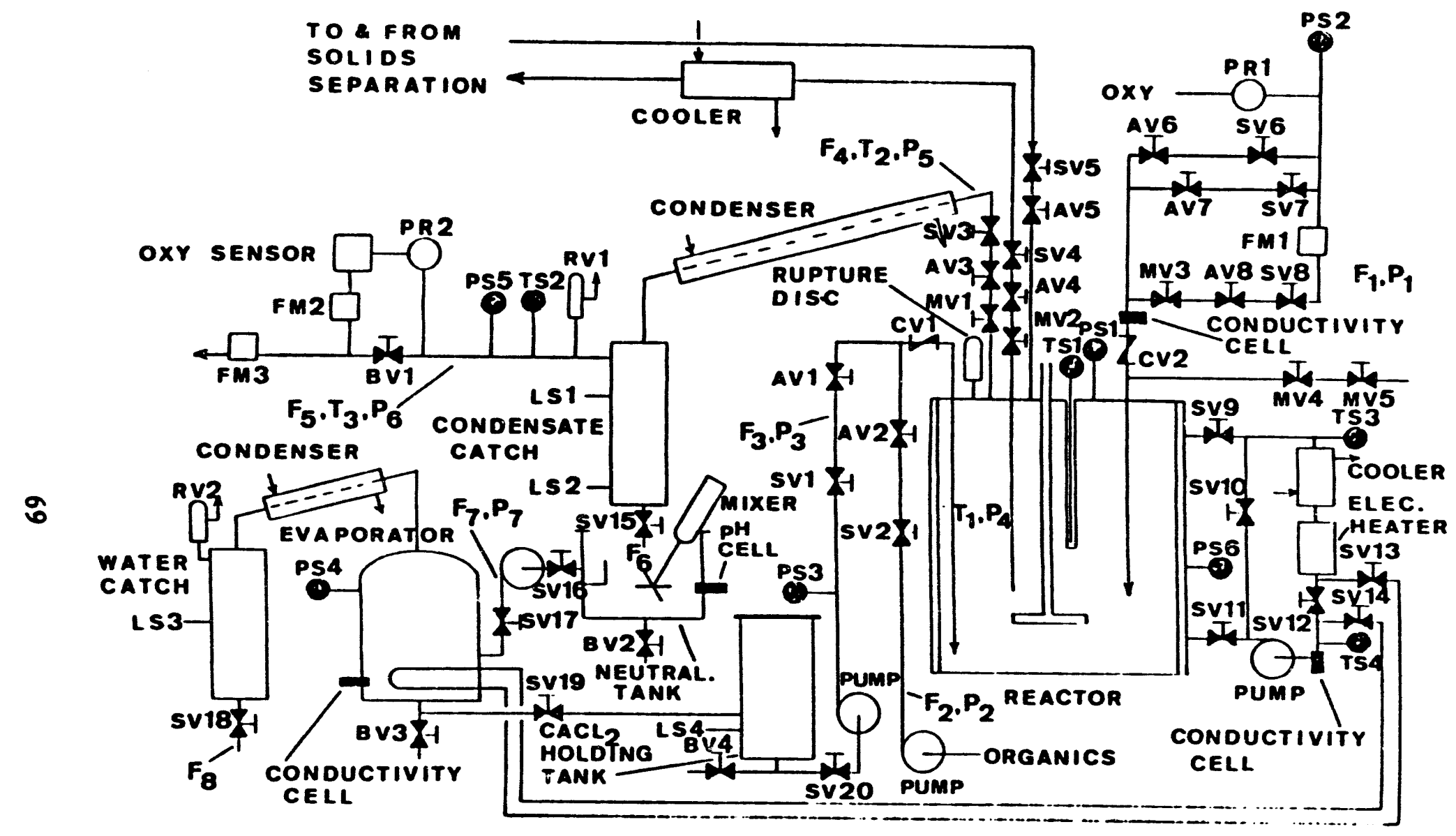

\section{LEGEND}

Labol Descripilon

Label Descripllon

Avi.5 Molering Valve PS1.6 Prese. Sonsor

AV Alr Valvo val.4 Tomp. Sonsor

BV1-4 Soll Vold Valvo LS1.4 Lovel Sonaor

$\begin{array}{lll} & \text { FM1-3 } & \text { Flow Molor } \\ \text { CV1,2 Chock Velve PRi,2 Prees. Rogulator }\end{array}$
CONTINUOUS REACTOR

PROCESS FLOW

WSS 001
Drawing: WSS 001

Drawn by: Rlchard Bell

Date: August 13, 1993

Checked by: Patrick Dhooge

DolphI Rosearch, Ine. 


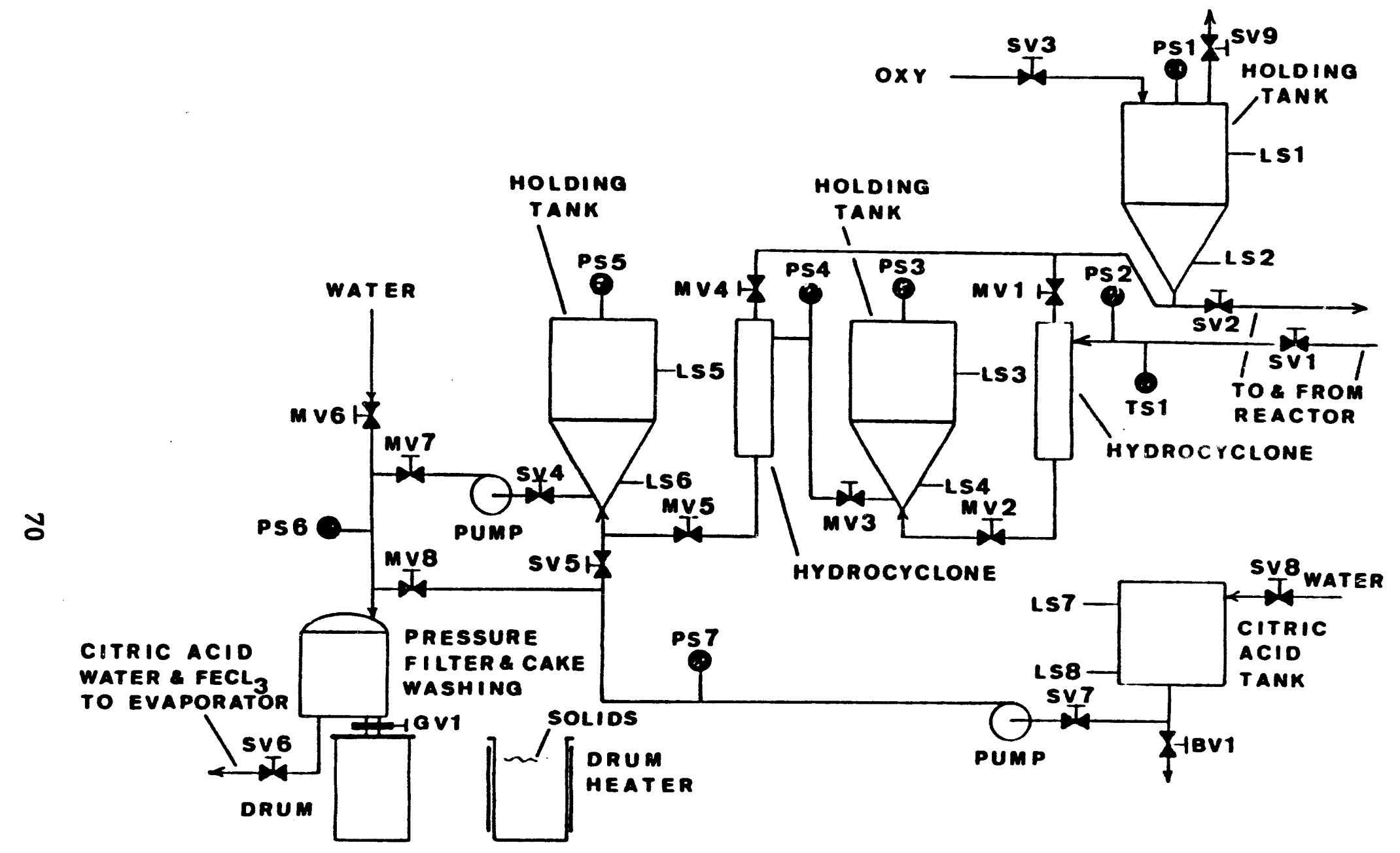

\section{LEGEND}

Labol Deacrlption

MV1-6 Motoring Valve

SV1-D Solenold Valve

BV1 Ball Valve

OV1 Cate Valve
Label Descriptlon

PS1.7 Prese. Seneor

TS1 Tomp. Sonsor

LS1.8 Lovel Soneor
SOLIDS SEPARATION

PROCESS FLOW

WSS002
Drawing: WSS002

Drawn by: Alcharo Boll

Date: August 16, 1993

Checked by: Patrlek Dhooge

Dolpili Resoarch, Ine. 


\subsubsection{Mass and Energy Balance}

The mass and energy balances for the WSS wastes are given in Tables XXVIII and $X X I X$.

The feed rate for TBP at WSS is about five times greater than for the PCB oils at RFP, and the amounts of products are correspondingly greater. A concern in the destruction of TBP is the amount of phosphate formed in the destruction process. Phosphate will have to be removed from the process solution, and this can be accomplished with the addition of calcium ion to the process solution. Since calcium in the process solution will be present as the chloride, excess hydrochloric acid will need to be removed from the process solution as the calcium reacts. The condensate would, therefor, be maintained at about $10 . \%$ by weight $\mathrm{HCl}$. The condensate will be neutralized with slaked lime to give additional calcium chloride. Excess water will be evaporated from the neutralized condensate, and the remainder of the neutralized condensate will be returned to the DETOX solution to supply water and more calcium for phosphate precipitation. Excess water will be an effluent stream from the process, but should be clean. Carbon dioxide will be vented. The amounts of metals in the waste are not sufficient to saturate the DETOX solution, and, thus, will be concentrated in solution for ultimate disposal.

The heat generated in oxidation of $25 . \mathrm{kg} / \mathrm{hr}$ TBP (including heat of solution of $\mathrm{HCl}$ and heat of reaction of calcium chloride with phosphoric acid) is aproximately $743,000 \mathrm{~kJ} / \mathrm{hr}$. Approximately $102,000 \mathrm{~kJ} / \mathrm{hr}$ will be removed by carbon dioxide, water, and $\mathrm{HCl}$ exiting the oxidation vessel. Approximately 205,000 . $\mathrm{kJ} / \mathrm{hr}$ will be used to evaporate excess water from the neutralized condensate and rinses, leaving a balance of approximately $436,000 . \mathrm{kJ} / \mathrm{hr}$ which must be removed from the reaction vessel. Some amount of this heat will be removed by the solids separation process solution cooler, but the oxidation vessel will require active cooling, which will be achieved through a jacketed tank and heat transfer oil. 
Table XXVII: Mass Balance for Oxidation of Tributyl Phosphate at Weldon Spring Site

Mass Balance for Oxddatlon of WSS TBP

\begin{tabular}{|c|c|c|}
\hline \multirow[t]{4}{*}{ Mass In: } & Tributyl Phosphate & $25,000.8 / h r$ \\
\hline & Oxygen & $59,082 . \mathrm{g} / \mathrm{hr}$ \\
\hline & Calcium Hydroxide & $3,478 . \mathrm{g} / \mathrm{hr}$ \\
\hline & Total In: & $87,560 . \mathrm{g} / \mathrm{hr}$ \\
\hline \multirow[t]{4}{*}{ Mass Out: } & $\begin{array}{l}\text { Oxygen } \\
\text { Carbon Dioxide }\end{array}$ & $\begin{array}{r}4,947 \cdot g / h r \\
49,624 \cdot 8 / h r\end{array}$ \\
\hline & Water & $21,147 \cdot 8 / \mathrm{hr}$ \\
\hline & $\mathrm{Ca}(\mathrm{H} 2 \mathrm{PO} 4) 2 \mathrm{H} 2 \mathrm{O}$ & 11,842. $\mathrm{g} / \mathrm{hr}$ \\
\hline & Total Out & $87,560 . \mathrm{g} / \mathrm{hr}$ \\
\hline
\end{tabular}

\section{Table XXIX: Energy Balance for Oxidation of Tributyl Phosphate at Weldon Spring Site}

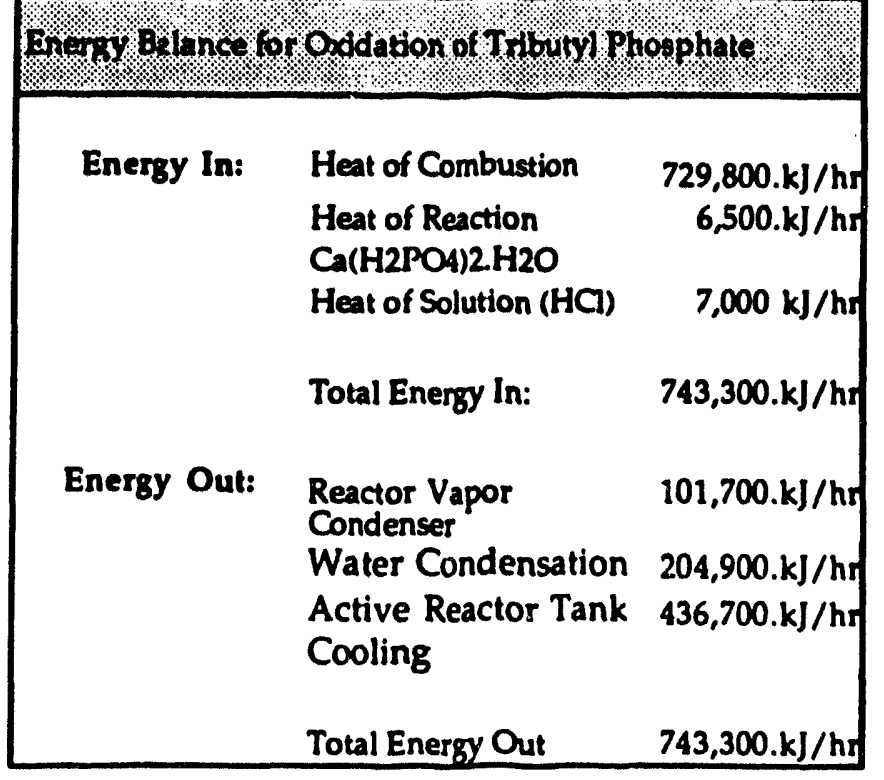




\subsubsection{Condenser}

For extended operation of the DETOX process, carbon dioxide, water, and other products must be removed from the main oxidation vessel. Because the reaction is conducted at around $473 .^{\circ} \mathrm{K}$, water vapor will be the primary constituent by volume in vapors vented from the oxidation vessel. Because much of the water vented from the reaction vessel must be returned to the reaction vessel, and because any $\mathrm{HCl}$ produced must be condensed from the vapors in order to be neutralized, a condenser must be used on the reaction vessel vapor outlet.

For oxidation of tributyl phosphate, it is assumed the condensate will be maintained at $10 . \%$ by weight $\mathrm{HCl}$. The vapors being passed through the oxidation vessel's output condenser will be approximately $37 . \%$ carbon dioxide, $5 . \%$ oxygen, $3 . \% \mathrm{HCl}$, and $55 . \%$ water by volume $(56 . \%, 6 . \%, 4 . \%$, and $34 . \%$ by weight, respectively). The heat loading on the condenser will be app: ximately $2.4 \times 10^{4} \mathrm{kcal} / \mathrm{hr}$. The parameters for a tube-in-shell condenser for this unit are given in Table $X X X$. A tube-in-shell configuration is relatively simple to calculate, and it is also relatively simple to fabricate and maintain. The condenser is of a realistic and manageable size if composed of two or four tubes in parallel.

One of the concerns in operation of the prototype process unit is the presence of volatile and/or semivolatile organic compounds in the outlet gases from the reaction vessel. Of the organic compounds which have been detected as reaction intermediates, concentrations in the process solution are in the milligrams per liter range, and only a few have boiling points less than water. Organic compounds with boiling points greater than water can be contained in the reaction vessel by using a reflux condenser on the gas outlet. While it is felt that this device will not be necessary due to the low concentrations of volatile and/or semivolatile organic compounds in the process solution, tests of a prototype unit with non-hazardous and non-radioactive materials will be able to determine whether such a device will be needed on the prototype before any hazardous and/or mixed wastes are treated with the unit. Organic compounds with boiling points less than water will come over into the condensate, and should be partitioned effectively into the aqueous phase at the concentrations which have been detected in laboratory studies. The condensate can be sparged with the oxygen being fed into the reaction vessel to remove the volatile organics if they present a problem due to their concentration in the condensate. 


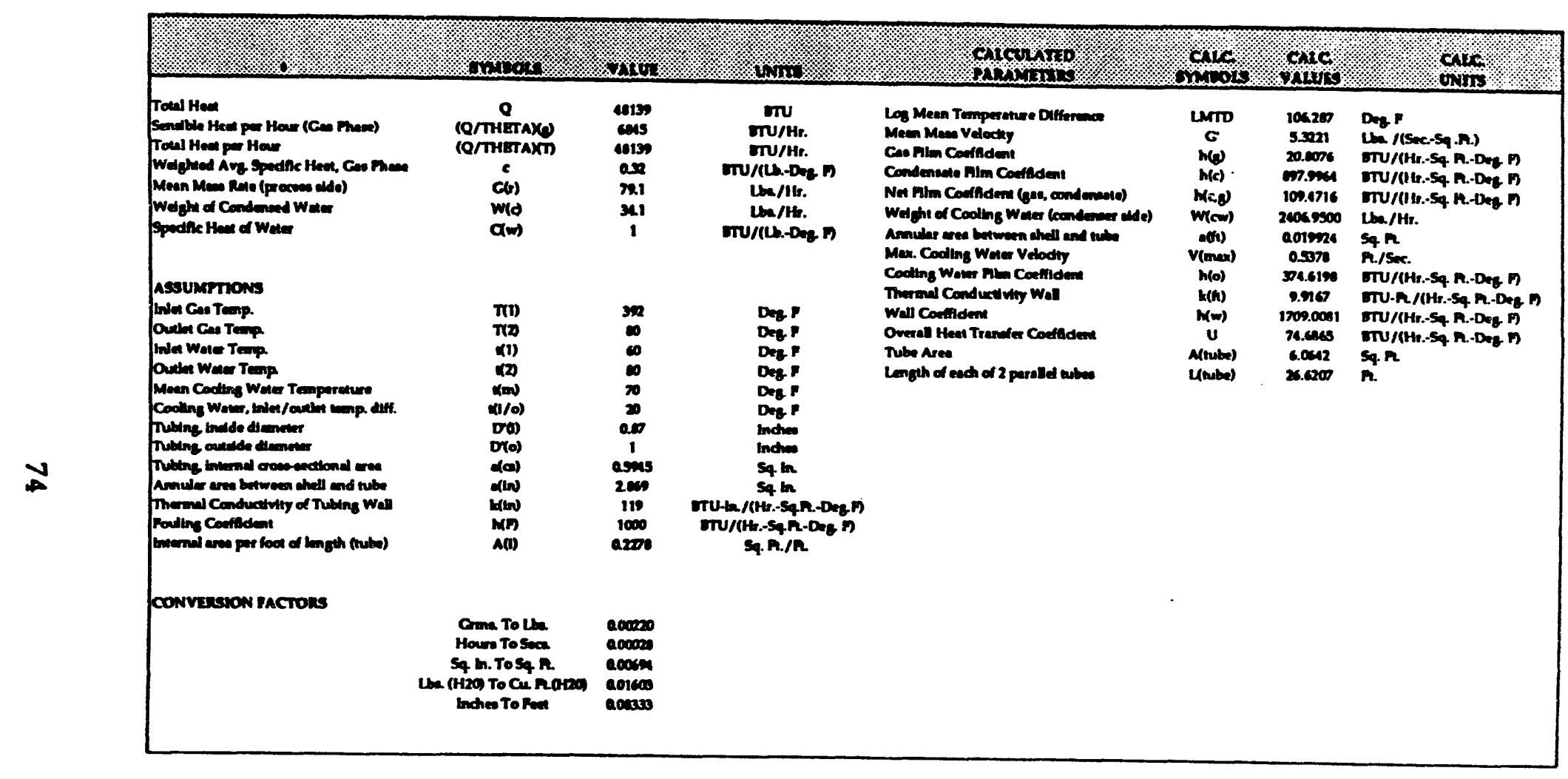




\subsubsection{Pumping/Filtration}

The main unit for oxidation of TBP, as shown above in Figure 26, requires five pumps. The organic feed pump is required to meter 26 . liters per hour of TBP against $1620 . \mathrm{kPa}$ or more. The reaction vessel liquid return pump is required to pump approximately 27.5 liters per hour of $35.1 \%$ by weight ferric chloride, $11.7 \%$ by weight calcium chloride, and $1.3 \%$ by weight citric acid in water against $1620 . \mathrm{kPa}$ or more. The neutralized condensate pump is required to pump approximately 35.2 liters per hour of $13.8 \%$ by weight calcium chloride solution into an evaporator tank against approximately 175 . $\mathrm{kPa}$. The citric acid rinse pump is required to pump approximately 300 . liters per hour of $2 . \%$ citric acid solution against $520 . \mathrm{kPa}$. The helical filter pressure pump is required to pump approximately 38. liters per minute of $26 . \%$ by weight calcium dihydrogen phosphate crystals, $23 . \%$ by weight ferric chloride, and $1 . \%$ citric acid in water against $520 . \mathrm{kPa}$. The cooling/heating oil pump is required to pump approximately 3500 . liters per hour of thermal oil fluid against approximately $300 . \mathrm{kPa}$ to control temperatures in the system.

In the oxidation of TBP, a great amount of phosphate anion will be produced. This material can be precipitated and removed from the process solution as calcium dihydrogen phosphate solid for ultimate disposal. Some brief tests were conducted in our laboratory to determine amounts of precipitate in the presence of varying amounts of phosphate in a process solution containing $1.0 \underline{\mathrm{M}} \mathrm{Ca}^{2+}$. Significant amounts of precipitate were observed, representing a large fraction of the phosphate even at $0.1 \mathrm{M}$ phosphate concentration. The precipitate was a light green, powdery solid with an average particle size of approximately $10 . \mu \mathrm{m}$. Approximately $50 \%$ of the solid settled out of an unstirred process solution within 30 . minutes, and the solid was filterable through standard filtration media. The salt formed is calcium dihydrogen phosphate monohydrate, $\mathrm{Ca}\left(\mathrm{H}_{2} \mathrm{PO}_{4}\right)_{2} \cdot \mathrm{H}_{2} \mathrm{O}$, apparently containing some amount of iron. For every $25 . \mathrm{kg}$ of TBP oxidized, about $11.8 \mathrm{~kg}$ of the calcium dihydrogen phosphate salt will be produced. Calcium dihydrogen phosphate will be separated from the process solution by periodically taking a stream of process solution from the reactor and passing it through a separator system. The separator system will most likely be two hydrocyclones and a helical filter. The solids content of the process solution in the oxidation vessel will be allowed to rise to about $10 . \% \mathrm{w} / \mathrm{w}$, and the flow exiting the reactor during separation will be about 182 . liters per hour. The assumed splits for the hydrocyclones are $60 / 40$ for the liquid and $20 / 80$ for the solids. Two hydrocyclones will remove about half the solids from the circulated stream. Each $2.5 \mathrm{hrs}$ of underflow from the first hydrocycione will be collected in a holding tank and then used to feed the second hydrocyclone for $1 . \mathrm{hr}$. The underflow from the second hydrocyclone ( 48.4 liters in $1 . \mathrm{hr}$ ) will be collected in a holding tank for filtration in the helical filter. The solids/process 
solution from the hydrocyclone will be mixed with the first rinse before it is passed into the helical filter. The overflow from both hydrocyclones will be passed into a return tank, which will be pressurized with oxygen to return the process solution to the oxidation vessel. Consultation with manufacturers of hydrocyclones has indicated that the cyclone suitable for this application will be about $5.1 \mathrm{~cm}$ in width by about $12.4 \mathrm{~cm}$ in height, with a $10 . \mathrm{mm}$ internal cyclone. The advantages of hydrocyclones and a helical filter in this application are small size, simplicity, and the fact that the separation and rinse assembly can be configured such that no manual handling of the solids is required.

\subsubsection{Rinsing/Extraction}

In the destruction of TBP, the calcium phosphate solids will be rinsed with a dilute ( $2 . \%$ by weight) citric acid solution, then with water, before being directed into drums for testing and ultimate disposal. The wet solids separated from the process solution with the hydrocyclones will be directed into a holding tank, where they will be mixed with 24.3 liters of citric acid solution and then directed to a helical filter. Two rinses with 24.3 liters of dilute citric acid solution and one rinse with 24.3 liters of water will be conducted in the helical filter. The citric acid and water rinses will be transferred by pressure to an evaporator where they will be combined with the calcium chloride solution from condensate neutralization to recover water for preparation of fresh citric acid and water rinse solutions. Citric acid and dissolved metals in the evaporator will be returned to the oxidation vessel with the calcium chloride solution. The final solids, which can be concentrated to as much as $\mathbf{8 0 . \%}$ by weight (the remainder of the weight being water), can be fed directly into a drum for ultimate disposal. If desired, a drum heater could be used to slowly evaporate excess water from the solids, although it may be beneficial to use the water content to aid in cementing the solids in the drums.

\subsubsection{Configuration/Materials}

The conceptual schematic for the unit has been given in Figure 26. It would be configured as a skid-mounted unit on two skids. The DETOX system is well suited for a skid-mounted configuration, because it can be utilized for smaller amounts of specialized wastes, then moved or removed as necessary.

WSS has indicated that a DETOX unit would be installed in an exterior location, on a pad connected to an existing building. It will most likely be necessary to erect some structure around the pad to protect the unit from weather. The unit would be configured on two skids. One skid would contain the organic feed pump, reaction vessel, reaction vessel cooler/heater, 
condensers, condensate catch, condensate neutralization tank, evaporator tank, calcium chloride holding tank, and water catch. The second skid would contain the citric acid rinse holding tank and the solids separation system. A control trailer will be necessary for control electronics and operations personnel. Table XXXI gives the flows, pressures, and temperatures in the unit for DETOX in application to the WSS waste.

Table XXXI: Flows, Pressures, Temperatures for Oxidation of TBP Oil

\begin{tabular}{|c|c|c|c|c|}
\hline 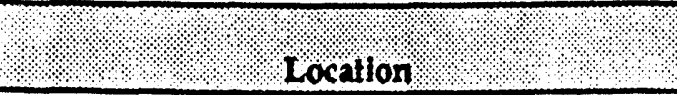 & $\begin{array}{l}\text { Avg. Flow } \\
(\mathrm{L} / \mathrm{hr}) \cdot \bullet\end{array}$ & $\begin{array}{l}\text { Max. Flow } \\
(\mathrm{L} / \mathrm{hr})^{\text {tit }}\end{array}$ & Temp. & Pressure \\
\hline Oxygen to Reactor & 2830 & 2830 & 293 & 1,620 \\
\hline Organics to Reactor & 26 & 26 & 293 & 1,620 \\
\hline $\begin{array}{l}\text { Water } / \mathrm{CaCl}_{2} / \mathrm{FeCl}_{3} / \mathrm{Citric} \text { Acid to } \\
\text { Reactor from Evaporator } \\
\text { Reactor Vescel }\end{array}$ & 27.5 & 27.5 & 389 & 1,620 \\
\hline $\begin{array}{l}\text { Reactor Vessel } \\
\text { Gases to Condenser }\end{array}$ & 46,200 & 46,200 & $\begin{array}{l}473 \\
473\end{array}$ & $\begin{array}{l}1,500 \\
275\end{array}$ \\
\hline $\mathrm{CO}_{2}+\mathrm{O}_{2}$ to Vent & 12,300 & 12,300 & 300 & 265 \\
\hline 10\% HCl From Condenser Tank & 34.1 & 34.1 & 300 & 83 \\
\hline $13.8 \% \mathrm{CaCl}_{2}$ to Evaporator & 35.2 & 35.2 & 339 & 175 \\
\hline Water from Water Tank (from Evaporator) & 56.2 & 56.2 & 300 & 83 \\
\hline DETOX to Solids Separation & 121 & 182 & 473 & 1,350 \\
\hline DETOX from Solids Separation & 102 & 1653 & 373 & 1,620 \\
\hline $\begin{array}{l}\mathrm{FeCl}_{3} \text {, Citric Acid, and Water Rinse to } \\
\text { Evaporator } \\
\\
\end{array}$ & $\begin{array}{l}\text { ws } \\
\text { ure and pre }\end{array}$ & ure given & 300 & 175 \\
\hline
\end{tabular}

Materials of construction for the unit will range from tantalum to polypropylene. The oxidation vessel must be capable of withstanding highly corrosive conditions. Consultation with experts in titanium alloys and tantalum have indicated that Grade 7 titanium should be suitable for the oxidation vessel, and that tantalum would experience even less corrosion. It is felt, therefore, that the best combination would be a Grade 7 titanium reactor shell with a tantalum liner. The tantalum liner would give superior resistance to chemical attack, and the Grade 7 titanium would act as a strong, corrosion-resistant secondary containment and pressure vessel. For valves and piping exposed to hot vapors from the process solution, and the condenser, it would also be desirable to have tantalum construction. Teflon ${ }^{\mathrm{TM}}$-lined plug valves can be used as on/off valves on the oxygen inlet line, the organic feed line, and the water return line, but are not suitable for exposure to the hot vapors in the gas outlet line. For the gas outlet line, 
hardened zirconium can be used if it is not exposed to iron from the process solution, but it may be advisable to remain with tantalum for this area. The condensate catch tank can be a commercial glass-lined steel vessel or it can be fabricated of EPDM-lined steel. The condensate neutralization tank and water catch tank can be polypropylene backed with fiberglass shells. Solids separation equipment can be of Grade 7 titanium, with Teflon ${ }^{\mathrm{TM}}$-lined plug valves. The evaporation tank and calcium chloride solution holding tank must be of Titanium Grade 7 construction. Valves and lines for the low temperature, neutralized part of the process can be polypropylene or polypropylene-lined steel. Pump materials will vary depending on the medium being pumped. The heat transfer fluid pump can be a standard steel pump. The organics feed pump can be a Teflon ${ }^{\mathrm{TM}}$ diaphragm metering pump with stainless steel head. The helical filter pressure pump can be an all Teflon ${ }^{\mathrm{TM}}$ diaphragm pump. The reaction vessel liquid return pump can be a reinforced Teflon ${ }^{\mathrm{TM}}$ diaphragm pump with a Kynar ${ }^{\mathrm{TM}}$ in armored metal head. The neutralized condensate pump can be a Teflon ${ }^{\mathrm{TM}}$ diaphragm pump with a PVC head. The citric acid pump can be an Alloy "C" and Teflon ${ }^{\mathrm{TM}}$ gear pump with a stainless steel housing.

\subsubsection{Monitors and Controls}

Figures 26a and 26b show the monitors for the unit as envisioned. Temperature, pressure, oxygen, flow, level, $\mathrm{pH}$, and conductivity sensors are shown on both figures. The amounts of organic, oxygen, and returned fluid added to the oxidation vessel will be metered or monitored. The amount of product gas and its oxygen content will be measured. The amounts of feeds and products thus measured will determine the mass balance, and whether one or more of the feed rates needs to be changed. Temperature and pressure sensors at critical points in the unit will be used to control oxidation vessel temperature, heating/cooling fluid flow, organic and oxygen feed rate, and product gas flow. Hardwired shut-offs will be built into the unit to provide high reliability system shutdown in the event of an upset condition. Operation and data acquisition will be controlled by a microcomputer with power conditioning and a backup power supply. Inputs from and outputs to the unit will be isolated from the PC to avoid any power surges to the control system. At critical points, sensors will be in duplicate to provide redundancy in critical measurements, such as oxidation vessel temperature and pressure.

\subsubsection{Secondary Waste Streams}

In the destruction of tributyl phosphate at Weldon Spring Site, there will be four end products of the reaction. These products will be the gases released from the system, the water produced from tributyl phosphate oxidation and evaporated from the neutralized condensate, wet calcium dihydrogen phosphate solids, and the neutralized process solution after waste processing 
is concluded. The product gases, consisting of approximately $49.6 \mathrm{~kg}$ per hour of carbon dioxide containing small percentages of oxygen and water vapor, will be vented. The gases will not contain any radioactive materials, and should contain environmentally compliant amounts of $\mathrm{HCl}$ and volatile organics. If the gases do contain small amounts of $\mathrm{HCl}$ and volatile organics, they can be passed through activated charcoal prior to release. When the charcoal is expended, or at the conclusion of waste processing, it can be introduced into the process solution and destroyed, thus eliminating it as a secondary waste stream. There will be approximately $21.1 \mathrm{~kg}$ per hour of water produced by the process, or a weight somewhat less than that of the waste which has been destroyed. Approximately $3.4 \mathrm{~kg} / \mathrm{hr}$ of the water is contained in the wet calcium dihydrogen phosphate solids, leaving the remainder, $17.7 \mathrm{~kg} / \mathrm{hr}$, as distilled water. The water will not contain any radioactive metals, but even though it will be sparged or passed through activated charcoal it might contain small amounts of volatile organics. If necessary, the water can be passed into the water treatment plant nearby at Weldon Spring Site. There will be $11.8 \mathrm{~kg} / \mathrm{hr}$ of calcium dihydrogen phosphate monohydrate salt produced, which will be isolated as a wet material (20. $-25 . \%$ by weight water content). The salt will be tested for the presence of radioactive materials, acidity, and hazardous organics. It is possible that the salt could be released as a non-hazardous waste if it meets the applicable standards. If the salt does not meet applicable standards for hazardous organics, it can be processed through the unit in batches to destroy any residual organic content. If the salt contains unacceptable amounts of radioactive isotopes or heavy metals, it can be solidified in its storage drums for disposal in the on-site burial cell at Weldon Spring Site. Calcium phosphate salts are sparingly soluble to insoluble in water, and should provide a good base for a fine textured cement. It is planned that the process solution at the conclusion of waste processing will be tested for the presence of hazardous organic compounds, toxic metals, and radioactive metals. If hazardous organic compounds are detected, the process solution will be heated again for some period until the organic compounds are destroyed. Following verification of the absence of organic compounds in any amounts which would render the process solution hazardous due tn organic content, the process solution will be pumped from the oxidation vessel at the conclusion of all waste processing, neutralized, and solidified by one of three candidate processes (cementation, vitrification, or encapsulation). The process solution as removed from the reaction vessel will contain any radioactive and/or toxic metals which were present in the waste, and will be corrosive. Neutralization will remove the corrosive characteristic, and will precipitate the iron and some other metals, giving a sludge. The amount of neutralized process solution will be approximately $1200 . \mathrm{kg}$, containing approximately $405 . \mathrm{kg}$ of water, approximately $235 . \mathrm{kg}$ of iron oxide, approximately $520 . \mathrm{kg}$ of sodium chloride, and an assumed $40 . \mathrm{kg}$ of residual inorganic material which was in the waste treated. The sludge will be a radioactive waste due to radionuclide content, and it may be a hazardous 
waste due to its toxic metal content. If it is not desirable to have a great chloride content in the final form of the process solution residue, there are at least two methods by which chloride may be removed. One method for chloride removal is to forego neutralization and heat the process solution, passing the vapors through sodium hydroxide solution or lime. Iron chloride in the presence of water spontaneously decomposes into hydrated iron oxide and $\mathrm{HCl}$, if the $\mathrm{HCl}$ is removed continuously. Another method for chloride removal is to neutralize the process solution with ammonium hydroxide, giving ammonium chloride which may be sublimated off the solids at approximately 573.K. Either of these methods will reduce the amount of final residue which must be immobilized and disposed to approximately $275 . \mathrm{kg}$, with very little chloride salt content.

\subsubsection{Critical Engineering Issues}

Critical engineering issues for the unit at Weldon Spring Site are virtually identical to those explained in Section 5.3.2.7 above for the Rocky Flats Plant unit. In addition to the issues discussed above, there is also the issue of filtration and handling of solid material from the reaction.

Effective removal of calcium dihydrogen phosphate produced by the oxidation reaction is critical to proper operation of the unit. Complicating the task of removing solids is the radioactivity in the system. The separation and filtration scheme proposed here limits any solids handling and yet should still provide effective solids removal. The primary material of construction for the system is Grade 7 titanium. The process solution will be cooled to approximately $373 . \mathrm{K}$ after exiting the reaction vessel and before it reaches the first hydrocyclone, so this grade of titanium should have a very low rate of corrosion in this application. What is of more concern is possible erosion/corrosion of the hydrocyclones due to particulate material scraping the surface. The hydrocyclones are small items, however, and contribute little to the cost of the system, so spares may be incorporated in the equipment design. It is highly recommended that the filtration system be designed for considerably more throughput than expected, so that solids can still be removed at a reasonable rate even should they prove more difficult to separate, filter, and rinse than anticipated. The expense of the solids separation system is such that having to build a larger or a second system would add a great amount of cost to the treatment unit, as well as resulting in delays in waste processing. Since some filtration and rinse tests have been performed in our laboratory, the uncertainty is not great, but providing excess capacity is a prudent course of action. In the event that tributyl phosphate can be destroyed more rapidly than expected, the excess capacity could allow faster treatment of the waste. 


\subsubsection{Health and Safety}

The same health and safety considerations apply to processing tributyl phosphate as were given for PCB in Section 5.3.2.8. For tributyl phosphate treatment the operators would all be Delphi Research, Inc. personnel trained in site safety by the site operator. The additional material which will be produced at Weldon Spring Site would be the calcium dihydrogen phosphate salt, which will be delivered into drums by the helical filter without handling. The Weldon Spring Site operator has indicated that it would perform drum transportation and solidification.

\subsubsection{Capital and Operating Costs}

Both of the applications described above are for relatively small quantities of waste, and as a result the capital and operating costs do not benefit from economics of scale. Capital and operating costs for the units are particularly great if one limits the use of the units to the specified type and quantity of waste, i.e., PCB or TBP, at the proposed demonstration sites.

Tables XXXII and XXXIII give partial lists of parts for the two units. Written quotes or catalogue prices were obtained for all of the items on the lists. For items of greater cost, such as the tantalum-lined tank and tantalum valves, two or three quotes were obtained to verify the price of the part. Based on the parts given, we have estimated that the capital costs will be $\$ 600,000-\$ 800,000$ for the Rocky Flats Plant unit and $\$ 900,000-\$ 1,200,000$ for the Weldon Spring Site unit. Capital cost for the units could be somewhat greater, depending on design constraints and requirements which may be added later.

Operating cost based on the amounts of PCB or TBP to be processed, and assuming that they are the only wastes which will be processed with these units, are $\$ 19.00$ and $\$ 4.40$ per kilogram, respectively. Table XXXIV lists the components of operating cost which were used to calculate these values. By far the largest cost contributor is labor, which is necessary in a demonstration unit and is great in proportion to the amount of waste processed. Under the constraints of a treatability program, the operational cost per weight of waste treated will be great for any technology. 
Table XXXII: RFP DETOX Treatment Unit Components

\begin{tabular}{|c|c|c|}
\hline Description & Materials of Construction & Size \\
\hline Jacketed Reaction Vessel & Tantalum-lined, Titanium Grade 7 & 190 liters \\
\hline Agitator for Reaction Vessel & Nucerile & 2. HP \\
\hline Dip Tubes (2) for Reaction Vessel & Nucerite & 1 in. \\
\hline Thermowell & Tantalum & $1 / 2$ in. \\
\hline Hot Oil Heating and Cooling System with Pump & Carbon Steel & $50 \mathrm{KW}$ \\
\hline Solids Feed Assembly with Augers and Pinch Valve & Teflon, Tantalum, ETFE-lined Steel & 190 liters \\
\hline Reaction Vessel Condenser & Tantalum & 4 sq. ft. \\
\hline Condensate Catch Vessel & ETFE-lined Carbon Steel Shell & 40 liters \\
\hline $\begin{array}{l}\text { Condensate Neutralization Vessel with Cover, Stand, and } \\
\text { Mixer }\end{array}$ & $\begin{array}{l}\text { Polypropylene-lined Fiberglass Shell } \\
\text { with Epoxy-coated Stainless Steel Mixer }\end{array}$ & 115 liters \\
\hline Evaporator Vessel and U-Tube Heater & Monel & 95 liters \\
\hline Evaporator Condenser & Stainless Steel & 4 sq. ft. \\
\hline Evaporator Water Catch Vessel, with Cover and Stand & Polypropylene-lined Fiberglass Shell & 40 biters \\
\hline Water Return Vessle, with Cover and Stand & Polypropylene-lined Fiberglass Shell & 40 liters \\
\hline Compressor for Product Gasses & Stainless Steel and Teflon & 120 liters/min. \\
\hline Carbon Dioxide Storage Tanks (2) & Carbon Steel & $1000 \mathrm{gal}$ \\
\hline Diaphragm Pump for Organics Feed to Reaction Vessel & Stainless Steel and Teflon & 5 liters $/$ hr. \\
\hline Diaphragm Pump for Water to Reaction Vessel & Stainless Steel and Teflon & 60 liters $/ \mathrm{hr}$. \\
\hline Diaphragm Pump from Neutralization Vessel & PVC and Teflon & 90 liters $/ \mathrm{hr}$. \\
\hline Metering Valve for Reaction Vessel Gas Outlet (MV1) & Tantalum & $1 / 2$ in. \\
\hline Metering Valve for Oxygen into Reaction Vessel (MV2) & Tantalum & $3 / 8$ in. \\
\hline Metering Valves (2) for Liquid Sampling (MV3 and MV4) & Tantalum & $1 / 4$ in. \\
\hline $\begin{array}{l}\text { Ball Valves (2) for Organic Feed and Water Return Shut- } \\
\text { off (AV1 and AV2) }\end{array}$ & Tantalum & $1 / 4$ in. \\
\hline Ball Valves (2) for Gas Outlet Shut-off (AV3 and SV3) & Tantalum & $1 / 2$ in. \\
\hline $\begin{array}{l}\text { Ball Valves (3) for Oxygen Inlet Shut-off (AV4, AV5, and } \\
\text { AV6) }\end{array}$ & Tantalum & $3 / 8$ in. \\
\hline Solenoid Valves (17) (SV1, SV2, SV4-14, SV18-20, BV3) & Stainless Sted & $1 / 4,3 / 8,1 / 2$ in. \\
\hline Ball Valves (5) (BV1, BV2, BV4, BV5, BV6) & Stainless Steel and Monel & $1 / 4$ and $3 / 8$ in. \\
\hline Ball Check Valves (2) (CV1 and CV2) & Tantalum & $3 / 8$ in. \\
\hline Ball Check Valve (CV3) & Stainless Steed & $3 / 8$ in. \\
\hline Relief Valves (RV1-3) & Stainless Sted & $3 / 8,1 / 2,3 / 4$ in. \\
\hline Ball Valves (BV15-17) & PTFE & $3 / 8$ in. \\
\hline Level Sensors (3) & Kynar & $3 / 4$ and 2 in. \\
\hline Mass Flow Meters for Gases (FM1 and FM4) & Stainless Steel & 200 SLM \\
\hline Fow Sensor for Water (FM3) & Stainless Steel & $500 \mathrm{ml} / \mathrm{min}$. \\
\hline Flow Meter for Oxygen Sensor & Stainless Steel and Glass & $500 \mathrm{sccm}$ \\
\hline Oxygen Sensor & Stainless Steel & $0-100 \%$ \\
\hline Pressure Transducers with Snubbers (PS1-7) & Stainless Steel & $0.500 \mathrm{psi}$ \\
\hline Pressure Sensor Isolator for PS1 & Tantalum Cad & $1 / 4$ in. \\
\hline Microprocessor Control System & & \\
\hline
\end{tabular}




\section{Table XXXIII: WSS DETOX Treatment Unit Components}

\begin{tabular}{|c|c|c|}
\hline Description & Materials of Construction & Size \\
\hline Jacketed Reaction Vessel & Tantalum-lined Grade 7 Titanium & 1000 liters \\
\hline Agitator for Reaction Vessel & Nucerite & 3 HP, 117 RPM \\
\hline Dip Tubes (3) for Reaction Vessel & Nucerite & $1.5 \mathrm{in}$. \\
\hline Thermowell for Reaction Vessel & Tantalum & $1 / 2$ in. \\
\hline Hot Oil Heating and Cooling System with Pump & Carbon Steel & $200 \mathrm{KW}$ \\
\hline Reaction Vessel Condenser & Tantalum & $6 \mathrm{sq} . \mathrm{ft}$ \\
\hline Condensate Catch Vessel & ETFE-lined Carbon Steel Shell & 95 liters \\
\hline $\begin{array}{l}\text { Condensate Neutralization Vessel } w / \text { Cover, Stand, and } \\
\text { Mixer }\end{array}$ & $\begin{array}{l}\text { Polypropylene-lined Fiberglass Shell w/ } \\
\text { Epoxy-coated Stainless Steel Mixer }\end{array}$ & 200 liters \\
\hline Evaporator Vessel and U-Tube Heater & Grade 2 and Grade 7 Titanium & 570 liters \\
\hline Evaporator Condenser & Stainless Steel & $8 \mathrm{sq} . \mathrm{ft}$. \\
\hline Evaporator Water Catch Vessel with Cover and Stand & Polypropylene-lined Fiberglass Shell & 115 liters \\
\hline Evaporate Holding/Return Vessel & ETFE-lined Carbon Steel Shell & 95 liters \\
\hline DETCX Solution Cooler & Tantalum & 6 sq. ft. \\
\hline Hydrocyclone Holding Vessel 1 & Titanium Grade 7 & 95 liters \\
\hline Hydrocydone Holding Vessel 2 & Titanium Grade 7 & 190 liters \\
\hline Hydrocydone Holding Vessel 3 & Titanium Grade 7 & 95 liters \\
\hline $\begin{array}{l}\text { Citric Acid Solution Preparation and Holding Vessel with } \\
\text { Cover, Stand, and Mixer }\end{array}$ & $\begin{array}{l}\text { Polypropylene-lined Fiberglass Shell, } \\
\text { with Stainless Steel Mixer }\end{array}$ & 570 liters \\
\hline Hydrocydones & Titanium Grade 7 & $10 \mathrm{~mm}$ \\
\hline Helical Filter Apparatus & Titanium Grade 7 & 1 cubic ft. \\
\hline Diaphragm Pump for Organic Feed so Reaction Vessel & Stainiess Sieel and Teflon & 25 liters $/ \mathrm{hr}$. \\
\hline Diaphragm Pump from Neutralization Vescel & PVDF/Teflon & 160 liters $/$ hr. \\
\hline Diaphragm Pump for Evaporate to Reaction Vessel & PVC and Teflon & 205 liters/hr. \\
\hline Diaphragm Pump for Solids to Filter Device & Tetion & 40 liters/min. \\
\hline Gear Pump for Citric Acid Solution to Filter & Stainless Steel and Teflon & 15 liters/min. \\
\hline \multicolumn{3}{|l|}{ Valves for Continuous Reactor Wssoon: } \\
\hline Metering Valve for Reaction Vessel Gas Outlet (MV1) & Tantalum & $1 / 2$ in. \\
\hline Metering Valve for DETOX to Solids Separation (MV2) & Tantalum & $1 / 2$ in. \\
\hline Metering Valve for Oxygen into Reaction Vessel (MV3) & Tantalum & $1 / 2$ in. \\
\hline Metering Valves (2) for Liquid Sampling (MV4, 5) & Tantalum & $1 / 4$ in. \\
\hline $\begin{array}{l}\text { Ball Valves (3) Organic Feed and Water Return Shut-off } \\
\text { (AV1, 2, SV1) }\end{array}$ & Tantalum & $1 / 4,3 / 8$ in. \\
\hline Ball Valves (2) for Gas Outlet Shut-off (AV3, SV3) & Tantalum & $1 / 2$ in. \\
\hline $\begin{array}{l}\text { Ball Valves (4) for DETOX Outlet and Inlet Shut-off } \\
\text { (AV4,5, SV4,5) }\end{array}$ & Tantalum & $1 / 2$ in. \\
\hline Ball Valves (3) for Oxygen Inlet Shut-off (AV6-8) & Tantalum & $1 / 2$ in. \\
\hline Solenoid Valves (5) Shut-off $(S V 2,6-8,18)$ & Stainless Steel & $1 / 4,3 / 8,1 / 2$ in. \\
\hline Solenoid Valves (6) Thermal Fuid Shut-off (SV9-14) & Stainless Steel & $1-1 / 2$ in. \\
\hline Ball Valve (1) Shut-off (BV1) & Stainless Steel & $1 / 2$ in. \\
\hline Ball Valves (8) Shut-off (SV15-17, 19, 20, BV2-4) & PTFE (Polytetrafluoroethylene) & $1 / 4,3 / 8$ in. \\
\hline Ball Check Valves (2) (CV1, 2) & Tantalum & $3 / 8,1 / 2$ in. \\
\hline Relief Valves (2) (RV1, 2) & Stainless Steel & $3 / 4$ in. \\
\hline
\end{tabular}


Table XXXII: WSS DETOX Treatment Unit Components (cont.)

\begin{tabular}{|c|c|c|}
\hline Description & Materials of Construction & Size \\
\hline $\begin{array}{l}\text { Valves for Solids Separation WSSOOR: } \\
\text { Metering Valves (6) for DETOX (MV1, 3, 4, 6-8) } \\
\text { Metering Valves (2) for DETOX (MV2, 5) } \\
\text { Ball Valves (5) for DETOX Shut-off (SV1, 2, 4-6) } \\
\text { Solenoid Valves (4) Shut-off (SV3, 7-9) } \\
\text { Ball Valve (1) Shut-off (BV1) } \\
\text { Level Sensors (10) } \\
\text { Mass Fow Meters for Gases (2) (FM1, 3) } \\
\text { Fow Meter for Oxygen Sensor (FM2) } \\
\text { Pressure Transducers with Snubbers (13) } \\
\text { Pressure Sensor Isolators } \\
\text { Oxygen Sensor } \\
\text { Midooprocessor Control System }\end{array}$ & $\begin{array}{l}\text { Titanium Grade } 7 \\
\text { Titanium Grade } 7 \\
\text { Titanium Grade } 7 \\
\text { Stainless Steel } \\
\text { Stainless Steel } \\
\text { Kynar and PFA } \\
\text { Stainless Steel } \\
\text { Stainless Steel and Glass } \\
\text { Stainless Steel } \\
\text { Tantalun Clad } \\
\text { Stainless Steel }\end{array}$ & $\begin{array}{l}1 / 2 \text { in. } \\
3 / 8 \text { in. } \\
1 / 2 \text { in. } \\
3 / 8,1 / 2 \text { in. } \\
1 / 2 \text { in. } \\
3 / 4 \text { and } 2 \text { in. } \\
50 \text { scim } \\
500 \text { scem } \\
1 / 4 \text { in. } \\
1 / 4 \text { in. } \\
1-100 \%\end{array}$ \\
\hline
\end{tabular}

\section{Table XXXTV: Operating Cost Components}

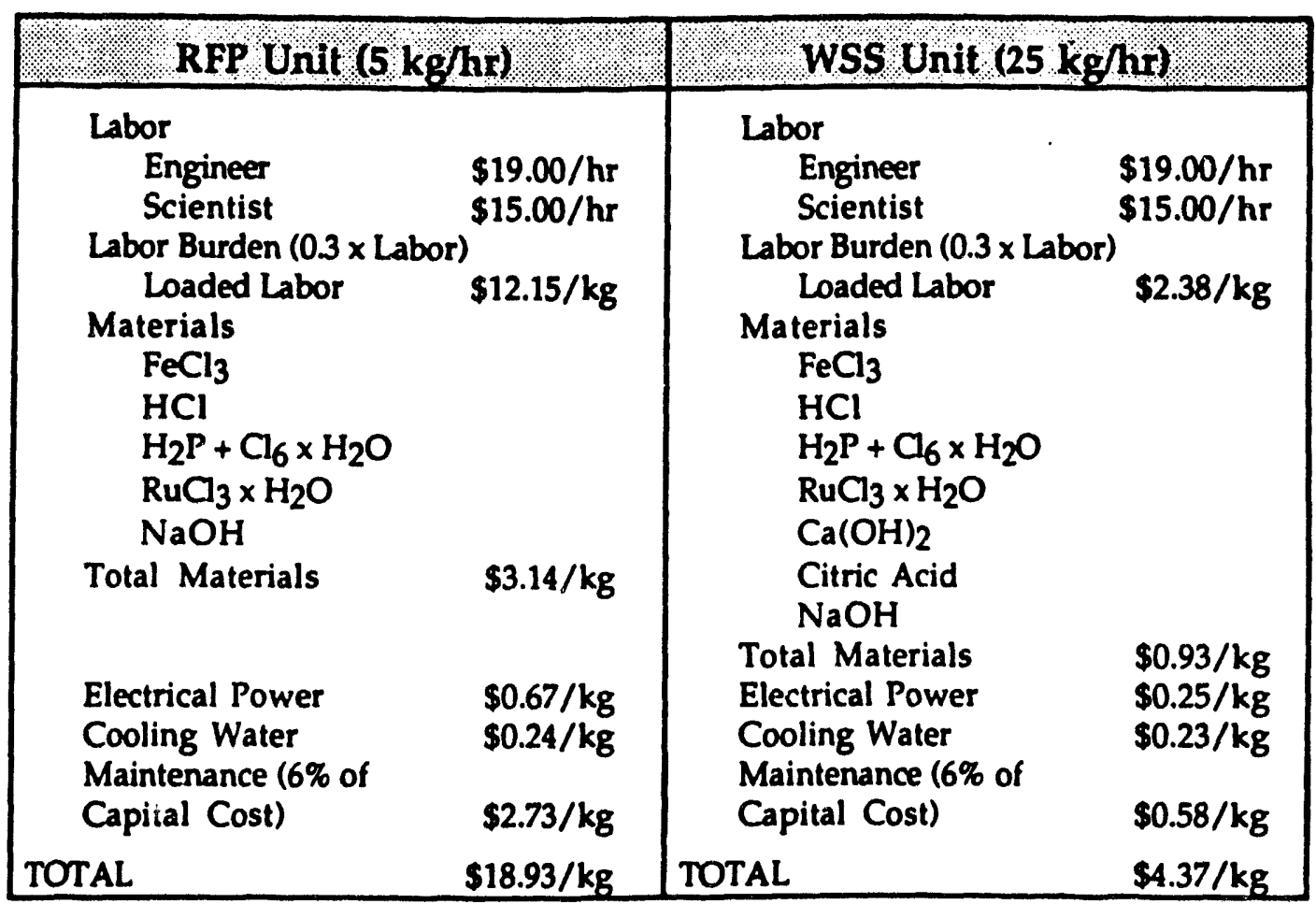


The capital and operating costs for the demonstration units are not indicative of the operating cost for a more practical size unit operated for its lifetime. Standard engineering assumptions for scaled cost (using the scaling factor to the 0.6 power to scale capital cost) can be used to estimate the cost for a range of "typical" waste treatment units. A small system for treatment of 1.0 kilogram per hour has an estimated capital cost of $\$ 230,000$. to $\$ 305,000$. Assuming that the 1.0 kilogram per hour system is used for ten years to treat 1000. kilograms of waste per year with one operator, its estimated total operating cost would be approximately $\$ 150$. per kilogram. This is a poor use scenario for a treatment unit, but even if one considers only operating cost, the minimum would be around $\$ 75$. per kilogram with this size unit if an operator has to be in attendance. Capital cost for a 10. kilogram per hour mixed waste treatment unit is estimated to be between $\$ 800,000$. and $\$ 1,000,000$. This type of unit could be configured as a skid-mounted, portable system for waste treatment on demand at a fixed location or mobile, on-site waste treatment at a variety of locations. Treatment of 10 . kilograms per hour for a total of 1500 . hours per year over ten years (with two operators) results in an estimated operating cost of approximately $\$ 15$. per kilogram, and an estimated total treatment cost of approximately $\$ 25$. per kilogram. Capital cost for a 100 . kilogram per hour mixed waste treatment unit is estimated to be between $\$ 2,100,000$. and $\$ 2,800,000$. A 100 . kilogram per hour unit would most likely be a fixed installation for processing waste on-site or at a centralized facility. The operating cost for a 100 . kilogram per hour unit would decrease to approximately $\$ 2.50$ per kilogram. Over a 10 . year processing lifetime, with 200. sixteen hour days of operation per year, total cost is estimated to be approximately $\$ 3.50$ per kilogram of mixed waste treated. These costs do not include any pre-treatment of the waste, posttreatment of residues, or any ultimate disposal cost for the residues. 
This page intentionally left blank 


\section{SECTION 6}

\section{CONCLUSIONS}

The DETOX process can oxidize most organic compounds, even highly stable compounds such as hexachlorobenzene. The only organic materials which DETOX either cannot oxidize or which it oxidizes only extremely slowly are fluorinated polymers such as Teflon ${ }^{\mathrm{TM}}$. The process solution is capable of dissolving heavy metals, leaving remaining inert materials sufficiently clean to be non-hazardous by the Resource Conservation and Recovery Act's Toxicity Characteristic Leach Procedure. Calcium should be included in the process solution when significant amounts of sulfate or phosphate are expected to be present. Chromium(VI) can be rendered non-hazardous by treatment with the solution, and lead can be selectively separated from the solution as the dichloride salt. Organic and metallic contaminants can be removed from soils by treatment with the DETOX solution, to levels which render the soils remediated. Thus, the DETOX process is capable of treating almost all organic, and most inorganic, wastes contaminated with hazardous organics and metals. The process will be able to accept a range of waste types in one system (depending on the versatility of the system design), such that multiple waste sources can be treated at one installation. The process will be most valuable at present in converting various organic mixed wastes to a radioactive-only form, volume reduction of organic mixed or radioactive wastes, and treatment of inert materials contaminated with hazardous organics, metals, and/or radionuclides. Rocky Flats Plant and Weldon Springs Site appear to be good candidates for demonstration of the process, and there are numerous other Department of Energy sites where the process could be used to treat wastes. At this point in development, there do not appear to be any engineering issues which would prevent the design, fabrication, and testing of a prototype DETOX waste treatment unit. 


\section{References}

1. P. M. Dhooge and S. M. Park, "Electrochemistry of Coal Slurries II. Studies on Various Experimental Parameters Affecting Oxidation of Coal Slurries", J. Electrochem. Soc. 130 pg 1029, May, 1983

2. U.S. Patent 4,925,540, "Method for Treating Organic Waste Material and an Oxidation Catalyst/Cocatalyst Composition Useful Therefor.", May 15, 1990.

3. U.S. Patent $5,047,224$, "Method for Treating Organic Waste Material and an Oxidation Catalyst/Cocatalyst Composition Useful Therefor.", Sep. 10, 1991.

4. "A Catalytic Wet Oxidation Process for Mixed Waste Volume Reduction/ Recycling", P. M. Dhooge, Proceedings of the Symposium on Waste Management, Tucson, Arizona, March 1-5, 1992.

5. "Continued Investigations of DETOX Wet Oxidation Process for Mixed Waste Volume Reduction/Recycling", P. M. Dhooge, Proceedings of the 1992 Incineration Conference, Albuquerque, New Mexico, May 11-15, 1992.

6. "Bench Scale Operation of the DETOX Wet Oxidation Process for Mixed Wastes", P. M. Dhooge, Proceedings of the Symposium on Waste Management, Tucson, Arizona, February 28 - March 4, 1993.

7. "Treating Contaminated Organics Using the DETOX Process, K. Elsberry and P. M. Dhooge, Proceedings of the Second International Symposium on Mixed Waste, Baltimore, Maryland, August 17 - 20, 1993. 


\section{Glossary of Terms}

absorbed ions - Ions which have been drawn into a solid and retained by chemical forces.

absolute oxidation efficiency - The percentage of all organic material destroyed after oxidation relative to the amount of organic compound oxidized.

adsorbed ions - Ions which are attached to the surface of a solid material by chemical forces.

anion - A negatively-charged ion or ionic complex.

aqua regia - Literally "royal water", a combination of nitric and hydrochloric acids capable of dissolving many metals.

atomic absorption spectrometry - A method for determining the concentration of an element in solution by the amount of a specific wavelength of light ahsorbed by the element, typically when the solution is aspirated into a flame through which the light beam is directed.

catalyst - A substance that modifies and especially increases the rate of a chemical reaction without being consumed in the process.

cation - A positively-charged ion or ionic complex.

cocatalyst - As used here, a second catalyst which works with the primary catalyst to further increase the rate of a chemical reaction.

colorimetry - A method for determining the concentration of a species by measuring the amount of a specific wavelength of light absorbed by the species or by a colored complex formed by the species in the presence of some reagent.

delisting - A process whereby solid wastes which are assumed to be hazardous or are derived from hazardous wastes are proven by chemical and physical testing to be non-hazardous, and are approved as non-hazardous by the U.S. Environmental Protection Agency or the applicable state environmental agency. 
destruction/removal efficiency - The percentage of destruction of an organic compound after treatment relative to the amount of organic compound treated.

evaporate - Used as a noun, it is the salts or other material remaining after a liquid has been evaporated.

ferric iron - Iron in the +3 oxidation state, also expressed as iron(III) or $\mathrm{Fe}^{3+}$.

ferrous iron - Iron in the +2 oxidation state, also expressed as iron(II) or $\mathrm{Fe}^{2+}$.

filtrate - A liquid which has been passed through a filter.

flame emission - Analysis of an element in a solution by measuring the intensity of emission of a particular wavelength of light when the solution is aspirated into a flame.

gas chromatography - A method for resolving chemical compounds by passing them as a vapor in a gas through a material which separates the compounds by boiling point or chemical affinity.

hazardous waste - Waste having one of the hazardous characteristics or components defined in the 40CFR 261.

included ions - In this report, included ions means those ions physically trapped within precipitated solids.

iron(II) - Ferrous iron.

iron(III) - Ferric iron.

matrix effect - In chemical analysis, the deviation of an analytical result from the true value due to the remainder of the components of the material being analyzed.

mixed waste - A waste containing a combination of hazardous and/or toxic components and radioactive isotopes.

neutralization - As referred to here, neutralization refers to the combination of an acid with a base to form a solution with very little or no acid or base characteristic. 
nitrated - Containing the nitro, or $-\mathrm{NO}_{2}$, group.

non-volatile organic compound - Typically a compound whose boiling point is above 523.K.

oxidation - As used in this report, the reaction of a compound with oxygen, either directly or indirectly.

radioactive waste - $\mathrm{A}$ waste containing an artifically produced or concentrated radioactive material, or which has come into contact with an artifically produced or concentrated radioactive material.

reaction bomb - A vessel, typically of metal or plastic-lined metal, which can be sealed, for conducting chemical reactions at elevated pressure and/or temperature.

rinsate - A rinse solution after it has been used to rinse a solid.

sample loop - Typically a length of tubing with a known volume.

secondary containment - A vessel or shell which contains the primary tank, piping, etc., of a process unit, to contain any release from the primary.

secondary waste - A waste produced as a result of treatment of a waste.

semivolatile organic compound -- Typically an organic compound whose boiling point is between 373.K. and 523.K.

sparging - The act of bubbling a gas through a liquid to remove low boiling materials as vapors.

spiking - The act of deliberately adding a known amount of a foreign species to a material.

standard addition - In chemical analysis, the addition of known amounts of a species to the material being analyzed, in order that a calibration curve for that species in the presence of the material(or matrix) may be generated.

thermal runaway - Uncontrolled temperature rise in a system, typically due to a heat-generating chemical reaction. 
toxic waste - A waste containing a compound or component having inimical effects on biological life.

volatile organic compound - Typically an organic compound whose boiling point is less than 373.K.

wet oxidation - An oxidation which takes place in a water solution and which ultimately utilizes oxygen as the oxidant. 


\section{List of Acronyms}

Aroclor 1260 - A PCB containing approximately $60 . \%$ by weight chlorine.

CERCLA - The Superfund Act.

DETOX - The process of catalyzed wet oxidation using iron(III) and selected cocatalysts.

DOE - Department of Energy.

FFCA - Federal Facilities Compliance Act.

NEPA - National Environmental Policy Act.

NRC - Nuclear Regulatory Commission.

PCB - Polychlorinated biphenyl.

PRDA - Program Research and Development Announcement.

RCRA - Resource Conservation and Recovery Act.

RFP - Rocky Flats Plant.

TBP - Tributyl Phosphate.

TSCA - Toxic Substances Control Act.

WSS - Weldon Spring Site. 
This page intentionally left blank 


\section{APPENDDX A}

\section{OTHER DETOX DEVELOPMENT EFFORTS}

\section{Development for Los Alamos National Laboratory}

Los Alamos National Laboratory (LANL) was the first organization to fund development of the DETOX process for treatment of mixed wastes. The development effort has been on-going since 1991, when feasibility studies were run on specific liquid organic mixed waste types of concern at LANL. The development project has concentrated on four liquid organic wastes: trichloroethene, vacuum pump oil, and two scintillation fluids. Reaction rate studies have confirmed that the oxidation reaction occurs at the contact surface of the DETOX solution with the organic, and have shown that a concentrated ferric chloride solution has desirable reaction rate characteristics. A one gallon bench top unit has been operated in batch mode and has demonstrated greater than $99.9999 \%$ destruction efficiencies for the organics. In on-going work, the bench top system is being converted to a continuous processing system to act as a test bed for prototype development concepts.

\section{Development for Rocky Flats Plant}

Delphi Research, Inc. has recently begun an effort for EG\&G Rocky Flats Plant to investigate the application of DETOX to a number of solid and liquid organic waste types at Rocky Flats Plant. The solids consist chiefly of material used in hot room operations, including paper towels, gloves, cotton coveralls, polyethylene bags, and similar. The liquids are the cutting and protective oils Trim Sol and Regal Oil. Reaction rate studies have shown that many of these materials can be oxidized at reasonable rates by the DETOX process at temperatures where the DETOX solution vapor pressure is at or below atmospheric pressure. A bench top unit is being assembled to study processing of these wastes in a pre-prototype system. 

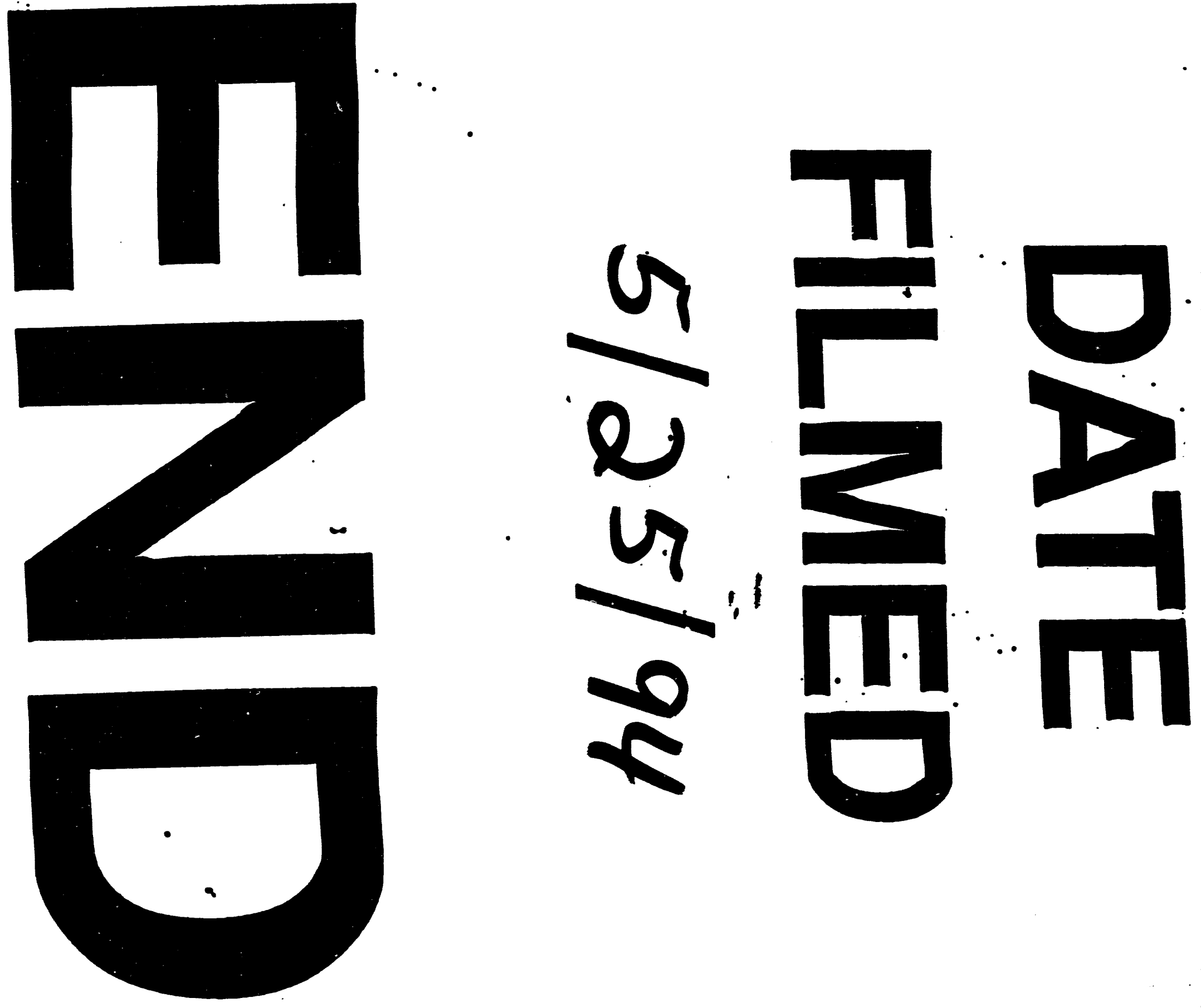
